by

Heloisa Westphalen Dornelas Camara

Bachelor of Chemical Engineering, Universidade Federal de Pernambuco, 2017

\author{
A thesis \\ presented to Ryerson University \\ in partial fulfillment of the \\ requirements for the degree of \\ Mater of Applied Science \\ in the program of \\ Chemical Engineering
}

Toronto, Ontario, Canada, 2019

CHeloisa Westphalen Dornelas Camara, 2019 


\section{AUTHOR'S DECLARATION FOR ELECTRONIC SUBMISSION OF A THESIS}

I hereby declare that I am the sole author of this thesis. This is a true copy of the thesis, including any required final revisions, as accepted by my examiners.

I authorize Ryerson University to lend this thesis to other institutions or individuals for the purpose of scholarly research.

I further authorize Ryerson University to reproduce this thesis by photocopying or by other means, in total or in part, at the request of other institutions or individuals for the purpose of scholarly research.

I understand that my thesis may be made electronically available to the public. 


\title{
In-Situ Ultrasound-Assisted Control of Polymeric Membrane Fouling
}

\author{
Heloisa Westphalen Dornelas Camara \\ Master of Applied Science, Chemical Engineering, Ryerson University, Toronto (2019)
}

\begin{abstract}
Membrane separation processes have been more widely applied to industrial activities, especially in water and wastewater treatment. However, there are still challenges associated to the use of membranes. Concentration polarization and fouling can cause significant permeate flux decay during the filtration process, hindering its efficiency and increasing cost. Among many strategies, the combination of membrane filtration with ultrasound (US) application has shown promising results in reducing membrane fouling. The main goal of this research was to identify the effect of US frequency, US power intensity and feed solution concentration on permeate flux during ultrafiltration of simulated latex paint effluent. Maximum increase in permeate flux of $19.7 \%$ was obtained by applying $20 \mathrm{kHz}$ and $0.29 \mathrm{~W} . \mathrm{cm}^{-2}$ to feed solution with $0.075 \mathrm{wt} . \%$ of solid concentration. The effect of feed flow rate was analyzed showing that an increase in feed flowrate is not beneficial to the fouling minimization process. Overall, the application of US improves permeate flux by reducing fouling of ultrafiltration polymeric membrane.
\end{abstract}




\section{ACKNOWLEDGMENTS}

First and foremost, I would like to express my deepest gratitude to Dr. Huu Doan for his immense support throughout this research project. Under his supervision, I have learned to work independently, to think critically and to believe in myself. Thank you for the endless patience, kind encouragement and trust during these two years. I would like to extend my gratitude to Dr. Ali Lohi for his technical guidance and valuable feedback. I feel very fortunate for having such respectful and caring supervisors.

I would like to express my sincere gratitude to the evaluating committee composed by Dr. Chil-Hung Cheng, Dr. Jiangning Wu and Dr. Simant Upreti for dedicating your time to review this work and provide valuable feedback.

I would like to express my profound gratitude Dr. Amira Abdelrasoul who has been a mentor and a friend. She believed in my potential and inspired me to pursue my master's degree. Thank you for your trust, caring support and life advice.

I would like to gratefully acknowledge the technical support from Mr. Ali Hemmati, Mr. Daniel Boothe and Mr. Tondar Tajrobehkar from the Department of Chemical Engineering at Ryerson University. I have learned and grew so much while working with such a professional, dedicated and supportive team. I extend my appreciation to all staff members in the Department of Chemical Engineering at Ryerson University for the support and advice throughout these two years. I would also like to acknowledge the help of Mr. Qiang Li, the Technical Officer of Scanning electron microscopy (SEM) imaging in the Department of Mechanical and Industrial Engineering at Ryerson University.

I am also very grateful for the support and friendship of my fellow students at Ryerson University. Sharing knowledge and experiences with you during this journey was so enriching and made me feel part of an amazing community. 


\section{DEDICATION}

This work is dedicated to my mother who has been my role model and source of inspiration to

pursue my dreams. Also, I would like to dedicate this work to all women in engineering and science. I hope this work inspires you to use your skills to make a positive change in the world. 


\section{TABLE OF CONTENTS}

$\begin{array}{ll}\text { Declaration } & \text { ii }\end{array}$

$\begin{array}{ll}\text { Abstract } & \text { iii }\end{array}$

Acknowledgments

Dedication $\quad$ V

List of Tables $\quad$ ix

List of Figures $\quad$ X

List of Appendices $\quad$ xiii

Nomenclature $\quad$ xiiiv

List of Abbreviations $\quad$ xvi

$\begin{array}{ll}\text { 1. Introduction } & 1\end{array}$

$\begin{array}{lr}\text { 2. Background Theory } & 3\end{array}$

2.1. Membrane Technology 3

2.1.2. Membrane Filtration Processes $\quad 6$

2.1.3. Transport Mechanisms $\quad 8$

2.1.4. Filtration Modes $\quad 11$

2.1.5. Membrane Systems and Modules $\quad 13$

2.2. Concentration Polarization and Fouling Mechanisms 13

$\begin{array}{ll}\text { 3. Literature Review } & 16\end{array}$

3.1. Fouling Control Strategies 16

3.2. Ultrasound Application in Membrane Separations Processes 17

$\begin{array}{lll}\text { 3.2.1. } & \text { Mechanism } & 18\end{array}$

3.2.2. Cleaning and Fouling Control Using US 21

3.2.2.1 Application of US Combined with Traditional Processes 22 
3.2.2.3 Ultrasonic Frequency 25

$\begin{array}{ll}\text { 3.2.2.4. Ultrasonic Power } & 27\end{array}$

3.2.2.5. Feed Solution Properties $\quad 29$

3.2.2.6. Feed Flow Rate $\quad 30$

3.2.2.7. Membrane Materials 33

$\begin{array}{ll}\text { 4. Methodology } & 36\end{array}$

4.1. Experimental Setup $\quad 36$

4.2. Ultrafiltration Membranes 39

4.3. Feed Solution 39

4.4. Operating Parameters 40

4.5. Operating Procedure 42

4.6. Experimental Design 43

4.7. Analytical Methods 45

4.7.1. Solid Content 45

4.7.2. Turbidity 45

4.7.3. Particle Size Distribution 46

4.7.4. Scanning-Electron Microscopy Imaging 47

$\begin{array}{lr}\text { 5. Results and Discussion } & 48\end{array}$

5.1. Preliminary Investigation 48

5.2. Response Surface Methodology (RSM) 53

5.2.1. Main Effects $\quad 55$

5.2.1.1. Effect of frequency $\quad 55$

5.2.1.2. Effect of Power Intensity

5.2.1.3. Effect of Concentration $\quad 58$ 
5.2.3. Statistical Analysis

5.2.4. Investigations Around the Best Operating Condition

6. Conclusions and Recommendations $\quad 72$

$\begin{array}{ll}\text { 6.1. Conclusions } & 72\end{array}$

$\begin{array}{ll}\text { 6.2. Recommendations } & 73\end{array}$

$\begin{array}{ll}\text { Appendix A - Experimental data collected } & 74\end{array}$

$\begin{array}{ll}\text { Appendix B - Response surface regression } & 78\end{array}$

$\begin{array}{ll}\text { Appendix C - Reproducibility } & 80\end{array}$

$\begin{array}{ll}\text { Appendix D - Sample calculations } & 81\end{array}$

$\begin{array}{ll}\text { References } & 85\end{array}$ 


\section{LIST OF TABLES}

Table 2-1. Structure, materials and separation mechanism of synthetic membranes (Strathmann, 2011a)

Table 4-1.Zeta potential measured for feed solution with different solid concentration ............. 39

Table 4-2. Solid content of feed solution with various concentration ................................... 41

Table 4-3. Experimental conditions for preliminary investigation ......................................... 43

Table 4-4. Levels of independent variables for Box-Behnken design ..................................... 44

Table 5-1. Total flux decay for best runs in preliminary investigation .................................. 52

Table 5-2. Experimental runs and results from Box-Behnken design ................................... 54

Table 5-3. Permeate flux obtained experimentally for various power levels ........................... 63

Table 5-4. Flow conditions inside membrane module for flow rate investigation ..................... 68 


\section{LIST OF FIGURES}

Figure 2-1. Different materials and structure classification of membranes (Strathmann, 2011b).. 5

Figure 2-2. Classification of membrane process by solute size (Singh, 2015a) ………................. 7

Figure 2-3. Generic transport through a membrane (Strathmann, 2011b) .................................. 10

Figure 2-4. Molecular transport by pore-flow (left) and solution-diffusion model (right) (Baker,

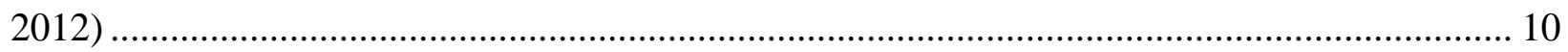

Figure 2-5. Membrane filtration modes: Dead-end filtration and cross-flow filtration (Singh,

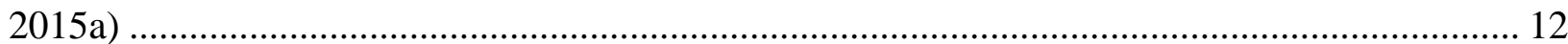

Figure 2-6. Concentration polarization phenomenon (Keir et al., 2014) ..................................... 14

Figure 2-7. Stages of flux decline (Li et al., 2008) ................................................................. 15

Figure 3-1 Possible mechanisms for particle detachment observed with ultrasound cleaning

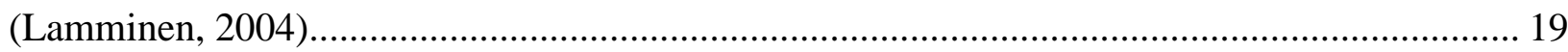

Figure 3-2. Schematic diagram of acoustic cavitation, bubble growth, and cavitational collapse

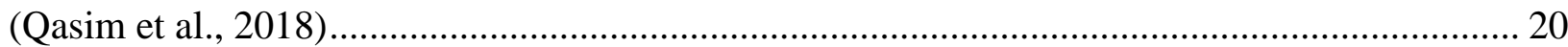

Figure 3-3. Illustration of the difference between the processes ............................................... 22

Figure 3-4. Example of an experimental setup using ultrasonic bath (Borea et al., 2018)........... 23

Figure 3-5.In-situ ultrasonic system Hengl et al. (2014) ......................................................... 24

Figure 3-6. Ultrafiltration process with or without ultrasound irradiation at transmembrane pressure of 0.4 bar (Cai et al., 2010) ....................................................................................... 27

Figure 3-7. Normalized permeate flux of the membranes over filtration process using particles of sizes, $1.0 \mu \mathrm{m}, 0.5 \mu \mathrm{m}$, and $0.3 \mu \mathrm{m}$. Ultrasonic cleaning performed using $620 \mathrm{kHz}, 0.21 \mathrm{~W} . \mathrm{cm}^{-2}$,

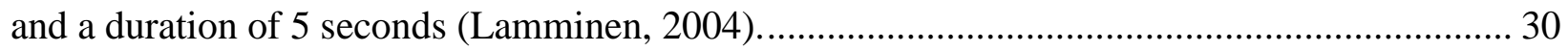
Figure 3-8.Response surface plot showing the effect of (a) TMP and CFV (b) CFV and power level (c) TMP and power level with cleaning efficiency when using mixed wave sonication mode

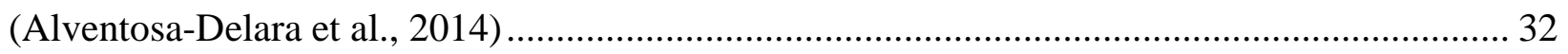

Figure 3-9. Effect of irradiation time and ultrasound intensity on water flux for different polymeric

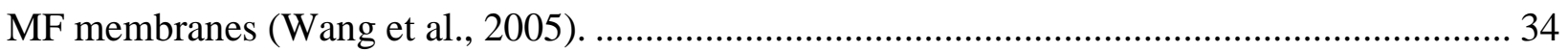

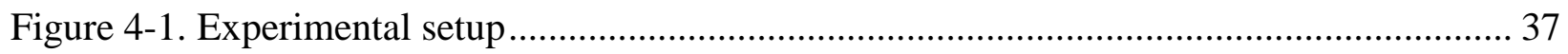

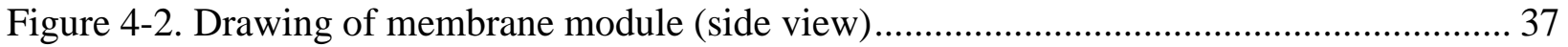

Figure 4-3. Schematic representation of ultrasonic transducers connected in series to achieve a

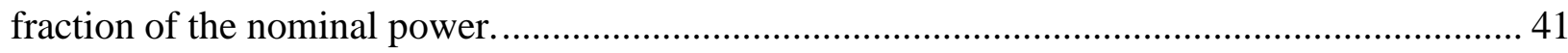


Figure 4-4. Mass reduction over time of $1 \mathrm{~mL}$ of latex paint ( 3 samples) in the oven at $105^{\circ} \mathrm{C} . .45$ Figure 4-5. Size distribution of latex particles in feed solution with various solid concentrations,

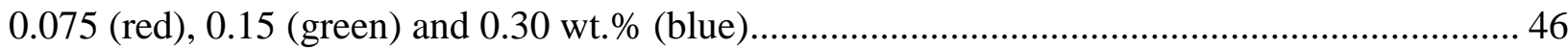

Figure 4-6. SEM image of PVDF membrane $0.03 \mu \mathrm{m}$, gold-coated ..................................... 47 Figure 5-1. Normalized flux $\left(\mathrm{J} / \mathrm{J}_{\mathrm{o}}\right)$ over time of US-assisted filtration using PCTE membrane $(\mathrm{F}=28$ $\mathrm{kHz}, \mathrm{Pw}=100 \mathrm{~W}, \mathrm{Q}=1.0$ L.min-1, $\mathrm{P}=5.0 \mathrm{psi}$ )

Figure 5-2. Total mass of permeate collected after 35 minutes using no ultrasound, $20 \mathrm{kHz}, 28 \mathrm{kHz}$ and $40 \mathrm{kHz}$ and various $\mathrm{Pw}$ levels $(\mathrm{Q}=1.0$ L.min-1, $\mathrm{P}=5.0 \mathrm{psi}, \mathrm{Cs}=0.15$ wt.\%) ..................... 50 Figure 5-3. Normalized flux decay over 35 minutes of filtration for three best runs of preliminary

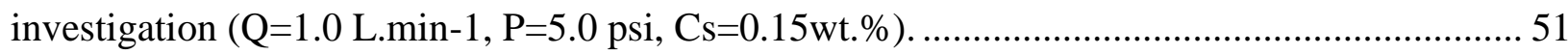

Figure 5-4. Main effects plot for Jus using data means. ...................................................... 55 Figure 5-5. Permeate flux decay over 35 minutes of filtration using 20 and $40 \mathrm{kHz}$ (Q=1.0 L.min-

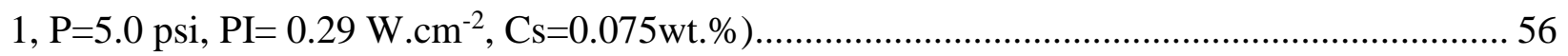

Figure 5-6. Turbidity of the permeate solution obtained applying $20 \mathrm{kHz}$ with various power intensity levels and various feed solution solid concentration................................................ 58

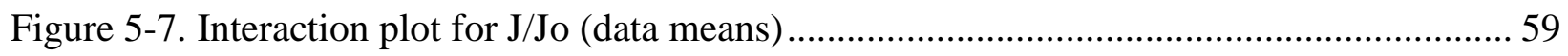

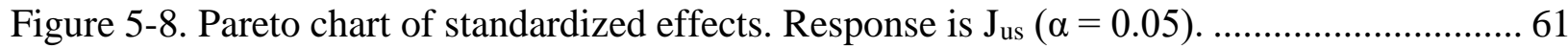

Figure 5-9. Response surface of Jus as a function of frequency and concentration................... 62 Figure 5-10. Permeate flux decay over 35 minutes of ultrafiltration using the best operating condition $\left(25 \mathrm{kHz}\right.$ and $\left.0.29 \mathrm{~W} . \mathrm{cm}^{-2}\right)$ and the control run (no US) (Q=1 L.min-1, P=5 psi, $\mathrm{Cs}=0.075 \mathrm{wt} . \%)$. 64

Figure 5-11. Permeate flux decay over 35 minutes of ultrafiltration the applying $25 \mathrm{kHz}$ and 0.29 $\mathrm{W} . \mathrm{cm}^{-2}$ and using various feed solution concentrations $(\mathrm{Q}=1 \mathrm{~L} . \mathrm{min}-1, \mathrm{P}=5 \mathrm{psi})$.... 65 Figure 5-12. Mass of permeate collected after 35 minutes of US-assisted filtration applying $20 \mathrm{kHz}$ and $0.29 \mathrm{~W} . \mathrm{cm}^{-2}$ and using various feed solution concentrations. 66 Figure 5-13 Turbidity of permeate solution obtained from different feed solutions with different solid concentrations $\left(\mathrm{F}=20 \mathrm{kHz}, \mathrm{P}_{\mathrm{wi}}=0.29 \mathrm{~W} . \mathrm{cm}^{-2}, \mathrm{Q}=1.0 \mathrm{~L}^{\mathrm{min}} \mathrm{min}^{-1}, \mathrm{P}=5.0 \mathrm{psi}\right)$ 67 Figure 5-14. Average particle size of permeate solution obtained from different feed solution with different solid concentrations $\left(\mathrm{F}=20 \mathrm{kHz}, \mathrm{P}_{\mathrm{wi}}=0.29 \mathrm{~W} . \mathrm{cm}^{-2}, \mathrm{Q}=1.0 \mathrm{~L}^{-\mathrm{min}^{-1}}, \mathrm{P}=5.0 \mathrm{psi}\right) \ldots \ldots \ldots .68$ Figure 5-15. Permeate flux ( $\left.\mathrm{J}_{\mathrm{us}}\right)$ obtained using various feed cross-flow velocities without US application $(\mathrm{Cs}=0.075$ wt. $\%)$ 
Figure 5-16. Permeate flux ( $\left.\mathrm{J}_{\mathrm{us}}\right)$ obtained using various feed cross-flow velocities with US

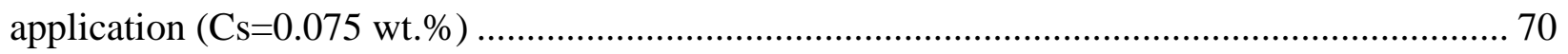

Figure 5-17. Total mass of permeate collected in 35 minutes of filtration using various feed crossflow velocities with and without ultrasound application $\left(20 \mathrm{kHz}, 0.29 \mathrm{~W} . \mathrm{cm}^{-2}\right), \mathrm{P}=5 \mathrm{psi}, \mathrm{C}_{\mathrm{s}}=0.075$

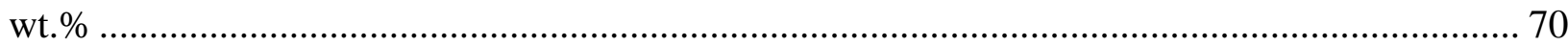

Figure 5-18. SEM image of PVDF membrane surface after 35 minutes of ultrafiltration (a) without ultrasound and (b) with application of $20 \mathrm{kHz}$ and $0.29 \mathrm{~W} \cdot \mathrm{cm}^{-2}\left(\mathrm{Q}=1 \mathrm{~L} \cdot \mathrm{min}^{-1}, \mathrm{P}=5 \mathrm{psi}, \mathrm{Cs}=0.07\right.$

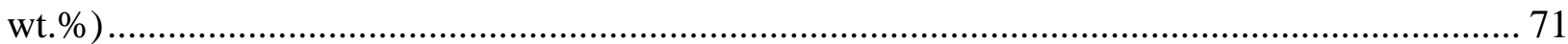




\section{LIST OF APPENDICES}

A-1 Permeate mass collected over 35 minutes of filtration applying $20 \mathrm{kHz}$ and various power levels, $\mathrm{Q}=1.0$ L.min-1, $\mathrm{P}=5.0$ psi, Cs=0.15 wt.\% 74

A-2 Permeate mass collected over 35 minutes of filtration applying $28 \mathrm{kHz}$ and various power levels, $\mathrm{Q}=1.0$ L.min-1, $\mathrm{P}=5.0 \mathrm{psi}, \mathrm{Cs}=0.15 \mathrm{wt} . \%$...

A-3 Permeate mass collected over 35 minutes of filtration applying $40 \mathrm{kHz}$ and various power levels, $\mathrm{Q}=1.0$ L.min-1, $\mathrm{P}=5.0 \mathrm{psi}, \mathrm{Cs}=0.15$ wt. $\%$... 75 A-4 Permeate mass collected over 35 minutes of filtration applying $28 \mathrm{kHz}$ and various power levels, $\mathrm{Q}=1.0$ L.min-1, $\mathrm{P}=5.0 \mathrm{psi}, \mathrm{Cs}=0.30$ wt.\%. 75 A-5 Permeate mass collected over 35 minutes of filtration applying $20 \mathrm{kHz}$ and various power

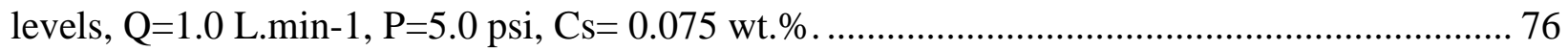
A-6 Permeate mass collected over 35 minutes of filtration applying $20 \mathrm{kHz}$ and $0.29 \mathrm{~W} . \mathrm{cm}^{-2}$ with various feed solution concentrations, $\mathrm{Q}=1.0 \mathrm{~L}$.min- $1, \mathrm{P}=5.0$ psi. 76

A-7. Permeate mass collected over 35 minutes of filtration using various feed flow rates and no ultrasound application, $\mathrm{P}=5.0 \mathrm{psi}, \mathrm{Cs}=0.075 \mathrm{wt} . \%$.

A-8. Permeate mass collected over 35 minutes of filtration using various feed flow rates and application of $20 \mathrm{kHz}$ and $0.29 \mathrm{~W} . \mathrm{cm}-2, \mathrm{P}=5.0 \mathrm{psi}, \mathrm{Cs}=0.075$ wt. \% ...................................... 77

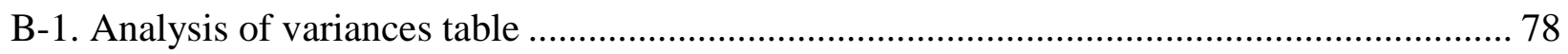

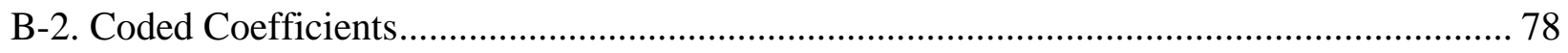

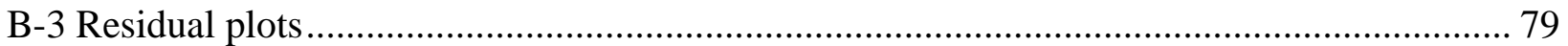

C-1. Permeate flux decay over 35 minutes of filtration applying $28 \mathrm{kHz}, 0.29 \mathrm{~W} . \mathrm{cm}^{-2}(\mathrm{Q}=1.0$

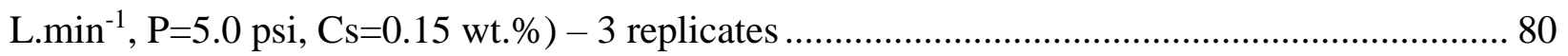

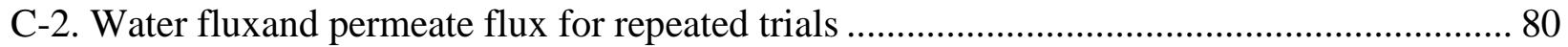

C-3. Mean and standad deviation of permeate flux and averaged normalized permeate flux ...... 80

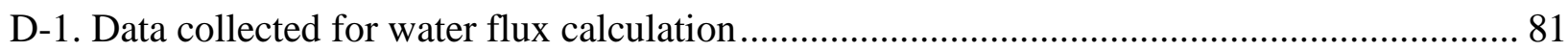

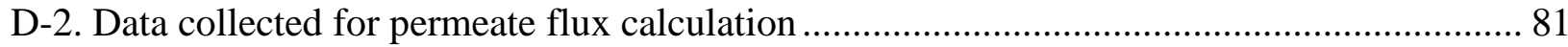

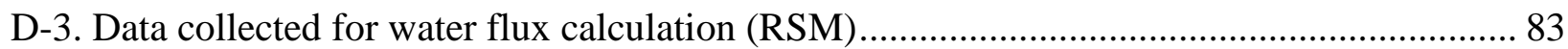

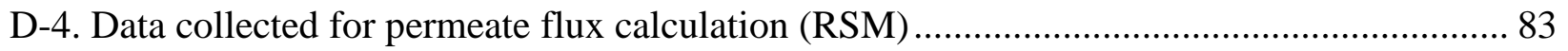


NOMENCLATURE

\section{Symbol Description}

A

$\mathrm{A}_{\mathrm{m}}$

$\mathrm{c}_{\mathrm{i}}$

Cs

$\mathrm{D}_{\mathrm{i}}$

F

$f_{o}$

J

$\mathrm{J}_{\text {avg }}$

$\mathrm{J}_{\text {avg }} / \mathrm{J}_{\mathrm{o}}$

$\mathrm{J}_{\mathrm{f}}$

$\mathrm{J}_{\text {us }}$

$\mathrm{J}_{\mathrm{i}}$

$\mathrm{J}_{\mathrm{o}}$

$\mathrm{J}_{\text {om }}$

$\mathrm{K}^{\prime}$

$\mathrm{L}$

$\mathrm{m}$

$\mathrm{P}$

$\mathrm{p}_{\mathrm{o}}$

$\mathrm{Pw}$

Pwi

Q

$\mathrm{R}_{\mathrm{o}}$

$\mathrm{t}$

V

wt.\%

$\mathrm{X}$

Permeate flux

Path length

Mass

Flow rate

Time

Volume

Displacement
Attenuation

Membrane area

Concentration of the component $i$

Solid concentration of feed solution

Diffusion coefficient

Ultrasonic frequency

Resonance frequency

Averaged permeate flux for 35 minutes of filtration

Normalized averaged permeate flux

Final permeate flux after 35 minutes of filtration

Corrected permeate flux

Flux of component $i$

Membrane water flux

Membrane water flux provided by the manufacturer

Coefficient reflecting the nature of the medium

Applied pressure

Ambient pressure

Ultrasonic Power

Ultrasonic Power Intensity

Radius of gas bubble

Weight per cent

\section{Units}

$\mathrm{dB}$

$\mathrm{cm}^{2}$

mol.m ${ }^{3}$

wt. $\%$

$\mathrm{m}^{2} \cdot \mathrm{s}^{-1}$

$\mathrm{kHz}$

$\mathrm{kHz}$

g. $\min ^{-1} \cdot \mathrm{cm}^{-2}$

g. $\mathrm{min}^{-1} \cdot \mathrm{cm}^{-2}$

$--$

g. $\min ^{-1} \cdot \mathrm{cm}^{-2}$

g. $\min ^{-1} \cdot \mathrm{cm}^{-2}$

g. $\mathrm{min}^{-1} \cdot \mathrm{cm}^{-2}$

g. $\min ^{-1} \cdot \mathrm{cm}^{-2}$

g. $\min ^{-1} \cdot \mathrm{cm}^{-2}$

$--$

$\mathrm{m}$

g

psi

psi

W

W.cm ${ }^{-2}$

L. $\min ^{-1}$

$\mu \mathrm{m}$

$\min$

$\mathrm{mL}$

--

$\mathrm{m}$ 
$\alpha$

$\delta$

$\rho$

$\kappa$
Attenuation coefficient

Permeate flux correction factor

Density

Polytropic index
$\mathrm{dB} \cdot \mathrm{kHz}^{-1} \cdot \mathrm{m}^{-1}$

$\mathrm{g} \cdot \mathrm{mL}^{-1}$

$--$ 


\section{LIST OF ABBREVIATIONS}

\begin{tabular}{|c|c|}
\hline Abbreviation & Meaning \\
\hline $\mathrm{CFV}$ & Cross-flow velocity \\
\hline $\mathrm{CN}-\mathrm{CA}$ & Cellulose nitrate with cellulose acetate \\
\hline $\mathrm{Cs}$ & Solid Concentration \\
\hline GS & Gas separation \\
\hline MF & Microfiltration \\
\hline MWCO & Molecular weight cut-off \\
\hline MIEX & Magnetic ion exchange \\
\hline NF & Nanofiltration \\
\hline $\mathrm{Nr}$ & Nylon 6 \\
\hline NTU & Nephelometric Turbidity Units \\
\hline PAN & Polyacrylonitrile \\
\hline PCTE & Polycarbonate Track Etch \\
\hline PES & Polyether sulfone \\
\hline PVDF & Polyvinylidene fluoride \\
\hline PVP & Polyvinylpyrrolidone \\
\hline RO & Reverse Osmosis \\
\hline RSM & Response Surface Methodology \\
\hline SEM & Scanning Electron Microscopy \\
\hline TMP & Transmembrane pressure \\
\hline UF & Ultrafiltration \\
\hline US & Ultrasound \\
\hline
\end{tabular}




\section{Chapter 1}

\section{Introduction}

With a fast-growing population, the worldwide demand for water is also increasing sharply. Many regions already suffer with water shortages and unacceptable water quality (Dixit et al., 2016). The consequences are reflected directly in the population's health and quality of life. Contaminated water consumption and lack of appropriate sewage systems are the major cause of illness around the world (Singh, 2015b). In this perspective, the development of efficient and affordable water treatment is crucial for life management in the planet.

For many years, great research effort has been devoted to the development of technologies that can deliver water quality in accordance to environmental health and safety standards. Municipal wastewater treatment plants have evolved significantly in terms of efficiency and technological advances. The industrial wastewater treatment facilities have also gained more importance, due to the stricter legislations which intend to protect the water bodies.

The evolution of the membrane technology has contributed significantly to this scenario. Membrane technology comprises the use of a physical barrier to separate certain components from a mixture. Membrane-based separation processes have been applied to various industrial processes such as food processing, drug manufacturing and wastewater treatment. Membrane separation processes have proven to be a promising alternative to traditional processes (e.g., distillation, evaporation and solid-phase extraction) that can be costlier and less efficient (Hoek, 2017). However, still there are many challenges associated to the implementation of membrane processes, especially for industrial applications. Concentration polarization and membrane fouling are two phenomena intrinsic to the nature of membrane filtration, that can significantly compromise the efficiency of the process due to flux decay (Baker, 1996).

The use of ultrasound (US) is among various strategies to control fouling. It creates turbulence near the membrane surface and detaches particles through the action of bubbles cavitation. The characteristics of the bubbles formed within the system play a major role in the effectiveness of 
the ultrasound application. The particle detachment can significantly decrease the overall resistance to flow across the membrane, increasing filtration performance.

In previous studies, the application of ultrasound has increased permeate flux between $25 \%$ and 90\% (Ahmad et al., 2018; Lamminen, 2004). A wide range of ultrasonic frequency and power levels have been investigated and, in most cases, lower frequencies have been more effective (Chai et al., 1999; Naddeo et al., 2015). The effectiveness of ultrasonic-assisted fouling control has also been tested using different feed solutions (e.g., peptone and milk aqueous solution, latex paint wastewater, and municipal wastewater). It has been observed that its properties play a major role in the overall performance (Ahmad et al., 2018; Borea et al., 2018; Kobayashi et al., 2003a).

Furthermore, different membrane materials have been investigated such as ceramic and polymeric membranes. Some polymeric materials experience significant increase in pore size and permeability when exposed to ultrasound, while others can suffer severe damage to the membrane structure. Accordingly, the application of ultrasound as a fouling control strategy should be done with caution when using polymeric membranes (Masselin et al., 2001). Most of the published reports have applied ultrasound using ultrasonic bath. This might be less aggressive to the membrane structure, but it is not very energy efficient as only a small fraction of the applied power reaches the membrane without any attenuation (Cai et al., 2010).

Considering the issues above, the objectives of this study are outlined as follows:

- To assess the feasibility of using ultrasound-assisted fouling control for two polymeric membranes.

- To investigate the effect of ultrasonic frequency and power applied continuously in situ to ultrafiltration process.

- To examine the effect of feed solution concentration and feed cross-flow velocity on the performance of the ultrasound-assisted ultrafiltration. 


\section{Chapter 2}

\section{Background Theory}

This chapter presents an overview of membrane technology. The development of membrane filtration processes and their advantages are presented. Membrane materials, filtration processes, filtration modes, and membrane systems and modules are explained based on published literature.

\subsection{Membrane Technology}

According to literature, the development of membrane technology started on early eighteenth century when Abbé Nolet, in 1748, used the term 'osmosis' for the first time. During the nineteenth and early twentieth centuries, difficulties were faced in industrial and commercial applications due to limited resources. However, membrane technology was still used in laboratory applications, leading to the understanding and development of many physical and chemical concepts widely used nowadays (Baker, 1996).

After World War II, membrane technology played a very important role in drinking water tests. Research efforts were devoted to the development of filters aiming to ensure safety of the population (Baker, 1996). However, it was only in the 1960's that the industrial application potential of membrane technology was verified. The development of desalination process using reverse osmosis membrane was a breakthrough, leading to the creation of crucial sources of funding and support for the development of many processes (Singh, 2015a).

Over the last few decades, great research efforts were devoted to making membrane processes more efficient, reliable, selective and affordable for various applications. Nowadays, membrane technology is applied for a variety of purposes such as desalination, water and wastewater treatment, food processing, drug delivery devices, fuel cells, petrochemical industry and many others (Strathmann, 2011b). 
Countless advantages have made membrane processes more attractive over the conventional systems. One of them is the low environmental impact associated with the use of membranes, as the only waste product from membrane processes is the unwanted component from the feed stream (Field et al., 2017). For the most part, there is no need to use hazardous chemical or biological agents, therefore, treatment and discharge of these kinds of materials can be avoided (Field et al., 2017; Strathmann, 2011b). Membrane processes are energy efficient and can operate at room temperature, which allows their application to a variety of process involving heat sensitive components such as dairy products and pharmaceuticals. Additionally, they do not require complex operating conditions. Furthermore, membrane processes yield high quality products and can be applied for sterilization, retaining particles and pathogenic microorganisms (Field et al., 2017; Kim et al. , 2015).

Although membrane processes have been extensively studied and applied in industrial scale, there are limitations inherent to the nature of the process. According to Field (2017), when scaling up a membrane process, the overall capital cost increases in a non-linear scale with the size of the plant to the power of 0.8 . This index is normally 0.6 for conventional processes. Hence, for a same percent increase on the plant size, the amount of energy saved would be smaller for the membrane processes when compared to conventional processes (Field et al., 2017). Another deterrent from the use of membranes is associated to concentration polarization and fouling (Rouvet et al., 1998). These phenomena can cause significant decrease in production due to permeate flux decay and increase in transmembrane pressure (TMP). Consequently, the energy consumption is increased leading to higher operational cost, while reducing the lifetime of the membrane (Abdelrasoul, 2015).

\subsubsection{Synthetic Membranes}

A membrane can be generically described as a thin physical barrier between two phases and which can moderate the permeation of the components in contact with it (Baker, 1996; Strathmann, 2011b). Nowadays, almost all industrial applications adopt polymeric membranes. Theses polymeric materials can be formed by spinning fibers, by coating tubes or sheets, or by casting a film (Field et al., 2017). In general, synthetic membranes can be fabricated using different materials, and hence, it will present different structures and properties as shown in Figure 2-1. 


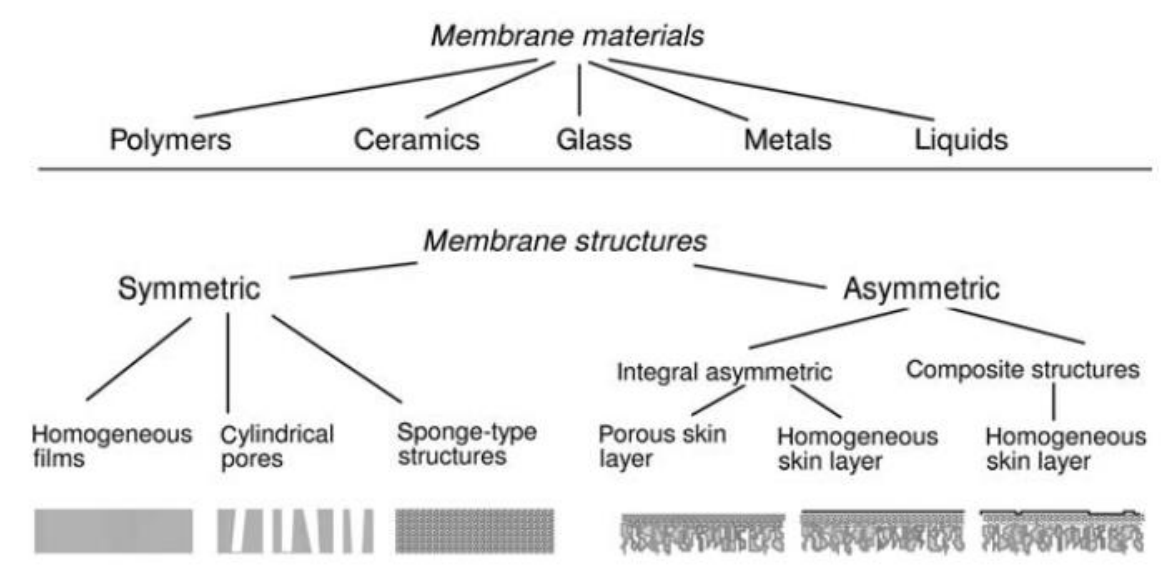

Figure 2-1. Different materials and structure classification of membranes (Strathmann, 2011b)

The advantages of using membrane-based process include the possibility of tailoring the membrane's surface according to the requirements of the process or the feed solution to be treated. The use of a range of materials, as shown in Figure 2-1, allows selection and combination of properties that can make the membrane more suitable for a specific application.

The two main classifications for the structure of membranes are symmetric and asymmetric. The difference between symmetric and asymmetric membranes is related to the pore structure and transport properties. For symmetric membranes, both are constant over the entire membrane thickness. These membranes are mainly used in dialysis and electrodialysis applications. For asymmetric membranes, structure and transport properties vary along the membrane thickness and it can consist of a $0.1-1 \mu \mathrm{m}$ 'skin' layer on a highly porous substructure $100-200 \mu \mathrm{m}$ thick (Strathmann, 2011b).

The membrane structure can also be classified into porous (macro- or microporous) or nonporous (dense) structure. Porous membranes relate more to the generic idea of a filter (Seader et al.,2006; Strathmann, 2011b) which contain an interconnected porous structure. The separation process occurs based on the size of the components and the pore size (Seader et al., 2006; Strathmann, 2011a). On the other hand, non-porous or dense membranes do not present well defined porous structure and the separation occurs based on solubility and diffusivity of the species in the membrane (Seader et al., 2006). Due to the different properties associated with membrane materials and its structures, selection of the appropriate membrane for a specific application is important. 


\subsubsection{Membrane Filtration Processes}

According to Singh (2015a), liquid separations represent most of membrane filtration applications. In liquid separation processes, the solid fraction (dissolved, colloidal or particulate constituents) from a pressurized fluid is separated by a porous material (Vigneswaran et al., 2012). In comparison to other separation processes such as distillation, the use of membrane is advantageous because it does not involve phase change of the components, and hence, is less energy consuming (Singh, 2015a).

Membrane processes can be classified by membrane pore size or molecular weight cut-off (MWCO) and applied pressure (Vigneswaran et al., 2012). According to the membrane pore size, membrane processes can be classified as shown in Figure 2-2. The main pressure-driven membrane processes applied in large scale industry are microfiltration (MF), ultrafiltration (UF), nanofiltration (NF) and reverse osmosis (RO). 


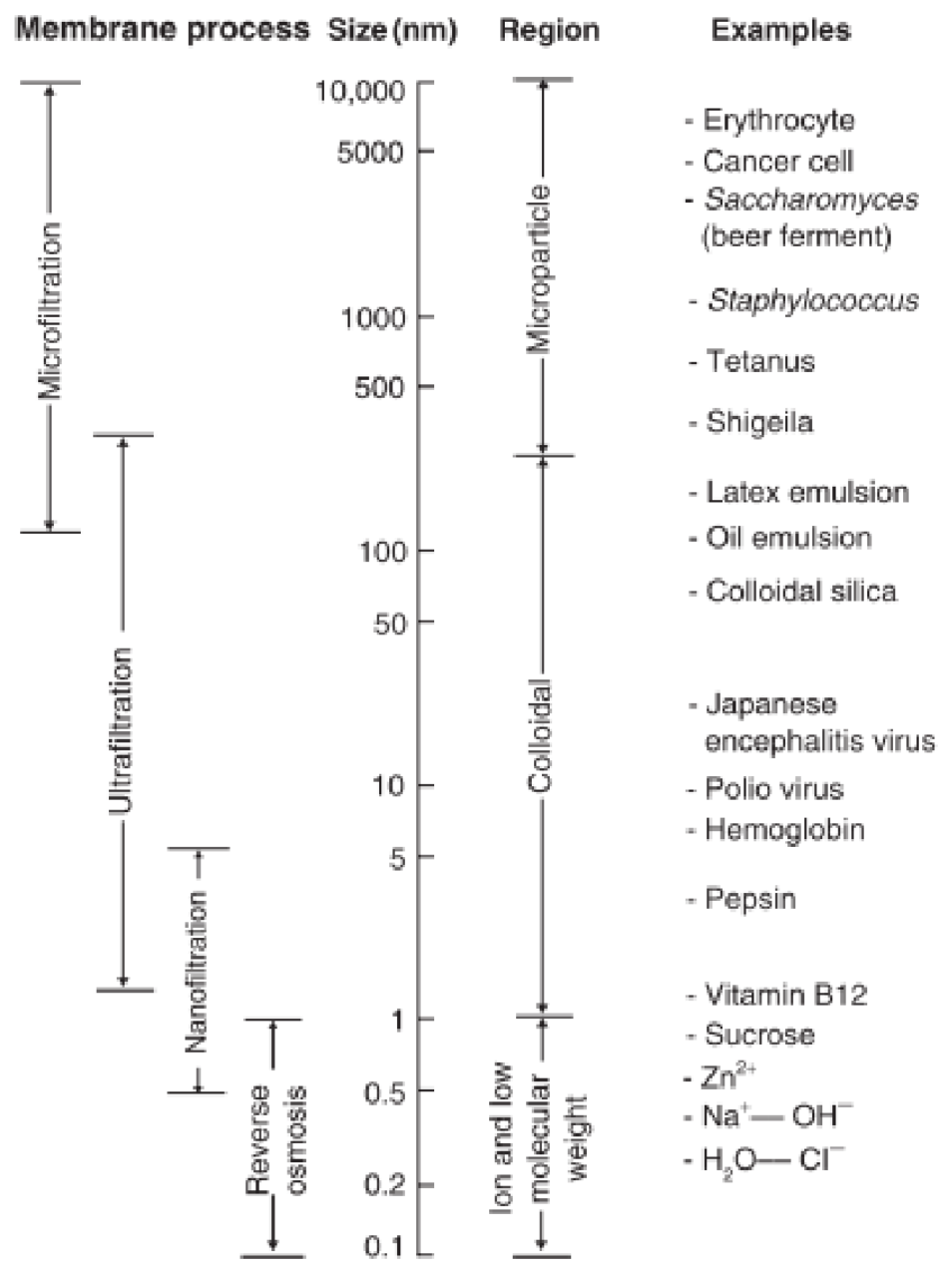

Figure 2-2. Classification of membrane process by solute size (Singh, 2015a)

Ultrafiltration has been studied since the early 1900's, and nowadays it is a very welldeveloped process and can no longer be considered an emerging technology (Abdelrasoul, 2015; Baker, 1996). UF is a low-pressure membrane filtration system (Gao et al., 2011), and UF membranes are anisotropic structures composed of a finely porous surface (pore size from 1 to approximately $500 \mathrm{~nm}$ ) supported by a more open substrate that provides mechanical strength (Baker, 1996). The separation occurs based on the size of the particles usually characterized by the MWCO.

A wide range of operation is feasible for UF, being able to separate colloidal particles such as latex emulsion but also virus and bacteria (Singh, 2015a). Due to its flexibility, UF is applied on a large variety of industrial processes. In the past few decades, the application of UF has grown 
significantly in municipal and industrial wastewater treatments as well as in the drinking water production (Abdelrasoul, 2015; Mohammad et al., 2012). When compared to conventional separation and concentration processes (e.g., floatation, sedimentation and media filtration) membrane separation processes can yield higher quality products, while reducing operational cost and having a lower environmental impact (Mohammad et al., 2012).

In municipal wastewater treatment facilities, UF can be applied as an additional step to the conventional process, and its application has been studied as pre-treatment for RO in desalination process to reduce fouling (Rautenbach \& Voßenkaul, 2001). With regards to industrial wastewater treatment using UF, the paint products industry is a great example. A large amount of wastewater is generated as result of equipment cleaning. Appropriate treatment of this wastewater must be performed before discharging to satisfy the environmental standards (Abdelrasoul et al., 2016). UF can remove a wide range of contaminants at a lower cost when compared to other processes, such as RO and NF. Additional advantages include compactness, ease automation and high removal rates of organic matter, turbidity, bacteria and virus (Gao et al., 2011).

Great research efforts have been devoted to improve these membrane processes in order to allow wider applicability in industrial processes. From these efforts, new membrane materials have been investigated, and optimal operating conditions, cleaning and fouling control strategies have been developed (Ghidossi et al., 2006).

\subsubsection{Transport Mechanisms}

Membrane filtration can be defined as a process that separates a solid fraction (particles) from a solution (Hoek, 2017). The separation is a result of differences in transport rate of chemical species through the membrane. The transport rate is defined by the driving force acting on the components, the mobility and the concentration of the components at the membrane surface (Strathmann, 2011b). A different transport model is applied depending on the driving force, solute and membrane properties. Table 2-1 shows the transport mode and separation mechanism associated to each membrane structure and material. 
Table 2-1. Structure, materials and separation mechanism of synthetic membranes (Strathmann, 2011a)

\begin{tabular}{|c|c|c|}
\hline Membrane structure & Membrane material & $\begin{array}{c}\text { Transport mode and } \\
\text { separation mechanism }\end{array}$ \\
\hline Porous film & Polymers, ceramics and metals & $\begin{array}{c}\text { Convection and diffusion } \\
\text { through pores }\end{array}$ \\
\hline Non-porous film & Polymers, ceramics and metals & $\begin{array}{l}\text { Solution and diffusion in a } \\
\text { solid film }\end{array}$ \\
\hline Supported liquid films & Liquids in porous membranes & $\begin{array}{l}\text { Solutions and diffusion in a } \\
\text { liquid film }\end{array}$ \\
\hline Electrically charged barriers & Polymers and ceramics & $\begin{array}{c}\text { Diffusion and migration } \\
\text { through a film with fixed } \\
\text { charges }\end{array}$ \\
\hline
\end{tabular}

Figure 2-3 represents the most general form of mass transport through a membrane where the mass transfer resistances at the membrane-fluid interfaces on both sides of the membrane are considered negligible. Component $\mathrm{A}$ is transported due to a driving force across the membrane. The driving force is the difference in the electrochemical potential of the specie on both sides of the membrane. The electrochemical potential gradient arises from changes in hydrostatic pressure, concentration, electrical potential, or temperature on the two phases separated by the membrane (Strathmann, 2011b). 


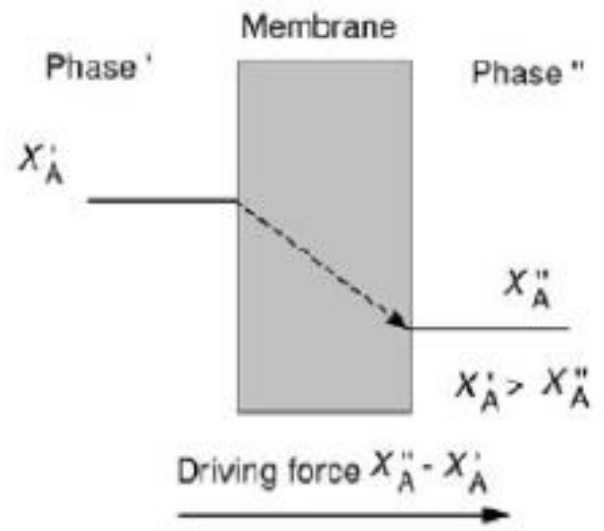

Flux of component $\mathrm{A}$

Figure 2-3. Generic transport through a membrane (Strathmann, 2011b)

Transport mechanisms and models which describe membrane filtration were developed during the 1950's and 1960's (Zhang et al., 2012). Baker (2012) used two models to describe the mechanisms of permeation: pore-flow model and solution-diffusion model, as shown in Figure $2-4$.

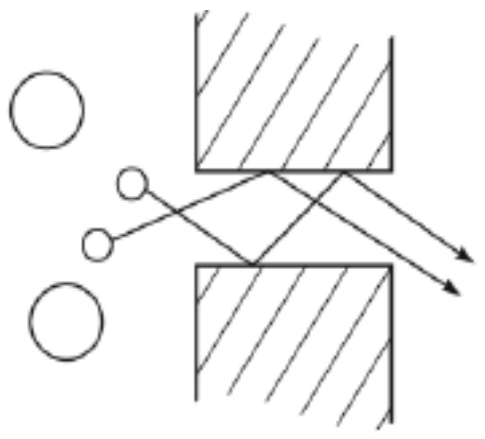

Microporous membranes separate by molecular filtration

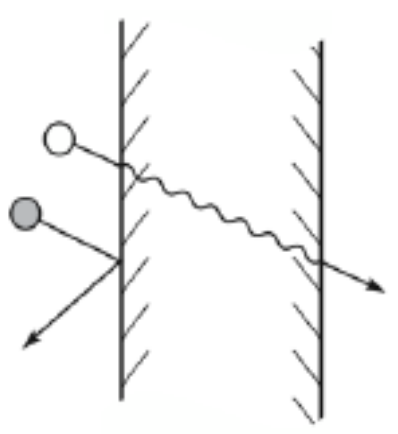

Dense solution-diffusion membranes separate because of differences in the solubility and mobility of permeants dissolved in the membrane material

Figure 2-4. Molecular transport by pore-flow (left) and solution-diffusion model (right) (Baker, 1996)

Pore-flow model refers to the transport of permeants by pressure-driven convective flow through the membrane pores. In this scenario, if the size of a molecule is larger than the pore size, it is rejected. This model is commonly used to describe the flow through porous medium, and the 
equation that governs this type of transport is known as Darcy's law, represented in Equation (1) (Baker, 1996):

$$
J_{i}=K^{\prime} c_{i} \frac{d p}{d x}
$$

Where $J_{i}$ is the flux of component $i$ through the membrane, $K^{\prime}$ is a coefficient reflecting the nature of the medium, $c_{i}$ is the concentration of the component $i$ and $\frac{d p}{d x}$ is the pressure gradient across the membrane. This transport mechanism is also referred as viscous flow and it is the dominant form of mass transport in MF and UF processes (Strathmann, 2011b).

In the solution-diffusion model the permeants dissolved into the membrane material are transported by diffusion due to concentration gradient. Thus, this model is based on the solubility and diffusion rate of the molecules. Since diffusion is the basis of this model, the driving force of the transport process is the concentration gradient. The solution-diffusion model can be described by Fick's law of diffusion, represented by Equation (2) (Strathmann, 2011b):

$$
J_{i}=-D_{i} \frac{d c_{i}}{d x}
$$

Where $D_{i}$ is the diffusion coefficient and $\frac{d c_{i}}{d x}$ is the concentration gradient of component $i$ across the membrane. Diffusion is the dominant mass transport mechanism for RO, gas separation (GS), pervaporation and dialysis.

\subsubsection{Filtration Modes}

The literature reports two main filtration modes: dead-end and cross-flow. Both types are schematically represented in Figure 2-5. 


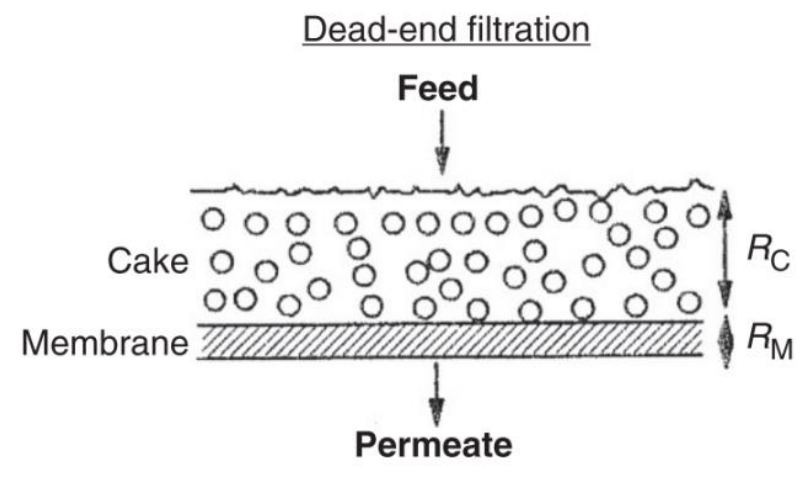

Cross-flow filtration

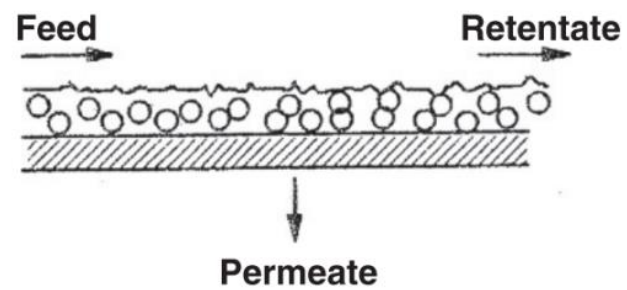

Figure 2-5. Membrane filtration modes: Dead-end filtration and cross-flow filtration (Singh, 2015a)

When the feed solution flows perpendicular to the membrane surface, the filtration mode is named dead-end filtration. The permeate flows across the membrane surface and the retained particles accumulate on the surface, thus, there is no retentate stream. This accumulation leads to a secondary filtration layer on the membrane surface. This cake-like layer increases the overall membrane resistance to permeation, leading to a drastic flux decline. As a consequence, higher pressure on the feed side is required to maintain the desired performance (Abdelrasoul, 2015; Singh, 2015a).

In cross-flow filtration mode, there are three streams: feed, permeate and retentate. The feed flows parallel to the membrane's surface. Due to pressure driving force, the permeate flows perpendicularly across the membrane and the rejected particles are carried by the retentate stream. Therefore, there is a smaller rate of particle accumulation on top of membrane and the retentate has increasing concentration along the process (Abdelrasoul, 2015; Singh, 2015a; Vigneswaran et al., 2012).

Although dead-end filtration requires less power consumption than cross-flow filtration (Abdelrasoul, 2015), the operation can be less efficient. Since the cake-layer build up occurs faster, dead-end filtration requires more frequent stops for cleaning, which can reduce membrane lifetime and increase operational cost. Hence, cross-flow filtration represents a more advantageous process (Singh, 2015a). 


\subsubsection{Membrane Systems and Modules}

Membrane systems are composed of a membrane module, pumps, piping, valves, controllers, and tanks (feed and product). These systems can be operated at constant TMP or constant permeate flux depending on the application. For industrial applications, membrane systems are often operated at constant permeate flux, because most of the processes are operated continuously. As membrane fouling occurs, an increase in pressure is required, making it more difficult to achieve and maintain constant permeate flux (Vigneswaran et al., 2012).

A membrane module is defined as structure that holds one or more membranes that separate feed, permeate and retentate (Koros et al., 1996). Its main purpose is to support the membrane and provide good fluid management. Each module presents characteristics (i.e., packing density, energy usage, replacement frequency, ease of manufacture, fluid management and fouling control) that make the module more appropriate for a specific process (Singh, 2015a).

\subsection{Concentration Polarization and Fouling Mechanisms}

Concentration polarization is considered a primary cause of fouling (Baker, 1996). This phenomenon is schematically represented in Figure 2-6. It consists of the gradual increase of the solute concentration at the boundary layer as the filtration process proceeds. The concentration at the membrane surface is higher than the concentration at the bulk feed solution. The phenomenon occurs due to the difference of diffusion rates of various species in a feed solution composed of multiple species (Abdelrasoul, 2015; Ghidossi et al., 2006). 


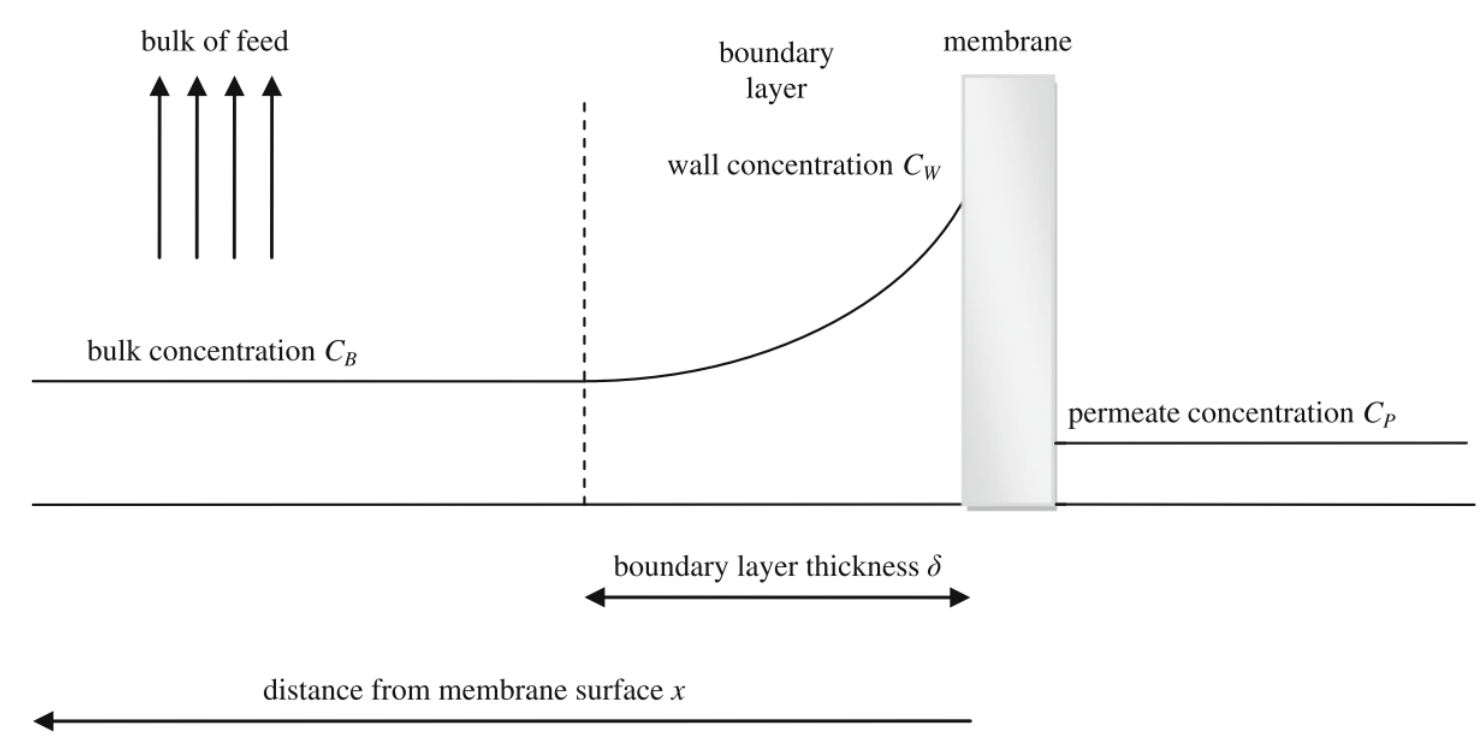

Figure 2-6. Concentration polarization phenomenon (Keir et al., 2014)

The consequences of concentration polarization include the reduction of permeate flux and membrane selectivity (Baker, 1996). Concentration polarization plays an important role on filtration processes, especially for RO and UF. It can represent a serious limitation in terms of cost, because it can decrease the lifetime of the membrane and compromise process productivity (Hoek, 2017).

Fouling is defined as a process that leads to loss of performance of a membrane due to the deposition of suspended or dissolved substances on its external surfaces, at its pore openings, or within its pores (Koros et al., 1996). In other words, fouling is a phenomenon that results from the cake build up of particles deposited on the surface (external fouling) and within the membrane pores (internal fouling). Transmembrane resistance is increased with fouling, leading to decline of permeate flux when operating at constant pressure, or increases TMP when operating at constant flux. Figure 2-7 shows a schematic representation of the flux decline with filtration time. 


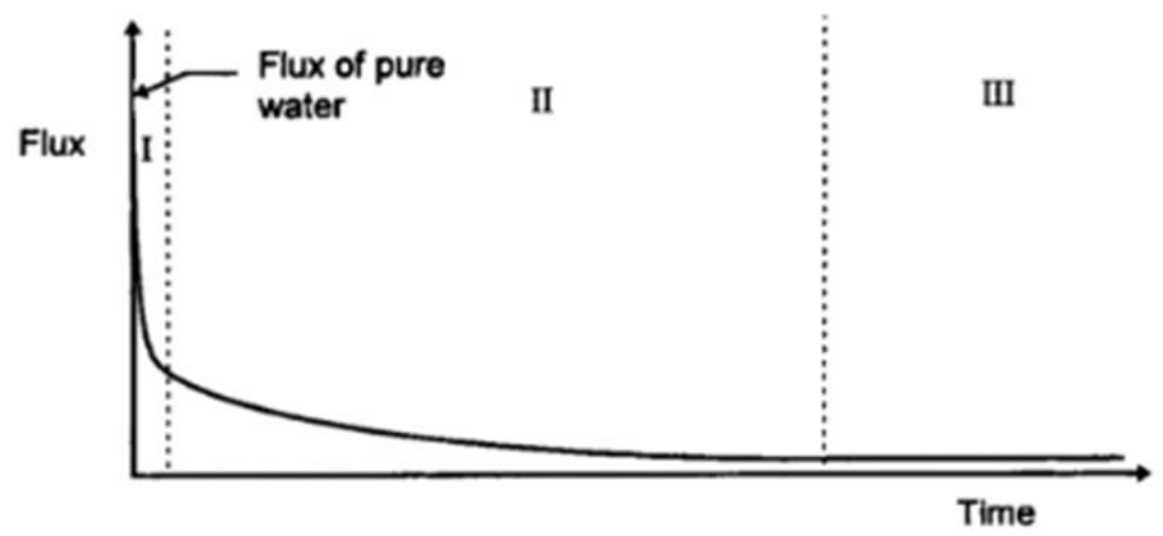

Figure 2-7. Stages of flux decline (Li et al., 2008)

At the beginning of the filtration process, the membrane pores are clean, so a maximum permeate flux is obtained. As the filtration proceeds, particles start to deposit on the membrane surface, blocking the pores and leaving the membrane only partially permeable (Seader et al., 2006). Region I shows the rapid flux decline in the first minutes of the filtration, due to the pore blockage. Region II corresponds to a longer period of gradual flux decay which is attributed to the cake build up. And finally, Region III represents the steady-state flux that is achieved after the cake layer is formed and compacted (Li et al., 2008).

The rate of fouling depends on properties of the membrane as well as the feed solution. In many membrane processes, the feed solution composition is complex. Therefore, there are intricate interactions including physical, chemical and biological phenomena which affect the membrane performance (Gao et al., 2011). The operating conditions of a filtration process (i.e., feed flow rate and applied pressure) also have an impact on membrane fouling rate. Since fouling is an intrinsic phenomenon to membrane filtration processes, fouling control strategies have been developed to overcome this major limitation to the use of membranes. 


\section{Chapter 3}

\section{Literature Review}

In this chapter a literature review on fouling control strategies is presented. The application of ultrasound in membrane separation processes is also reviewed. Previous research findings in the field are presented and discussed.

\subsection{Fouling Control Strategies}

According to the reported literature, fouling is a significant barrier to the widespread application of membrane filtration in industrial processes (Mohammad et al., 2012; Xie et al., 2016). Because it is an inherent problem to the nature of membrane filtration processes, several strategies and techniques to control fouling have been studied and reported (Gao et al., 2011; Singh, 2015a).

Cleaning strategies aims in the removal of the cake layer to recover permeability after membrane has been fouled. On the other hand, fouling control strategies (also referred as flux improvement techniques) focus to avoid or delay the formation of a cake layer on the membrane surface and back diffusion of the solute from the membrane surface. Before selecting a cleaning or fouling control strategy for a specific process, favourable operating conditions including feed flow rate and applied pressure should be determined. The importance of defining operating conditions is related to the trade-off between permeate flux and particle accumulation. Higher flow rate and higher pressure promote a rapid build up of a denser cake layer, which is harder to clean. On the other hand, lower flow rate and lower pressure promote slower build up of a less dense cake layer, but it yields lower productivity (Waterman et al., 2016). Thus, it is important to evaluate the balance between feed flow rate and applied pressure in order to control fouling.

According to Abdelrasoul (2015), fouling can be reduced by modifying particles-tomembrane and particle-to-particle interactions. For this purpose, there is a wide variety of feed 
pre-treatment options that can be used. The most common options include: coagulation, adsorption, preoxidation (using ozone, chlorine or permanganate), magnetic ion exchange (MIEX) resins and biological treatment. There is also the possibility of integrating different treatments according to the feed solution and process properties. However this can rapidly increase operational cost and complexity (Gao et al., 2011).

Cleaning processes are important for the removal of foulant particles even when other strategies are adopted. Chemical cleaning consists of the use of acid, alkali or biocide solution to prevent inorganic fouling, organic fouling and biofouling, respectively (Gao et al., 2011). Almost full recovery of permeate flux can be achieved through chemical cleaning; however, it can increase cost and complexity of filtration process due to the use of hazardous chemicals. Furthermore, it produces by-products that are threatening to the environment.

Physical cleaning includes periodic rinsing (backwashing and flushing), which consists of passing water through the membrane in the reverse direction of the permeate flux. Backwash with air (air scouring) can also be applied to remove particles through surface shear and increase in mass transferring motion, but it is not compatible to all types of feed solution (Gao et al., 2011). Another physical technique is the use of pulsed electric or ultrasonic fields during the filtration process to avoid particle deposition (Vigneswaran et al., 2012; Waterman et al., 2016).

For both conventional chemical and physical cleaning techniques, the frequency and severity of its application have great impact on the lifetime of the membrane and overall process cost. In order to perform these cleaning techniques, the filtration process must be interrupted which significantly decreases productivity. As an alternative to these techniques, the use of ultrasonic field in membrane cleaning and fouling control has been investigated.

\subsection{Ultrasound Application in Membrane Separations Processes}

Many research efforts have been devoted to observing and understanding how the application of the ultrasonic field can be beneficial for the membrane filtration process. The combination of US application with aforementioned techniques have also been investigated and shown promising results. One of the main advantages of US is the possibility of on-line application. In this case, the filtration process is not interrupted, and productivity is increased along with fouling reduction. 


\subsubsection{Mechanism}

The application of ultrasound has been considered a promising strategy for membrane cleaning, fouling control and flux enhancement (Kyllönen et al., 2005). As mentioned, fouling is an intrinsic challenge associated to membrane separation processes. It occurs due the deposition of particles on the membrane surface and within its pores. Ultrasound consists of longitudinal mechanical waves that propagate through various media, gas, liquid or solid, with frequency of 20 $\mathrm{kHz}$ to several $\mathrm{gHz}$. Ultrasound can be applied to create turbulence and cause detachment of particles via different mechanisms (Kyllönen et al., 2005; Lamminen, 2004; Reuter et al., 2017).

Lamminen (2004) described four main mechanisms including microstreamers, micro-jets, microstreaming and acoustic streaming, through which ultrasound can promote particle detachment from membrane surface as shown in Figure 3-1. 


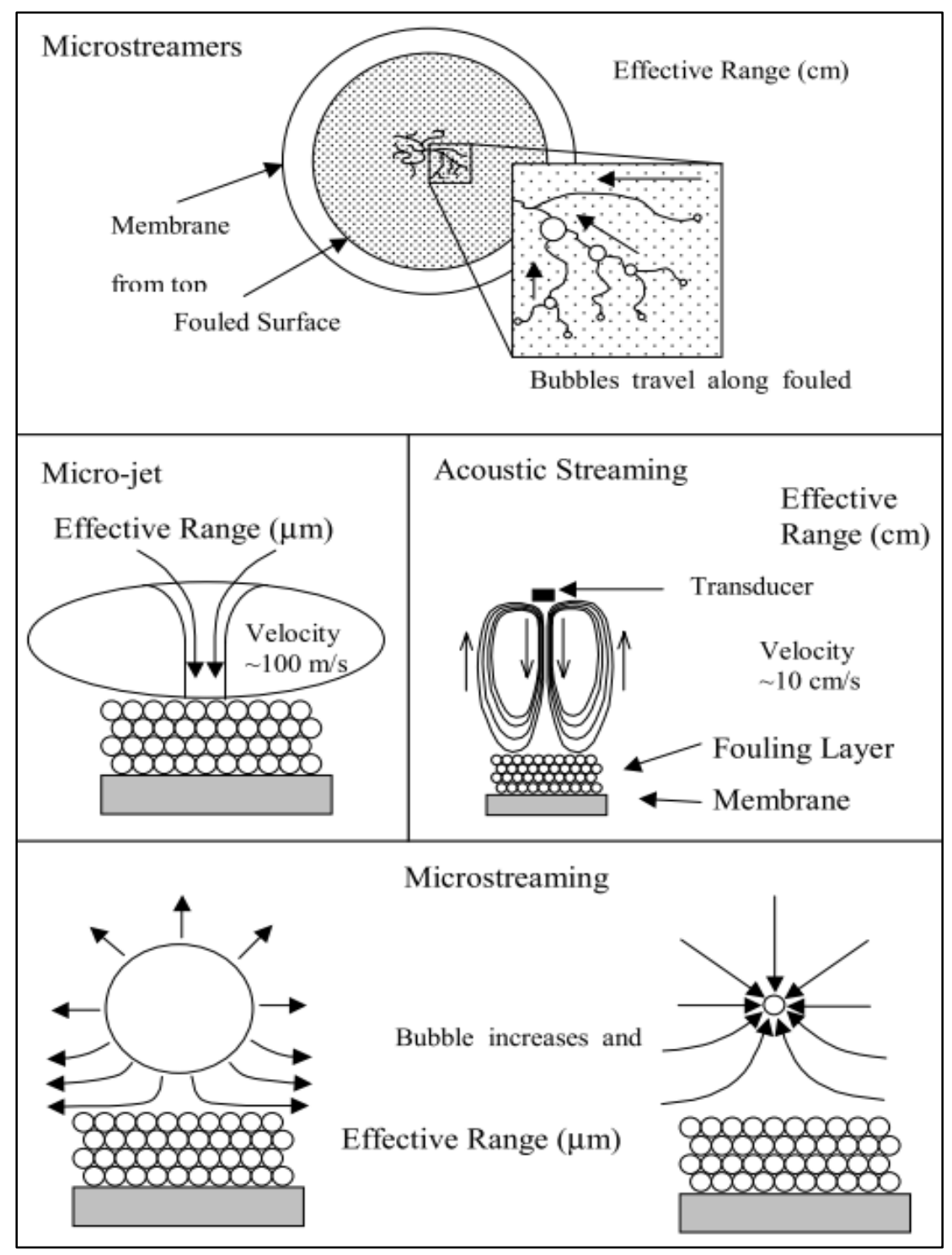

Figure 3-1 Possible mechanisms for particle detachment observed with ultrasound cleaning (Lamminen, 2004)

Acoustic streaming describes the fluid flow resulting from the absorption of acoustic energy, and it depends on ultrasound frequency and power intensity. When high-intensity US is applied in low-viscosity liquids, it produces extreme turbulent conditions (Masselin et al., 2001). Hence, movement of the fluid away and towards the surface can wash-off particles from the cake layer due to increase in shear (Lamminen, 2004). 
Cavitation bubbles result from the acoustic cavitation phenomenon that describes the growth and collapse of pre-existing microbubbles under influence of an ultrasonic field (Qasim et al., 2018). The formation of cavitation bubbles occurs when the pressure amplitude exceeds the tensile strength of the liquid during the rarefactions of sound waves (Ahmad et al., 2018). Figure 3-2 summarises the growth and collapse of cavitation bubbles.

Microstreamers, microstreaming and micro-jets are mechanisms in which particles from the cake layer are detached by the action of cavitation bubbles. They differ in the way the bubbles move and collapse near the membrane surface. Microstreamers consist of ribbon like structures that travel in the fluid, coalescing with other bubbles as they collide. The particle detachment is a result of acoustic radiation forces as the bubbles interact with the cake layer. Microstreaming is a mechanism in which the oscillations in bubble size cause fluctuations in the magnitude and direction of the fluid movement. Particle removal from the surface is a result of the drag forces originated from the dynamic velocity profile created (Lamminen, 2004).

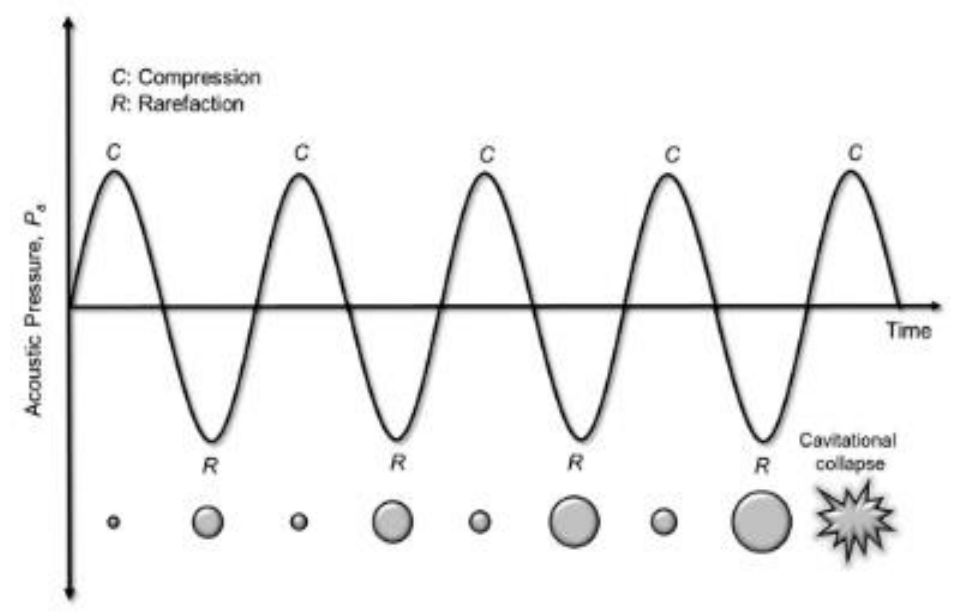

Figure 3-2. Schematic diagram of acoustic cavitation, bubble growth, and cavitational collapse (Qasim et al., 2018)

When cavitation bubbles collapse near a surface, micro-jets are formed, and a large amount of energy is released in the form of heat. Extremely high temperatures are generated within the bubbles for a short period of time (Lamminen, 2004). In these hot spots, temperature and pressure can reach up to $5000 \mathrm{~K}$ and $1000 \mathrm{~atm}$, respectively (Qasim et al., 2018). This represents a potential drawback for membrane cleaning and fouling control, especially when polymeric membranes are 
used. Depending on the material of the membrane, the collapse of cavitation bubbles can cause significant change in permeability and membrane pore density. In some cases, severe damage to the pore structure can occur, compromising membrane selectivity and the overall efficiency of the filtration process (Masselin et al., 2001).

Another consequence of US application is the potential physical and chemical changes in liquid systems. Due to the violent collapse of the bubbles and consequent increase in temperature, sonochemical reactions may occur. If the medium is water based, hydrogen and hydroxyl radicals can be dissociated and react with other components, leading to its oxidation and other secondary reactions (Qasim et al., 2018). Furthermore, US application can break large molecules into smaller ones, which impact the efficiency and fouling mechanism of the filtration processes (Chai et al.,1998).

\subsubsection{Cleaning and Fouling Control Using US}

Figure 3-3 illustrates the difference between US-aided cleaning process and US-aided filtration process. Non-aided filtration is operated without the assistance of additional techniques to prevent fouling. During a non-aided filtration, the cake layer is formed gradually, increasing the total transport resistance until constant flux is achieved. For US-aided filtration, US is applied on-line, as filtration takes place. The turbulence caused by acoustic cavitation prevents particle-tomembrane attachment and reduces fouling.

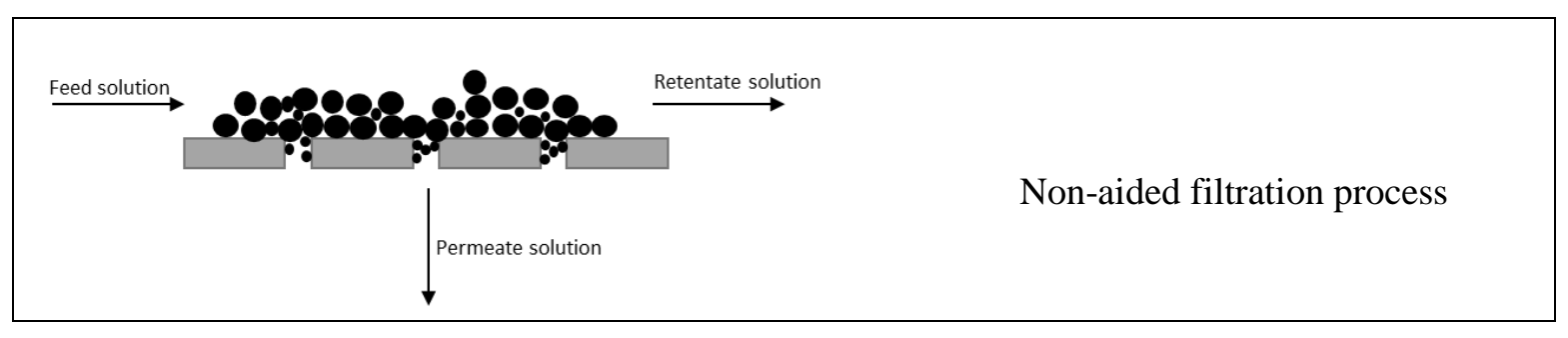




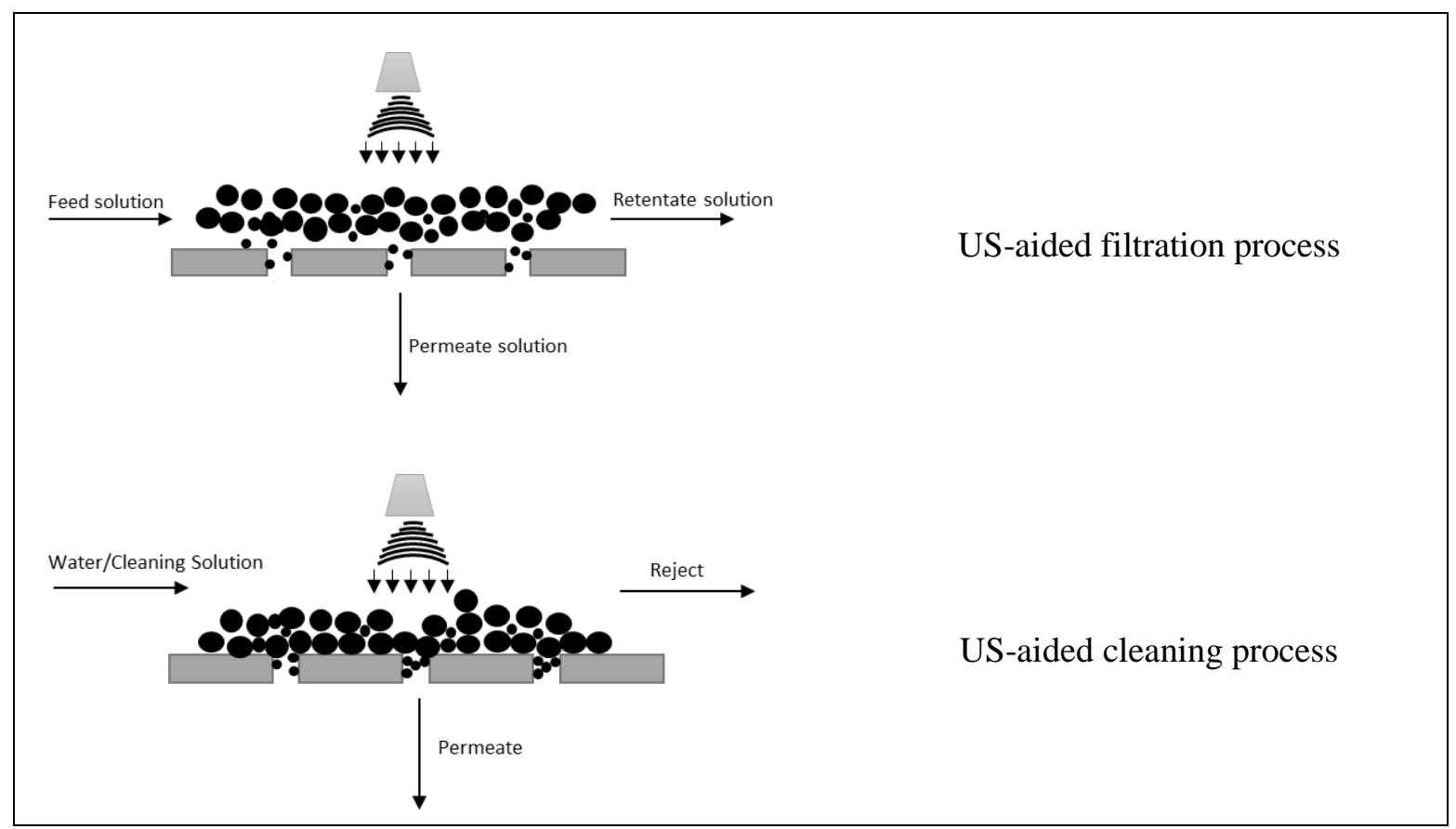

Figure 3-3. Illustration of the difference between the processes

US-aided cleaning processes are performed after the membrane is fouled. Feed solution is replaced by water (water cleaning) or other cleaning solution (chemical cleaning), and ultrasound is applied during the cleaning. In some cases, the fouled membrane is removed from the module for off-line cleaning. US can be applied directly to the membrane module or used for off-line cleaning of membranes in an ultrasonic bath. US-aided cleaning techniques combine conventional cleaning methods with US application as an attempt to improve flux recovery. Literature reports application of US during water cleaning as well as chemical cleaning (Chai et al., 1999; LujánFacundo et al., 2016b).

\subsubsection{Application of US Combined with Traditional Processes}

Applying US concurrently to water cleaning of membranes can improve its efficiency. Chai et al. (1999) reported that up to 55\% improvement was obtained when using water cleaning under sonication for polymeric membranes fouled by peptone solution. However, when compared to USaided filtrations, US-aided cleaning methods are not so advantageous, having similar or lower efficiency. According to Kobayashi et al. (2003), US-aided filtrations were more effective in enhancing permeability at low frequencies. Cai et al. (2010) observed very similar performance between US-aided cleaning and US-aided filtration with intermittent application of US at various 
frequencies. Lamminem (2004) compared off-site membrane US-aided cleaning and US-aided filtration. Although similar flux improvement was achieved, the severity of the US-aided filtration caused membrane damage.

The application of US to enhance chemical cleaning have also been attempted. US-aided chemical cleaning using $\mathrm{NaOH}$ can be $25 \%$ more efficient than using water (Alventosa-Delara et al., 2014). Lujan-Facundo et al. (2016a, 2016b) applied low frequency US to chemical cleaning using $\mathrm{NaOH}$ and Ultrasil. No significant difference was observed for the two chemicals, and cleaning efficiency was only improved by $9 \%$ when compared to the conventional method.

Although some improvement can be obtained using traditional processes combined with US application, it seems to have more disadvantages than benefits. These procedures (e.g., US-assisted chemical cleaning and US-assisted water cleaning) require interruption of the filtration process which represents a major drawback in terms of productivity. The use of water for backwashing is costly and generates more wastewater. Furthermore, the use of chemicals like $\mathrm{NaOH}$ and Ultrasil can increase the cost and complexity of the operation. Such cleaning chemicals are hazardous, can lead to membrane damage and corrosion of metal parts which can be a major limitation.

\subsubsection{US Application Modes}

Most of the published work have used ultrasonic baths instead of direct application to the membrane module. In ultrasonic baths, the membrane module is submerged in a water bath and the ultrasonic transducers are placed on the outside of the bath as exemplified in Figure 3-4.

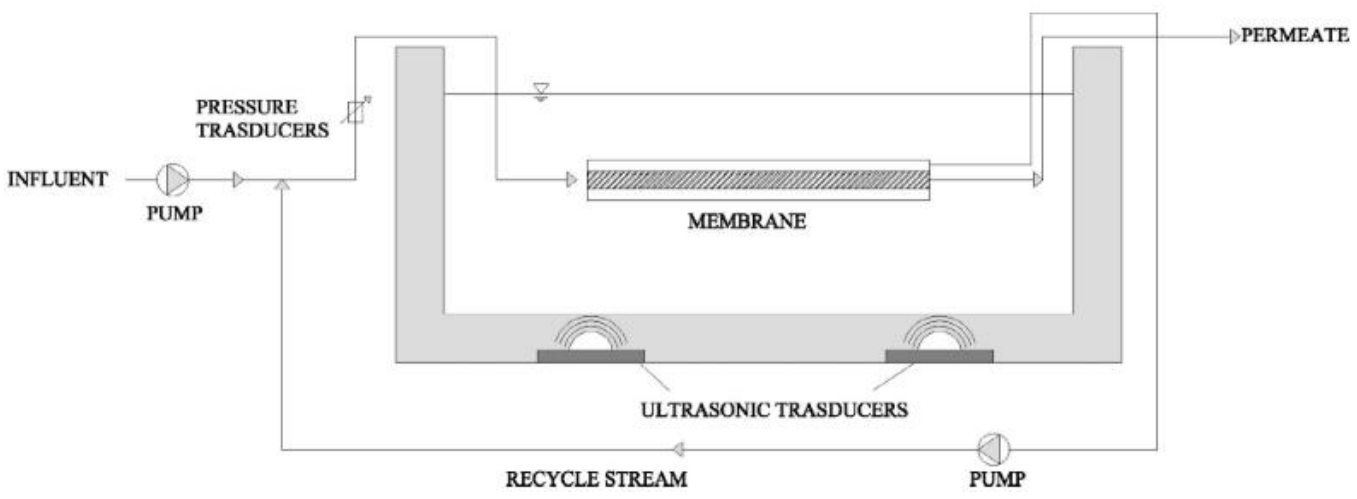

Figure 3-4. Example of an experimental setup using ultrasonic bath (Borea et al., 2018) 
A great amount of energy is dissipated since there is a significant separation between the transducer and the membrane surface. The ultrasonic waves generated near the water bath surface must travel across the water to reach the membrane module. Then, the waves must travel through the membrane module material in order to form cavitation bubbles inside the membrane module. According to observations by Cai et al. (2010), when using a commercial ultrasonic bath (3 L capacity), only $6 \%$ to $8 \%$ of US power reaches the membrane without any frequency alteration as consequence of US attenuation. Having ultrasound applied on-line and directly to the membrane surface can be more challenging to design, but it requires less energy and hence should be more cost efficient.

Few studies have applied US directly to the membrane module. Hengl et al. (2014) developed an ultrasonic device that can be coupled with membrane process to enhance permeate flux. Figure 3-5 shows the device which consisted of a metallic blade connected to an ultrasonic transducer linked to a generator. The blade was immersed in the feed channel at $8 \mathrm{~mm}$ from the membrane surface.

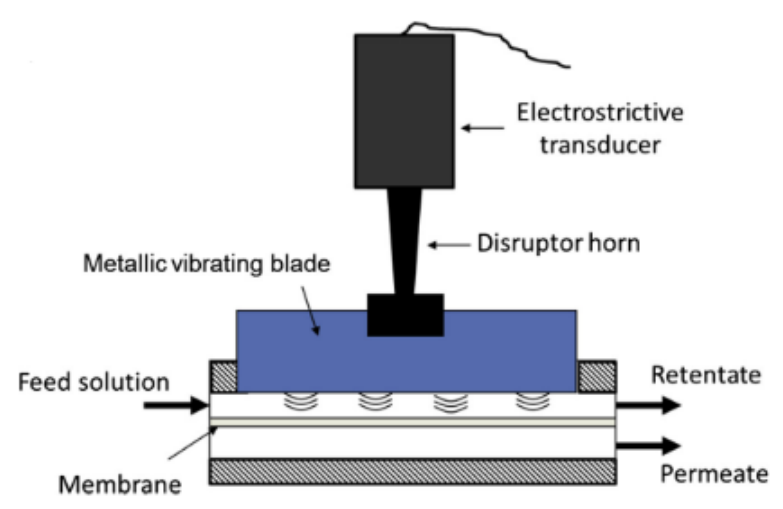

Figure 3-5.In-situ ultrasonic system Hengl et al. (2014)

Significant flux improvement was obtained and no damage to the polymeric membrane surface was observed. However, the apparatus has small flexibility regarding to the range of frequency that can be applied. Additionally, the dimensions and heavy weight of the apparatus can be a challenge for scaling-up of the process.

The position of the US transducers can have an impact on the filtration performance using an ultrasonic bath or applying in-situ. In most studies, US transducers have been placed at the 
bottom of the ultrasonic bath and good flux improvement have been reported. Latt \& Kobayashi (2006)investigated the effect of the distance between the US transducers attached to the water bath and the membrane surface. Significant differences in pressure distribution within the water bath was observed and flux enhancement was also affected.

Effect of US propagation direction on US-aided filtration was investigated by Kyllonen et al. (2006) using US transducers attached to a dead-end membrane module, either on the feed or permeate side. Better results were obtained with application on the feed side for UF membranes, while MF membranes had better results when US was applied on the permeate side. Authors related this behaviour to the pore size of these membranes. UF membranes have smaller pore size, hence US is more effective in avoiding penetrating particles to the pores when applied on the feed side.

The application of US during membrane filtration process can be done continuously or intermittently. Several studies have used these US application modes, which demonstrated to be effective in avoiding fouling and enhancing permeate flux. However, in many cases continuous application mode has presented superior performance. Observations by Cai et al. (2014) indicate that continuous application mode can yield almost double flux enhancement. In accordance to this observation, Chai et al (1998) and Lamminen (2004) also found continuous application more efficient. However, it is important to consider that continuous application can be more prone to cause membrane damage for certain experimental conditions.

\subsubsection{Ultrasonic Frequency}

Ultrasonic frequency determines the size and number of cavitation bubbles formed in the system (Fuchs, 2011). According to Leighton (1998), the size of an air bubble in water is related to the frequency according to the following equation (3).

$$
f_{o}=\frac{1}{2 \pi R_{o}} \sqrt{\frac{3 \kappa p_{o}}{\rho}}
$$

where $f_{o}$ is the resonance frequency, $p_{o}$ is the ambient pressure, $\kappa$ is the polytropic index and $R_{O}$ is the radius of the gas bubble. This equation is valid for pre-existing bubbles with radius of at least $10 \mu \mathrm{m}$. According to this relationship, resonance frequency and air bubble radius are 
inversely proportional. For this reason, when lower frequencies are applied, larger bubbles are produced.

The effect of frequency has been investigated in previous studies. For most cases lower frequencies have shown to be more efficient in improving permeate flux for both US-aided cleaning processes and US-aided filtration processes. At lower frequencies, large size bubbles, but fewer in numbers, are produced and collapse more energetically. The violent collapse of the large bubbles causes strong vibration, micro-jetting, and localized turbulence, improving permeate flux. At higher frequencies, more bubbles are formed; however, they are smaller and tend to collapse less violently. As a consequence, the use of higher frequencies is not as efficient in detaching particles from the cake layer. The difference between these two cases (lower and higher frequencies) can be explained by the attenuation of sound which is correlated to US frequency as shown in Equation (4) (Ahmad et al., 2018).

$$
A=\alpha F L
$$

Where $A$ is attenuation $(\mathrm{dB}), \alpha$ is the attenuation coefficient $\left(\mathrm{dB} \cdot \mathrm{kHz}^{-1} \cdot \mathrm{m}^{-1}\right), \mathrm{F}$ is frequency $(\mathrm{kHz})$, and $L$ is the path length $(\mathrm{m})$. According to this correlation, at higher frequencies sound is attenuated more readily and as consequence less energy is available to detach particles.

Several researchers studied the effects of ultrasound on the performance of membrane filtration where the membrane module was immersed in an ultrasonic bath. Borea et al. (2018) compared the performance of membrane filtration under $35 \mathrm{kHz}$ and $130 \mathrm{kHz}$; and lower frequency resulted in better performance. Chai et al. (1999) achieved significant flux improvement applying $45 \mathrm{kHz}$ to water cleaning process of polymeric membranes. Chai et al. (1998) observed increase in permeate flux of polyacrylonitrile (PAN) membrane applying $45 \mathrm{kHz}$ continuously during 80 minutes of filtration. Kobayashi et al. (2003) also applied $28 \mathrm{kHz}, 45 \mathrm{kHz}$ and $100 \mathrm{kHz}$ continuously during filtration process. All frequencies promoted flux improvement, but $28 \mathrm{kHz}$ was the most efficient. Similarly, Cai et al. (2010) also used the same frequency levels and obtained similar results for $28 \mathrm{kHz}$ and $45 \mathrm{kHz}$, however, no noticeable effect was observed for $100 \mathrm{kHz}$, as shown in Figure 3-6. 


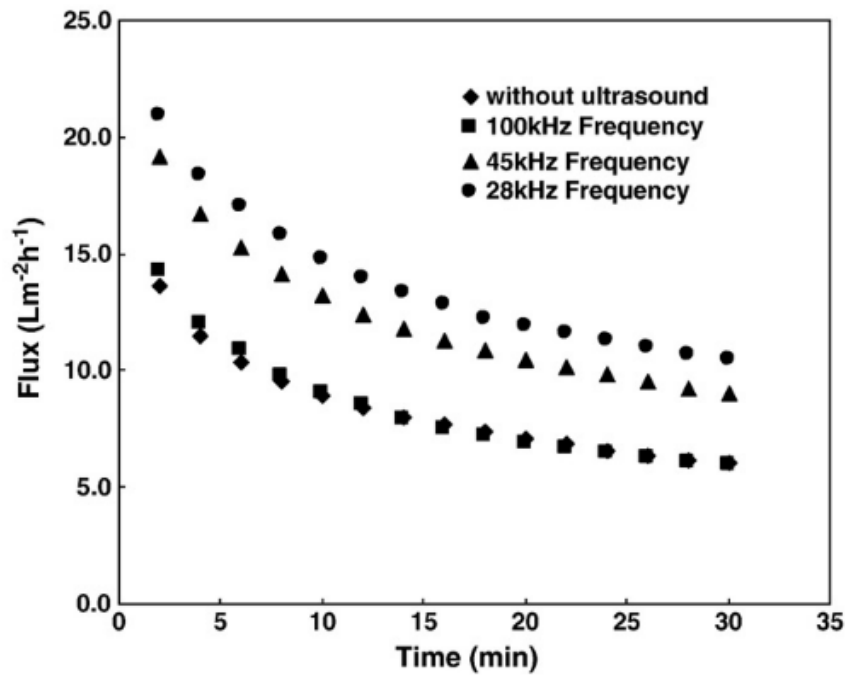

Figure 3-6. Ultrafiltration process with or without ultrasound irradiation at transmembrane pressure of 0.4 bar (Cai et al., 2010)

According to observations by Cai et al. (2010), the total and reversible resistances to permeation were significantly lower at $28 \mathrm{kHz}$ and $45 \mathrm{kHz}$, leading to an increase in permeate flux. The mechanism of action of US was not specified for this particular case, but its main contribution was the reduction of the reversible resistance which is associated to concentration polarization and cake layer formation. Although many studies have indicated that lower frequencies are more efficient in improving filtration performance, this result depends on other factors and operating conditions such as membrane module configuration, membrane material, TMP, feed flow rate and power supply.

\subsubsection{Ultrasonic Power}

The power intensity of US also plays an important role in flux improvement. Ultrasonic power determines the number of cavitation bubbles formed (Fuchs, 2011). As power intensity is increased, there is more energy available to activate pre-existing bubbles into cavitation bubbles, thus the number of cavitation bubbles is increased as well as the size of the cavitation zone. At higher power intensities, higher pressure amplitude is achieved, and as a consequence, hydrodynamic turbulence is enhanced due to increased intensity of implosion of bubbles (Lamminen, 2004). 
Because of the great amount of energy released by the collapse of cavitation bubbles, the application of US can also lead to the breakage of molecules from the feed solution. For that reason, it is possible to observe the formation of hydrogen peroxide which can act as an oxidizing agent breaking organic molecules (Lamminen, 2004). Another possible outcome from particle breakage is the increase in fouling rate, due to smaller particle size distribution (Chai et al., 1998). Smaller particles tend to penetrate the membrane pores more easily than larger particles, leading to increase in fouling rate. Furthermore, the effectiveness of ultrasound cleaning can be reduced because smaller particles tend to form more compact fouling layer which is harder to be removed with ultrasound application.

Using an ultrasonic bath, Cai et al (2014) observed that ultrasonic power has a great impact on fouling resistances. According to their published study, higher power yields lower fouling and higher permeate flux. Additionally, lower frequencies are more efficient than higher ones, and require less power to achieve the desired flux enhancement. Reuter et al. (2017) experimented a stacked configuration of polymeric flat-sheet membranes. US transducers were placed parallel to the membrane module that was submerged in the ultrasonic bath. US frequencies investigated were $35 \mathrm{kHz}$ and $130 \mathrm{kHz}$, and US power ranged from $100 \mathrm{~W}$ to $1000 \mathrm{~W}$. The US-aided cleaning processes was operated after filtration and consisted of backwashing with US application and air flushing. No cleaning effect was observed using $35 \mathrm{kHz}$ and sufficient cleaning was obtained with $130 \mathrm{kHz}$, reaching almost double cleaning efficiency at optimum operating condition. No membrane damage was observed, and the best result was achieved with nominal power of $350 \mathrm{~W}$. One of the disadvantages of the proposed process is that the filtration needs to be interrupted to clean the membrane. Furthermore, the combination of backwash and air flushing increase complexity of operating conditions and overall cost.

The mode of application has been shown to impact the effect of power in flux improvement. When US is applied through ultrasonic bath, higher power is necessary to create cavitation bubbles and turbulence inside the membrane module. This is also related to the attenuation of sound which, in this case, needs to pass through different materials and path lengths. As consequence, the direct application of US requires less power since the path length is significantly smaller. Most of the studies that applied US through ultrasonic bath the nominal power ranged from $200 \mathrm{~W}$ to $1000 \mathrm{~W}$. 
On the other hand, the previously mentioned study by Hengl et al. (2014), in which US was applied directly to the membrane module, significant improvements were observed, and the nominal power was $90 \mathrm{~W}$. This indicates that direct application to the membrane module represents a more cost-efficient process since less energy is required. Although direct application of ultrasound have been shown to be successful in controlling fouling (Hengl et al., 2014), the main challenge associated to the direct application is finding the balance between removing particles from the cake layer without damaging the membrane or fragmenting particles in the feed solution. Another challenge with on-line application of US is the uneven ultrasonic field created under

pressurized conditions. According to Kyllonen et al. (2006), the higher the applied pressure, the more uneven the ultrasonic field becomes. This might cause membrane damage and represent a limitation for fouling control at higher pressures.

\subsubsection{Feed Solution Properties}

The use of US for fouling control have been tested using various solutions, such as peptone solution (Chai et al., 1999; Kobayashi et al., 2003), milk solution (Kobayashi et al., 2003b), dextran solution (Chai et al., 1998), colloidal solutions (Hengl et al., 2014), latex (Ahmad et al., 2018; Lamminen, 2004) and dairy wastewater (Luján-Facundo et al., 2016). Feed properties have direct influence on the efficiency of US application. For high feed concentrations, lower improvement of permeate flux is observed when US is applied. Qasim et al. (2018) attributed this behaviour to an increase in the number of nuclei available for the generation of cavitation bubble. When a large number of bubbles are produced, the ultrasound waves are attenuated due to scattering and absorption.

The particle size also affects the performance of US in improving fouling control. There is evidence that US is more effective when particle size is smaller. This can be associated to lower lift and drag forces (created in turbulent regime) experienced by smaller particles. With this, very small particles tend to get trapped and create a denser cake layer which is harder for US to break. However, the particle size is not the only property of the feed solution influencing the cleaning effect of ultrasound. Lamminen (2004) tested the performance of US using different particle sizes $(1 \mu \mathrm{m}, 0.5 \mu \mathrm{m}$ and $0.3 \mu \mathrm{m})$ of surfactant-free polystyrene latex particles with sulfate functional groups. Figure 3-7 shows the change in the normalized permeate flux (ratio of flux of latex solution filtration to flux of particle free filtration) over time for filtration with latex particles (various sizes) 
followed by ultrasonic cleaning at $620 \mathrm{kHz}$ for 5 seconds. The flux recovery due to US application is indicated by the dashed line shapes in the Figure 3-7.

The most effective cleaning was observed with intermediate particle size $(0.5 \mu \mathrm{m})$. The largest and smallest particles yielded small improvement of permeate flux. The author attributed these results to the fact that the feed solution with intermediate particle size had the most negatively charged zeta potential. This way, a thinner and more porous cake layer is created with the intermediate particle size. Furthermore, with this charge, particle-to-particle detachment is easier due to repulsive forces.

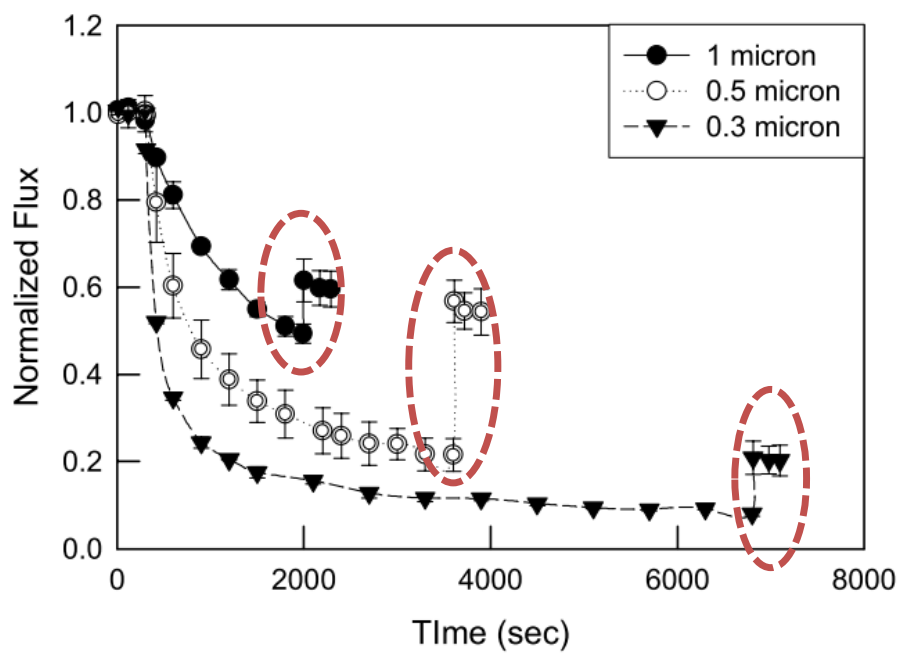

Figure 3-7. Normalized permeate flux of the membranes over filtration process using particles of sizes, $1.0 \mu \mathrm{m}, 0.5 \mu \mathrm{m}$, and $0.3 \mu \mathrm{m}$. Ultrasonic cleaning performed using $620 \mathrm{kHz}, 0.21 \mathrm{~W} . \mathrm{cm}^{-2}$, and a duration of 5 seconds (Lamminen, 2004).

\subsubsection{Feed Flow Rate}

The effect of feed flow rate (and cross-flow velocity) has also been investigated in the application of US for fouling control. According to Kyllonen et al. (2006), the effect of cavitation is expected to decrease when filtration is operated in cross-flow mode. In stagnant conditions, cavitation bubbles can become trapped on the membrane surface and cause damage due to repeated oscillations at the same point. However, a balance between cross-flow velocity and fouling control using US should be determined. If cross-flow velocity is too low, bubbles are susceptible to 
stagnation. In this case, erosion and membrane damage can negatively impact the filtration process. On the other hand, if cross-flow velocity is too high, larger bubbles might be carried away through the reject stream without reaching the membrane surface.

Alventosa-deLara et al. (2014) reported an optimization of factors affecting US-assisted cleaning of UF ceramic membrane fouled by dye particles. Three factors in three different levels were analyzed: TMP (0.5 bar, $1.5 \mathrm{bar}, 2.5 \mathrm{bar})$, cross-flow velocity $\left(1 \mathrm{~m} . \mathrm{s}^{-1}, 2 \mathrm{~m} . \mathrm{s}^{-1}, 3 \mathrm{~m} . \mathrm{s}^{-1}\right)$ and US frequency levels (37 kHz, $80 \mathrm{kHz}$ and mixed wave). Figure 3-8 shows the 3D response surface relating each investigated factor with cleaning efficiency. As observed in Figure 3-8, cleaning efficiency was found to increase linearly with the cross-flow velocity (CFV). Maximum cleaning efficiency was obtained when the highest cross-flow velocity of $3 \mathrm{~m} \cdot \mathrm{s}^{-1}$ was applied. However, because only three cross-flow velocities were investigated, there is no proof that this represents a global maximum. 


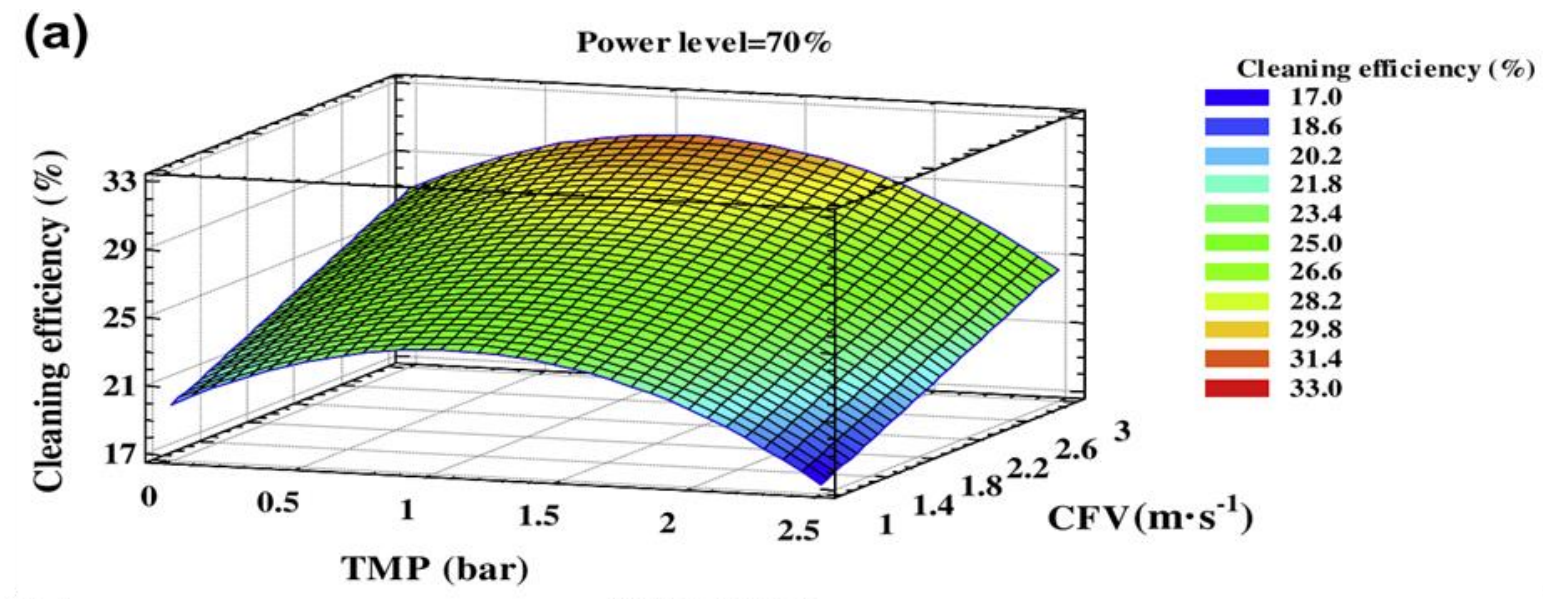

(b)

TMP=1.5 bar
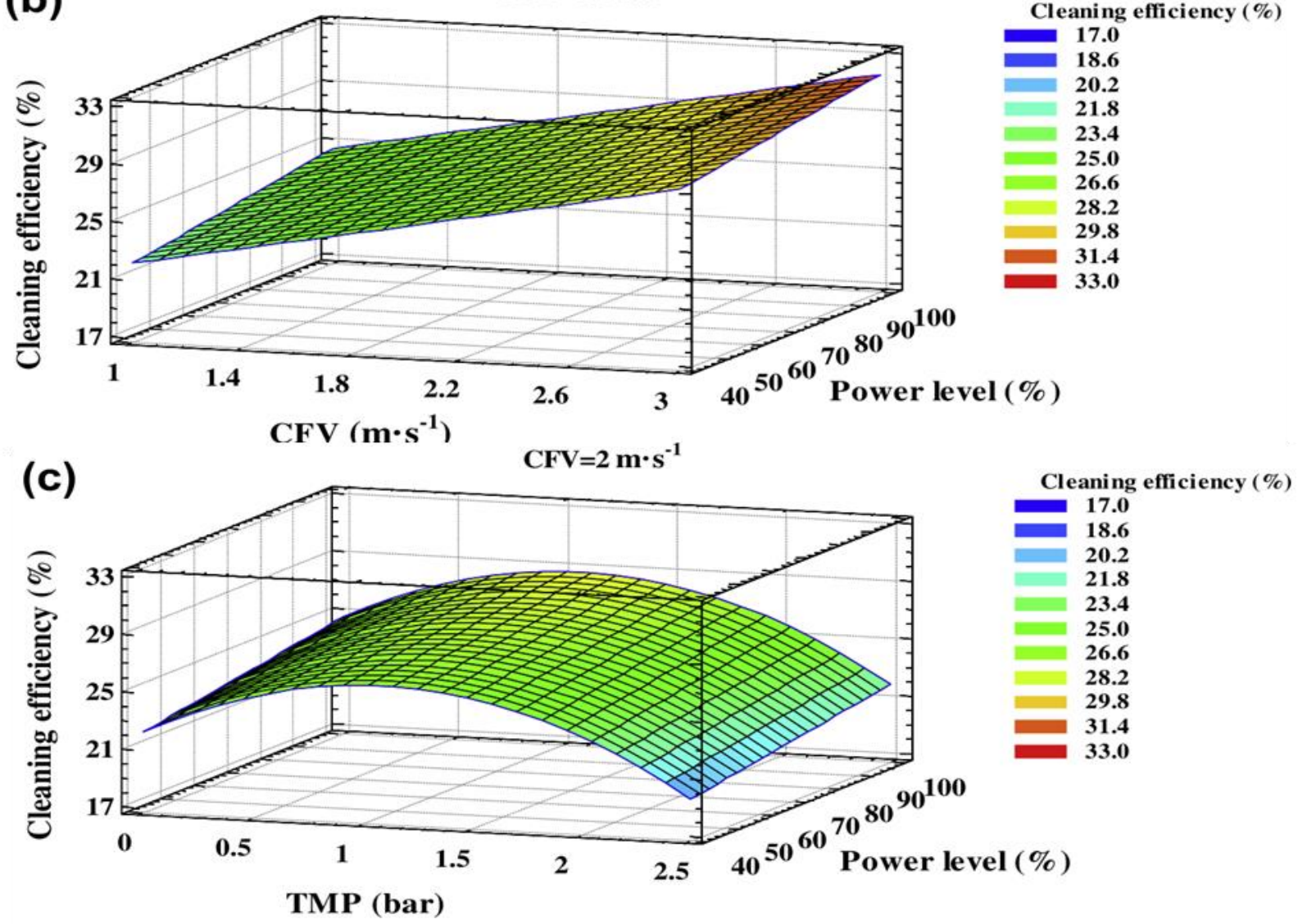

Figure 3-8.Response surface plot showing the effect of (a) TMP and CFV (b) CFV and power level (c) TMP and power level with cleaning efficiency when using mixed wave sonication mode (Alventosa-Delara et al., 2014)

Borea et al (2018) investigated the effect of feed flow rate and ultrasonic frequency in USaided UF using hollow fibre polysulfone membrane. Two membrane fluxes $\left(75 \mathrm{~L} . \mathrm{m}^{-2} \cdot \mathrm{h}^{-1}\right.$ to 150 
L. $\left.\mathrm{m}^{-2} \mathrm{~h}^{-1}\right)$ and two frequencies $(35$ and $130 \mathrm{kHz}$ ) were analyzed. Ultrasound was applied using a water bath with power intensity set to $800 \mathrm{~W}$. The largest reduction of fouling rate of $57.3 \%$ was achieved when both feed flow rate and frequency were at their highest levels. The flow rate appears to have a significant effect on the UF performance under ultrasonic field, and higher flux improvement was observed when the feed flow rate was increased from $75 \mathrm{~L} \cdot \mathrm{m}^{-2} \cdot \mathrm{h}^{-1}$ to $150 \mathrm{~L} \cdot \mathrm{m}^{-2}$ $\mathrm{h}^{-1}$ under $130 \mathrm{kHz}$.

\subsubsection{Membrane Materials}

Literature reports US-aided fouling control using membranes of various materials (i.e. polymeric or ceramic), pore sizes and structures (i.e. homogeneous, non-homogeneous and modified surfaces). Ceramic membranes are more robust and mechanically stable than polymeric membranes, however, the cost is significantly higher. For example, based on the prices provided by Sterlitech Corp. (Kent, WA, USA), the cost of ceramic membrane can be 65 times higher than polyvinylidene fluoride (PVDF) membranes. Lujan-Facundo et al. (2016) investigated the cleaning efficiency improvement by US for different membranes used in dairy industry. Fouling was performed using three different solutions and four UF membranes of different MWCO and materials (polymeric and ceramic). Better results were obtained using ceramic membranes, but no clear relation between the material and US application was found.

Many studies have demonstrated that the application of US for fouling control is feasible for polymeric membranes when using ultrasonic bath (Cai et al., 2010; Chai et al., 1998, 1999; Lamminen, 2004; Muthukumaran et al., 2005) as well as using direct application (Hengl et al., 2014). Due to the violent nature of the cavitation bubble collapse, polymeric membranes are susceptible to membrane erosion, but some polymers are more resistant than others. Investigation by Masselin et al. (2001) observed the effect of $47 \mathrm{kHz}$ ultrasonic waves on polyether sulfone (PES), PVDF and polyacrylonitrile (PAN) membranes immersed in an aqueous bath (outside the membrane module). Membranes were placed in a beaker which was immersed in an ultrasonic bath. PVDF and PAN membranes showed higher structural resistance and presented less damage.

Wang et al. (2006) tested different polymeric MF membranes under $40 \mathrm{kHz}$ and various power levels using an ultrasonic bath. The main goal of the study was to analyze the endurance of different membrane materials to US application. The membranes tested were PES, the mixed ester of cellulose nitrate with cellulose acetate (CN-CA), nylon $6(\mathrm{Nr})$, and PVDF. Figure 3-9 shows the 
variation of each membrane water flux under application of ultrasound. On the left, the water flux is shown as function of the US application time. On the right, the water flux is shown as function of the US power intensity. An increase in water flux indicates that the membrane material experienced change in permeability due to application of US.
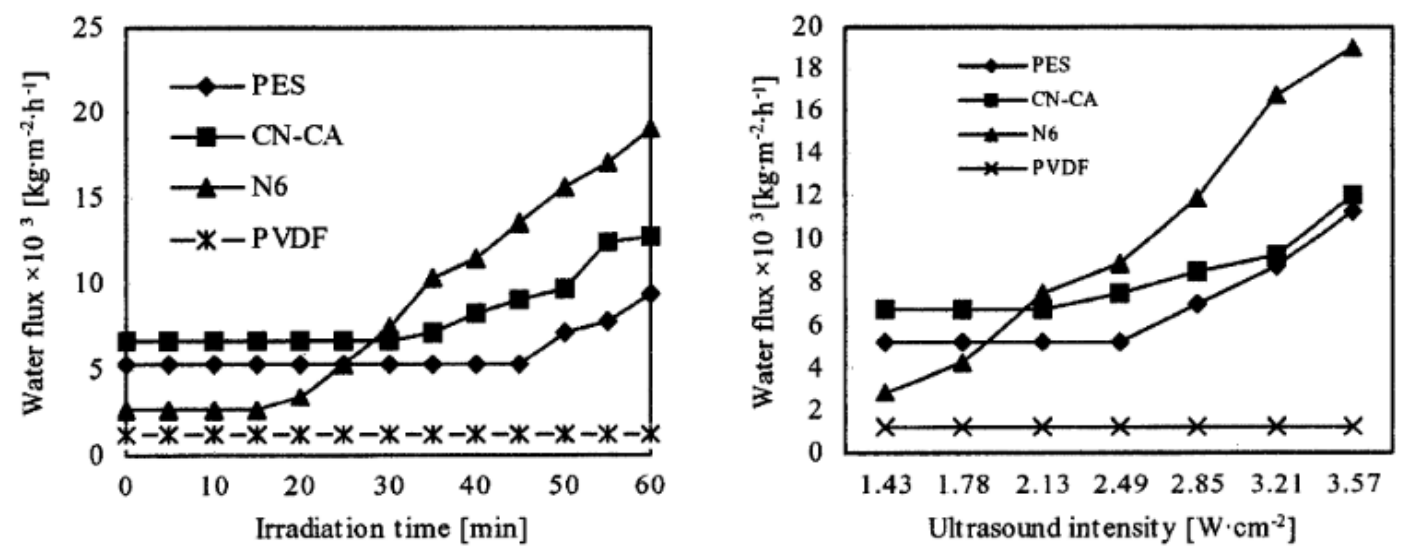

Figure 3-9. Effect of irradiation time and ultrasound intensity on water flux for different polymeric MF membranes (Wang et al., 2005).

Figure 3-9 shows that the water flux for PVDF was constant during US application for various irradiation times and US power intensity. This result indicates that PDVF was the only material with no significant change in permeability and selectivity. Furthermore, PVDF is strong enough to endure the high temperature and pressure created by the collapse of cavitation bubbles. PVDF thus represents a cost-effective option for many processes and can be benefited from USaided fouling control.

In summary, the application of US represents a promising technique to control fouling of polymeric membranes, increasing permeate flux between 20 and 90\%. US-assisted filtrations have potential to be applied for various feed solutions with high solid content such as latex paint wastewater and can be advantageous for the simple operation and energy efficiency.

The generation of high volumes of wastewater is a major environmental impact associated to paint industry. The main source of wastewater in latex paint industry is from equipment cleaning which is very important to avoid damage due to the properties of the raw materials and final product. One of the challenges for the wastewater treatment is the high solid concentration, and for this reason, US-aided ultrafiltration represents a promising technique. 
The direct application to the membrane module seems more cost efficient than the use of ultrasonic bath due to lower attenuation of ultrasonic waves, requiring lower power intensity Regarding membrane materials, PVDF membranes have been reported as a feasible option for USassisted filtration due to its structural properties. With all that considered, the goal of the presented study is to investigate the effect of ultrasonic frequency and power on US-aided UF of simulated latex wastewater of various concentrations. Where the ultrasound applied continuously directly to the membrane module from the feed side. 


\section{Chapter 4}

\section{Methodology}

This chapter details the experimental setup, ultrafiltration procedure, analytical methods and all materials used in this study.

\subsection{Experimental Setup}

A schematic diagram of the experimental setup is shown in Figure 4-1. It was composed of a feed tank connected to a centrifugal pump (Model 7505, Schmitt-Kreiselpumpen GmbH \& Co. $\mathrm{KG}$, Germany) which pumped fluid downstream passing through a rotameter and reaching the feed side of the membrane module. A pressure sensor (Model Omega PX303-100G5V, $\pm 0.25 \%$ ) was connected on the feed side of the module to monitor applied pressure. The permeate was collected using a beaker and its mass was monitored gravimetrically using an electronic balance, $\pm 0.1 \mathrm{~g}$ (Model Adventurer Pro AV2101, Ohaus Corporation, New Jersey, USA). Both pressure sensor and electronic balance were connected to a data acquisition system. 


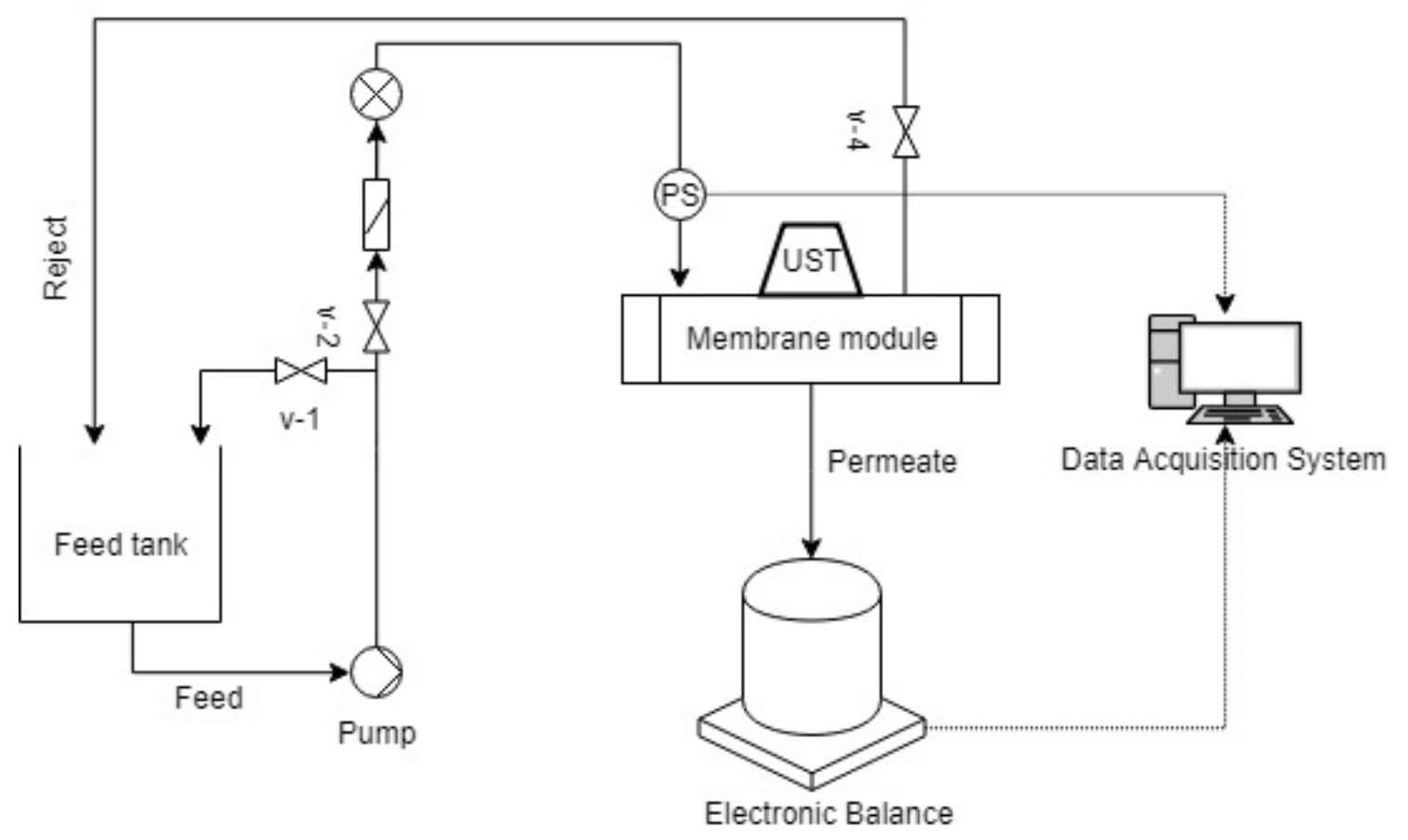

Figure 4-1. Experimental setup

Figure 4-2 shows the membrane module that was designed to fit an US transducer on the feed side. The module was composed of two solid plates constructed out of aluminum possessing mechanical properties that allow sound to travel at high rates. The total distance between the transducer and the membrane surface was fixed at $8 \mathrm{~mm}$.

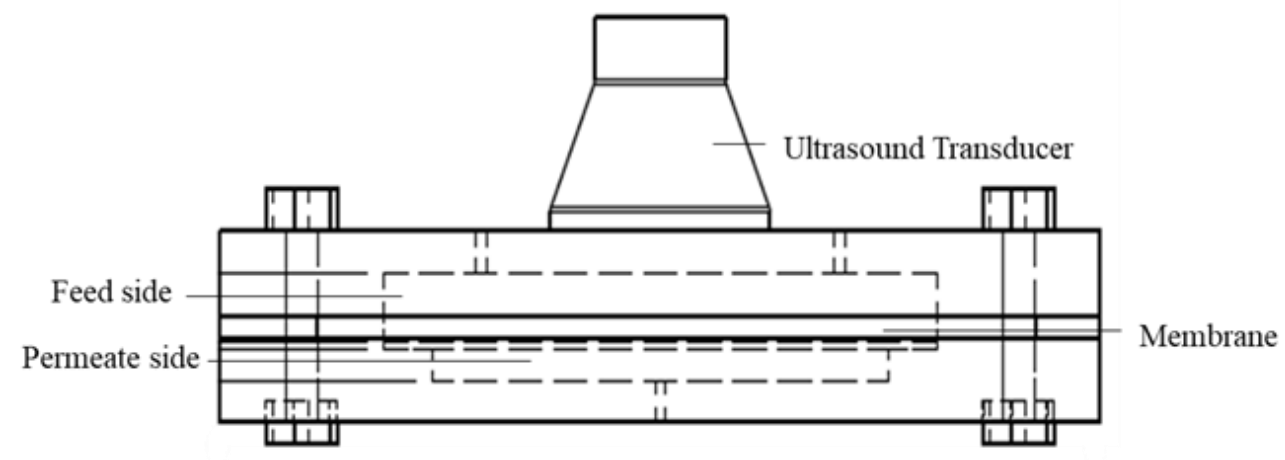

Figure 4-2. Drawing of membrane module (front view) 
Figure 4-3 shows each part of the membrane module except the US transducer in an exploded view. A rubber gasket (2) was placed between the plates (1 and 5) to prevent liquid leaking. The membrane (3) was placed on top of a porous metal support (4) to prevent bursting due to applied pressure. The feed solution entered the module on the left side (6) and the reject stream exited through the right size (7). The membrane transducer was placed between feed inlet and reject outlet.

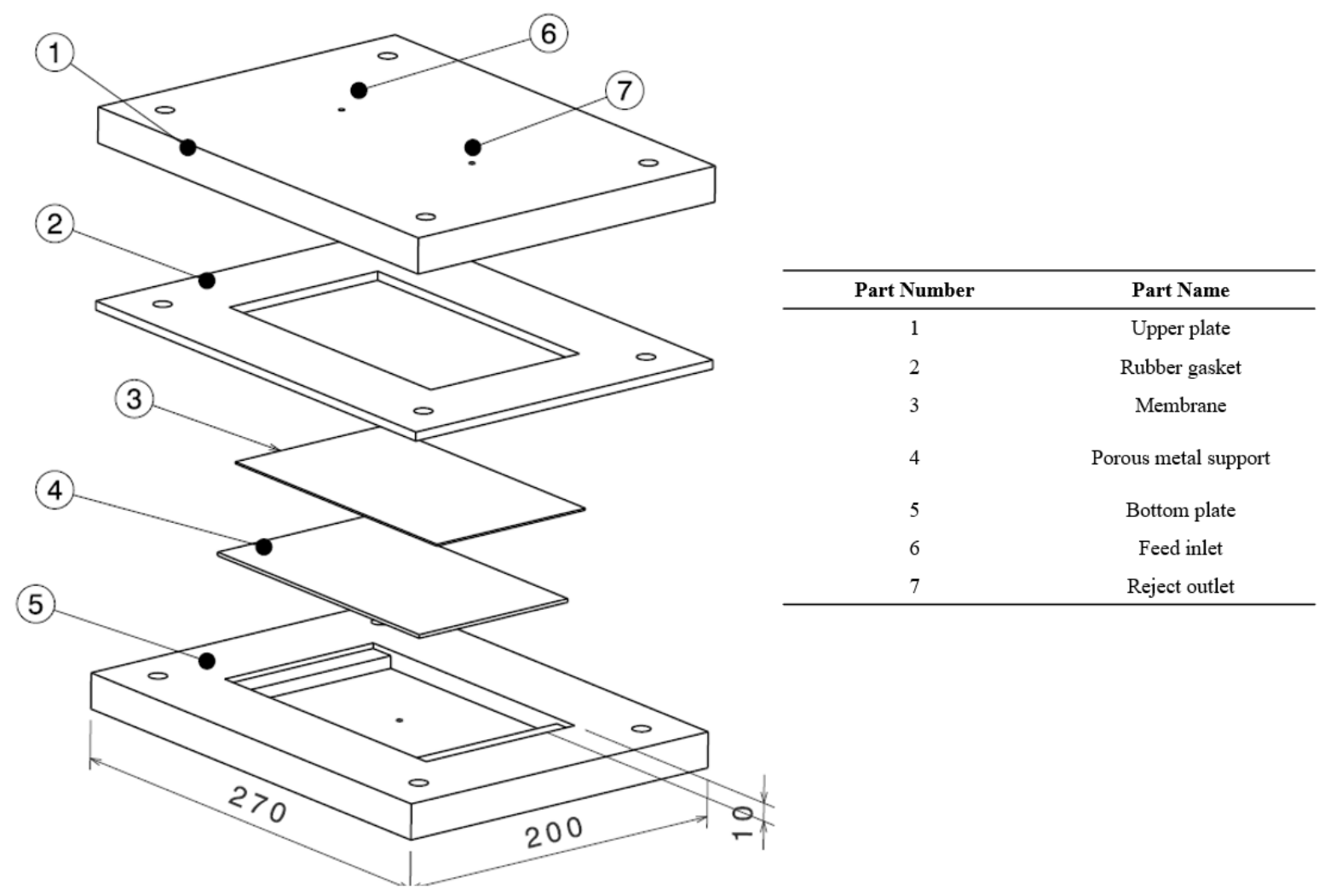

Figure 4-3. Exploded view of the membrane module (dimensions are in millimeters).

As the feed solution passed through the membrane module, fouling takes place as the solid particles accumulated on top of the membrane, and the water (permeate solution) passed through the membrane reaching the permeate side. Permeate solution was accumulated in a small reservoir and exited through the bottom of the module. The application of US to the membrane module generated cavitation bubbles on the top plate (feed side) and on the bottom plate (permeate side). 


\subsection{Ultrafiltration Membranes}

Two polymeric flat sheet ultrafiltration membranes were used in this investigation. Polycarbonate Track Etch (PCTE) membrane filters with nominal pore size of $0.1 \mu \mathrm{m}$ (Sterlitech Corp., Kent, WA, USA) have homogenous structure with narrow pore size distribution and are coated with polyvinylpyrrolidone (PVP) to enhance hydrophilicity. These membranes are very thin (nominal thickness of $3 \mu \mathrm{m}$ to $24 \mu \mathrm{m}$ ), can operate within $\mathrm{pH}$ level of 4 to 8 and at maximum operating temperature of $140{ }^{\circ} \mathrm{C}$. PVDF membranes with nominal pore size of $0.03 \mu \mathrm{m}$ (MicrodynNadir) have non-homogeneous structure and backing material of non-woven polyester. The zeta potential of the PVDF membrane is $-2.5 \mathrm{mV}$. These membranes have thickness of $160 \mu \mathrm{m}$ to 200 $\mu \mathrm{m}$ and can operate within a wide range of $\mathrm{pH}$ and temperature.

\subsection{Feed Solution}

The feed solution used in this study simulates the wastewater from latex paint industry. The solution was prepared by mixing distilled water and a measured volume of commercial latex paint (Easyflow Interior Latex Paint, White, Flat) in the feed tank of the experimental setup. The density of the commercial paint is $1.46 \mathrm{~g} . \mathrm{mL}^{-1}$ and the solid content was determined using solid content analysis. For each experiment, approximately $12 \mathrm{~L}$ of solution was prepared at a desired solid concentration by varying the measured volume of paint. Table 4-1 shows the measured zeta potential of the feed solutions at different solid concentrations.

Table 4-1.Zeta potential measured for feed solution with different solid concentration

\begin{tabular}{cc}
\hline Concentration $(\mathbf{w t} . \%)$ & Zeta potential $(\mathbf{m V})$ \\
\hline 0.075 & -19.3 \\
0.15 & -15.6 \\
0.30 & -13.2 \\
\hline
\end{tabular}

In general, paints are composed of four main ingredients: binder, solvent, pigment and additives. The binder is the main ingredient and consists of a polymer which is responsible for holding pigment particles throughout the coating. The paint used in this study has vinyl acrylic latex as binder material, but its exact composition is proprietary. 


\subsection{Operating Parameters}

As the goal of this study is to investigate the effect of continuous in-situ ultrasound application to avoid fouling during ultrafiltration of simulated latex wastewater, three operating parameters were controlled: ultrasonic frequency $(\mathrm{F})$, ultrasonic power $(\mathrm{Pw})$ and feed solution solid concentration (Cs). The feed solution was kept at room temperature for all experiments. Feed flow rate $(\mathrm{Q})$ and pressure $(\mathrm{P})$ were also kept constant at $1.0 \mathrm{~L} \cdot \mathrm{min}^{-1}$ and 5 psi, respectively. These conditions are similar to what has been applied in other research papers regarding ultrafiltration of latex wastewater (Abdelrasoul, 2015; Bedasie, 2010; Naddeo et al., 2015). The Reynolds number for the flow inside the membrane module was calculated as 322 using Equation (5)

$$
R e=\frac{\rho D \bar{v}}{\eta}
$$

Where $\rho$ is the density of water at $22{ }^{\circ} \mathrm{C}\left(0.998{\mathrm{~g} . \mathrm{cm}^{-3}}^{-3}, \mathrm{D}\right.$ is the hydraulic diameter of the opening on the feed side of the membrane module (a rectangle with dimensions $100 \times 30 \mathrm{~mm}), \eta$ is the dynamic viscosity of water at $22^{\circ} \mathrm{C}(0.955 \mathrm{cP})$ and $\bar{v}$ is the fluid velocity $\left(0.021 \mathrm{~m} . \mathrm{s}^{-1}\right)$.

Ultrasound was applied using piezoelectric ultrasonic transducers which convert electrical energy from the ultrasonic generator into ultrasonic waves. The ultrasound transducers available for this study operated at $20 \mathrm{kHz}, 28 \mathrm{kHz}$ and $40 \mathrm{kHz}$ and had a nominal power $100 \mathrm{~W}$. The power supply available for each transducer had a fixed power of $100 \mathrm{~W}$. For that reason, to achieve a fraction of the nominal power two or more transducers of the same frequency were connected in series, but only one of them was attached to the membrane module. For example, to operate at 28 $\mathrm{kHz}$ and $50 \mathrm{~W}$, two $28 \mathrm{kHz}$ transducers were connected in series as shown Figure 4-4. One of these transducers was attached to the module while the other was kept over a foam surface away from the membrane module. 


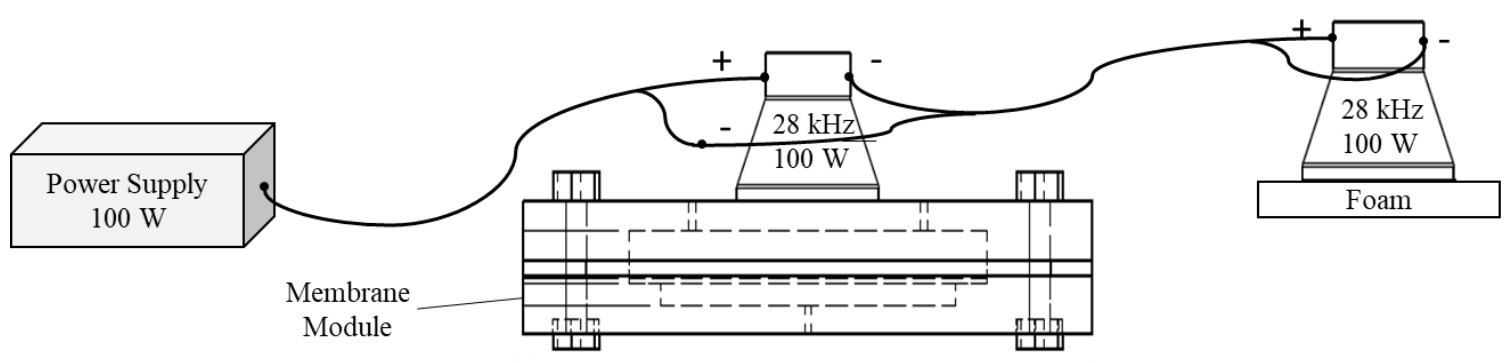

Figure 4-4. Schematic representation of ultrasonic transducers connected in series to achieve a fraction of the nominal power.

The feed solution concentration was controlled by the volume of paint added to the distilled water. First, the solid content of latex paint was determined by standard solid concentration analysis (APHA/AWWA/WEF, 2012) and used as a basis for the feed solution concentration calculation. Each millilitre of paint contained $0.828 \mathrm{~g}$ of solid which represents approximately $55.8 \%$ of the weight of the paint. So, in order to prepare feed solution with $0.15 \mathrm{wt} . \%, 1.82 \mathrm{~mL}$ of paint was added to each litre of distilled water. Table 4-2 summarizes the solid content for each concentration used.

Table 4-2. Solid content of feed solution with various concentration

\begin{tabular}{cc}
\hline Cs $($ wt. \%) & Solid content $\left(\mathbf{m g . L}^{-\mathbf{1}}\right)$ \\
\hline 0.075 & 751.80 \\
0.15 & 1503.59 \\
0.30 & 3007.19 \\
\hline
\end{tabular}

The range of solid concentration studied was based on literature reports of actual latex paint wastewater. Yapicioglu (2018) analyzed the composition of wastewater collected from a paint industry in Turkey and the solid concentration was approximately $1500 \mathrm{mg} . \mathrm{L}^{-1}$. Other studies have also used similar concentrations to investigate fouling control strategies (Abdelrasoul, 2015; Bedasie, 2010). 


\subsection{Operating Procedure}

For each experimental run, a polymeric flat sheet membrane was cut to size $(10 \mathrm{~cm} \mathrm{x} 17 \mathrm{~cm})$ and placed in the membrane module. Following recommendations from the manufacturer, membranes were preconditioned by running distilled water at desired operating pressure until constant permeate flux was achieved. Permeate was discarded and the volume of distilled water in the tank was adjusted to prepare the feed solution.

Feed solution was prepared in the feed tank by mixing distilled water and a measured volume of latex paint to obtain the desired solid concentration. The tank was filled with $12.0 \mathrm{~L}$ of distilled water. Mixing was done using the recycle line (v-1) of the experimental setup. For this, the recycle valve was fully opened and the feed valve (v-2) completely closed. A volume of paint measured using a syringe was added to the tank to prepare the feed solution. The mixing time prior to the

beginning of the filtration was kept constant to all experiments because the amount of air in the system can impact the formation of cavitation bubbles.

Once the solution was well mixed, the feed valve was opened slowly, allowing the solution to reach the membrane module. Feed flow rate and pressure were set by adjusting feed, recycle and reject valves. Feed flow rate was monitored using a rotameter located above the feed valve. The applied pressure was monitored using a pressure sensor connected to the feed side of the membrane module. The pressure reading was recorded every second and displayed on a computer using the software LabVIEW. For the runs with ultrasound application, power supply was manually turned on at the beginning of the filtration.

The permeate stream was collected using a beaker on an electronic balance which was connected to a data acquisition system, allowing precise reading of the permeate mass every 5 seconds. As filtration proceeded, pressure increased, and feed flow rate decreased due to fouling. To run the experiments at constant pressure, reject and feed valve were manipulated to adjust feed flow rate and pressure. Filtration time was kept constant at 35 minutes for all experiments. The reject stream was recirculated to the feed tank so to maintain a long run time without the need of make-up solution. The concentration of the feed solution changed less than $1 \%$ during 35 minutes of filtration. Therefore, the recirculation of the reject stream should not have a significant impact on the filtration performance at a specified solid concentration. 


\subsection{Experimental Design}

In the present study, the experimental investigation was divided in three main parts: preliminary investigation, response surface methodology and an investigation around the best ultrasonic setting.

A preliminary investigation was performed to ensure that the application of ultrasound could improve permeate flux of two polymeric membranes. Three levels of ultrasonic frequency and power were combined in 9 experiments as shown in Table 4-3. A control run, without US application, was also performed to serve as a comparison basis. PTCE and PVDF membranes were tested for the presented operating conditions, and their compatibility with the proposed process was analysed. The solid concentration of the feed solution was fixed at $0.15 \mathrm{wt}$. $\%$. Feed flow rate and applied pressure were kept constant for all experiments at $1.0 \mathrm{~L} . \mathrm{min}^{-1}$ and $5.0 \mathrm{psi}$, respectively.

Table 4-3. Experimental conditions for preliminary investigation

\begin{tabular}{cccc}
\hline & \multicolumn{3}{c}{ Parameters } \\
\cline { 2 - 4 } Run & Frequency (kHz) & Power $(\mathbf{W})$ & Concentration (wt.\%) \\
P.1 & 20 & 25 & 0.15 \\
P.2 & 28 & 25 & 0.15 \\
P.3 & 40 & 25 & 0.15 \\
P.4 & 20 & 50 & 0.15 \\
P.5 & 28 & 50 & 0.15 \\
P.6 & 40 & 50 & 0.15 \\
P.7 & 20 & 100 & 0.15 \\
P.8 & 28 & 100 & 0.15 \\
P.9 & 40 & 100 & 0.15 \\
Control & n/a & n/a & 0.15 \\
\hline
\end{tabular}

Box-Behnken design of Response Surface Methodology (RSM) was used to further analyse flux improvement promoted by continuous in-situ US application. The factors under investigation (independent variables) were ultrasonic frequency, power intensity (Pwi), and feed solution solid concentration. A total of 15 experiments were performed in random order, including 3 replicates of the centre point to minimize the error margin. This experimental design method was selected for being compatible with some experimental limitations, such as the frequency and power levels 
that could only be set to specific values. The range of operating conditions in coded and uncoded values is summarized in Table 4-4.

Table 4-4. Levels of independent variables for Box-Behnken design

\begin{tabular}{cccc}
\hline & \multicolumn{3}{c}{ Levels } \\
\cline { 2 - 4 } Factors & $\mathbf{+ 1}$ & $\mathbf{0}$ & $\mathbf{- 1}$ \\
\hline Frequency $(\mathrm{kHz})$ & 40 & 28 & 20 \\
Power Intensity $\left(\mathrm{W} . \mathrm{cm}^{-2}\right)$ & 0.59 & 0.29 & 0.15 \\
Concentration (wt.\%) & 0.30 & 0.15 & 0.075 \\
\hline
\end{tabular}

After identifying the ultrasonic setting that yielded the highest average normalized permeate flux, the effect of feed solution solid concentration and feed flow rate were analysed. The solid concentration in the feed solution was varied from $0.075 \mathrm{wt} . \%$ to $0.30 \mathrm{wt} . \%$ and the feed flow rate was increased from 1.0 to $5.0 \mathrm{~L} \cdot \mathrm{min}^{-1}$ in $1.0 \mathrm{~L} \cdot \mathrm{min}^{-1}$ increments.

Before every experimental run, the membranes were preconditioned by passing distilled water through it at the same operating conditions of the filtration. The water flux was calculated using Equation (6)

$$
J_{o}=\frac{\rho \Delta V_{\text {water }}}{\Delta t \cdot A_{m}}=\frac{\Delta\left(m_{\text {water }}\right)}{\Delta t \cdot A_{m}}
$$

where $J_{o}$ is the water flux $\left[\mathrm{g} \cdot \mathrm{min}^{-1} \cdot \mathrm{cm}^{-2}\right], \rho$ is the density of water $\left[\mathrm{g} \cdot \mathrm{cm}^{-3}\right], \Delta V_{\text {water }}$ is the volume of water collected from the permeate side [mL], $\Delta t$ is the time interval [min] and $A_{m}$ is the membrane surface area $\left[\mathrm{cm}^{2}\right]$.

For all experimental runs, the permeate was collected for 35 minutes and its mass was totaled every minute using an electronic balance. The total amount of permeate was used to assess the overall performance of each case. The mass of permeate collected during the filtration was used to calculate the permeate flux using Equation (7).

$$
J=\frac{\rho \Delta V_{\text {perm }}}{\Delta t A_{m}}=\frac{\Delta\left(m_{\text {perm }}\right)}{\Delta t A_{m}}
$$




\subsection{Analytical Methods}

\subsubsection{Solid Content}

Solid content analysis was used to obtain the amount of solid material in the latex paint. Three samples (A1, A2, A3) were prepared by measuring $1 \mathrm{~mL}$ of paint and transferring it to an aluminium plate that was placed in the oven at $105^{\circ} \mathrm{C}$ for 5 days. The plates were weighed every day until there was no change. Figure 4-5 shows the mass decay over time for the three samples. Comparing the initial and final weight of the samples, the solid content was determined as $55.80 \%$.

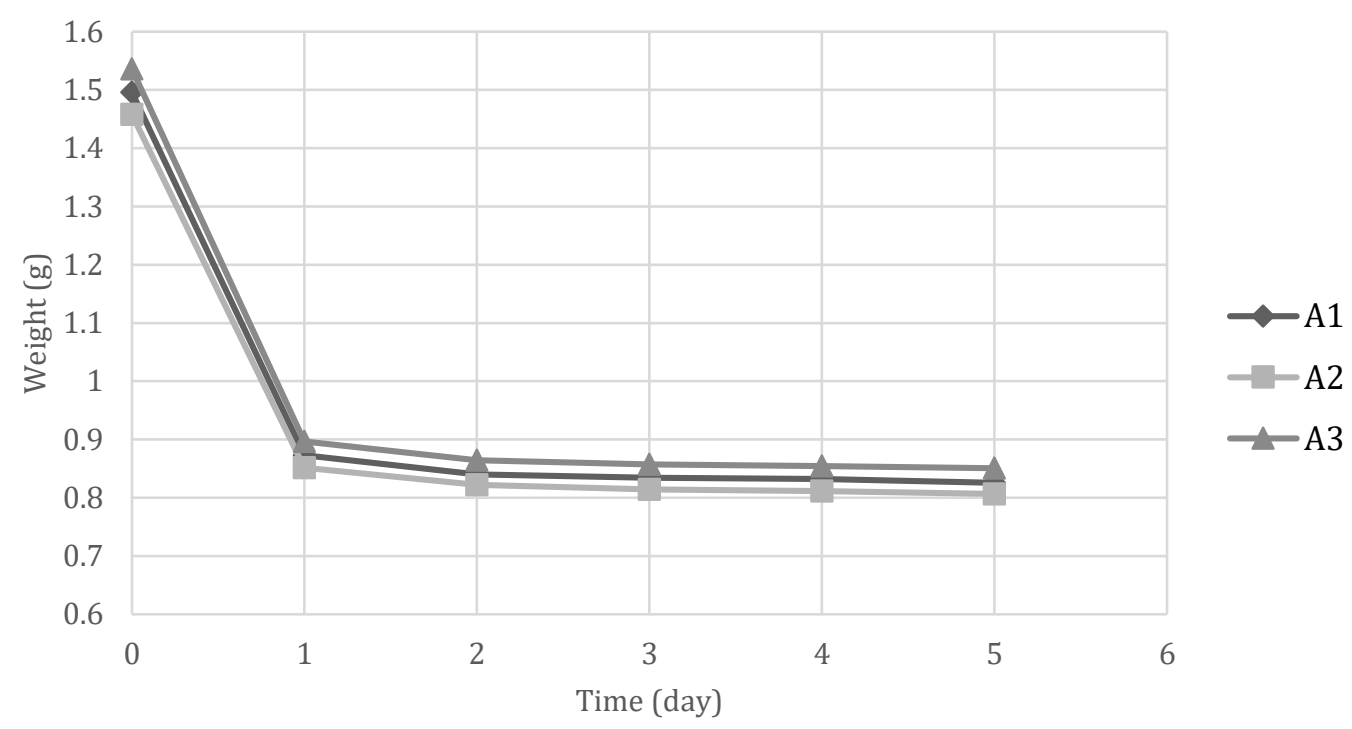

Figure 4-5. Mass reduction over time of $1 \mathrm{~mL}$ of latex paint (3 samples) in the oven at 105 ${ }^{\circ} \mathrm{C}$.

\subsubsection{Turbidity}

Turbidity was measured using a turbidimeter (La Motte 2020t Turbidimeter, USA, $\pm 2 \%$ ) to assess the quality of the permeate solution for all experiments performed. Turbidity is defined as the cloudiness or lack of clarity of a fluid due to the presence of suspended solids. It is measured in terms of Nephelometric Turbidity Units (NTU) which indicates the amount of light scattered by the solid particles in the solution. The lower the number of particles, the more the light can pass through the solution, hence lower the turbidity. In Canada, water discharges with turbidity between 25 and 100 NTU are considered potentially hazardous to the biota of water bodies (Birtwell et al., 
2008). According to the World Health Organization the turbidity of drinking water should be lower than 5 NTU, and ideally 1 NTU (World Health Organization, 2017).

\subsubsection{Particle Size Distribution}

Particle size distribution was measured using a particle size analyzer (Model 2000 Malvern Mastersizer). This measurement is based on laser diffraction technique in which a laser beam passes through the sample containing solid particles. The size of the particles is calculated according to the scattering pattern. The particle size distribution was measured for the feed solution in different solid concentrations. The average particle size diameter was $227.4 \mathrm{~nm}, 499.3 \mathrm{~nm}$ and $302.5 \mathrm{~nm}$ for $0.075 \mathrm{wt} . \%, 0.15 \mathrm{wt} . \%$ and $0.30 \mathrm{wt} \%$, respectively. The difference in average particle size is associated to the particle size distribution for each solution. Figure 4-6 shows the particle size distribution of the feed solution with different concentrations.

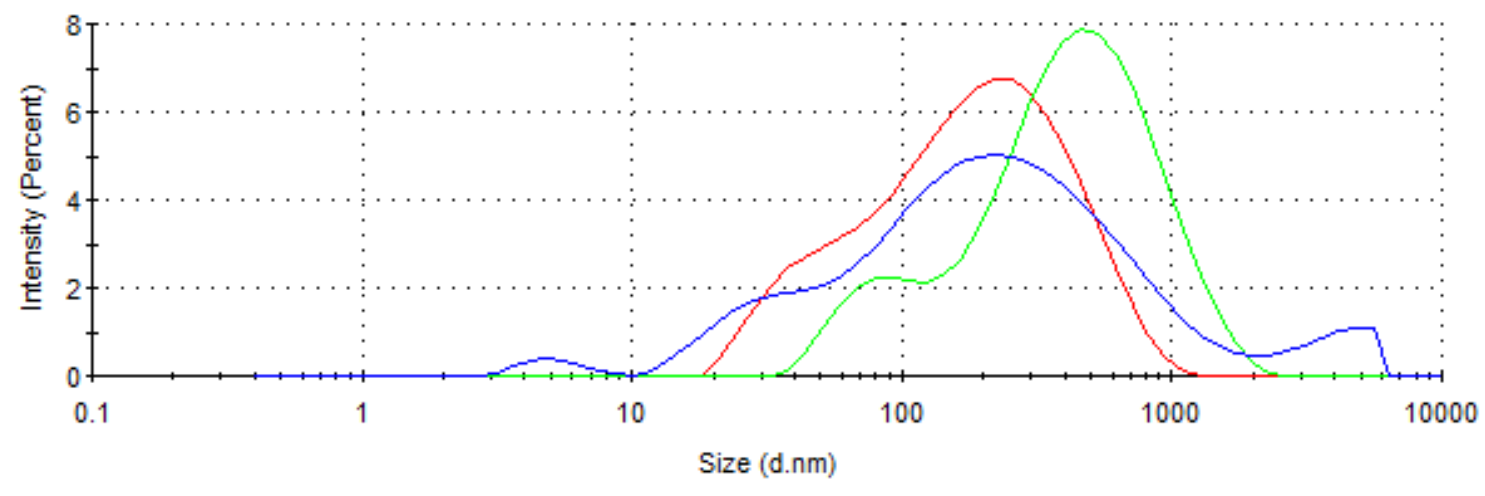

Record 163: 0.075 feed 1 Record 210: 0.15 FEED 3

Record 247: FEED 0.33

Figure 4-6. Size distribution of latex particles in feed solution with various solid concentrations, 0.075 (red), 0.15 (green) and $0.30 \mathrm{wt} \%$ (blue)

The particle size distribution was also measured for the permeate solution. For every sample, three measurements were performed to ensure the reliability of the measurements. Although this analysis does not identify the components of the sample, it provides insights about properties of the cake layer and the overall performance of the proposed process. 


\subsubsection{Scanning-Electron Microscopy Imaging}

Scanning electron microscopy (SEM) was used to obtain images of the membrane before and after the filtration process. For this purpose, a scanning electron microscope (Model JEOL, JSM-6380 LV, Oxford Instrument, U.K.) was used. The membrane samples were coated with a thin layer of gold to improve conductivity and enhance image resolution. Figure 4-7 shows the SEM image of a PVDF clean membrane with nominal pore size of $0.03 \mu \mathrm{m}$.

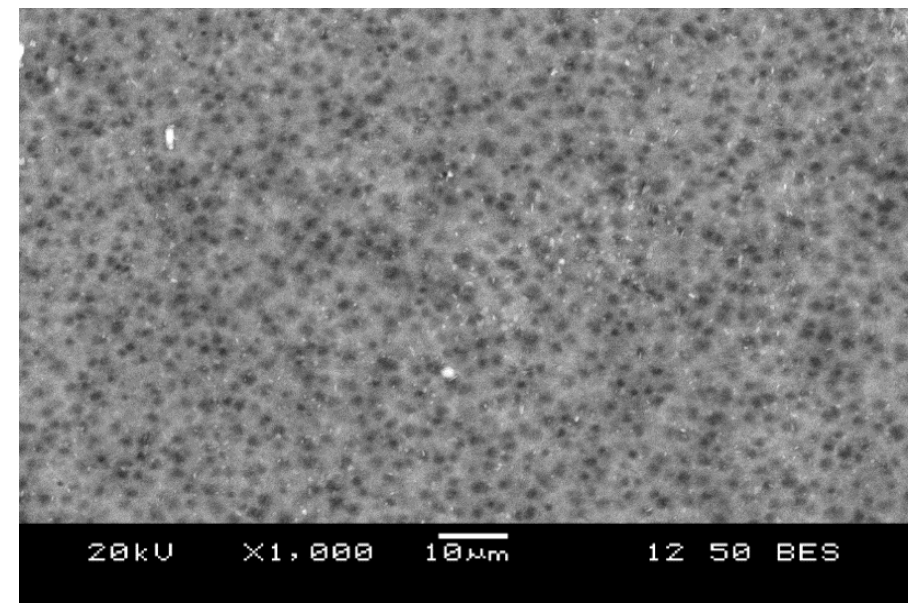

Figure 4-7. SEM image of PVDF membrane $0.03 \mu \mathrm{m}$, gold-coated 


\section{Chapter 5}

\section{Results and Discussion}

In this chapter, the results obtained from the experimental runs are presented and discussed. This investigation was divided in three main parts. First, a preliminary investigation was performed to ensure that the application of ultrasound could improve permeate flux of two polymeric membranes. Second, RSM was applied to further investigate the effect of ultrasonic frequency, power intensity and concentration on permeate flux improvement. A mathematical model of the permeate flux was obtained, and an optimal operating condition was identified. Finally, the performance of the system (running with the best ultrasonic setting identified) was evaluated under various feed solution solid concentration levels and feed cross-flow velocities.

\subsection{Preliminary Investigation}

The aim of the preliminary investigation was to observe if the application of ultrasound is feasible using the designed membrane module and the selected membranes for this study. Furthermore, the preliminary investigation offers insight into the effect of ultrasonic frequency and power on fouling control.

Three levels of frequency $(20 \mathrm{kHz}, 28 \mathrm{kHz}$ and $40 \mathrm{kHz})$ and three levels of power $(25 \mathrm{~W}, 50$ $\mathrm{W}$ and $100 \mathrm{~W}$ ) were combined in 9 experiments, as previously shown in the Table 4-3. A control run, without ultrasound, was also performed to compare the flux improvement due to ultrasound application. The solid concentration of the feed solution was fixed at $0.15 \mathrm{wt} \%$. Feed flow rate and applied pressure were also fixed for all the runs at $1.0 \mathrm{~L} \cdot \mathrm{min}^{-1}$ and $5.0 \mathrm{psi}$.

During the preliminary investigation, PCTE membrane suffered severe damage to its surface when exposed to the ultrasonic field. Within approximately 3 minutes of filtration applying 28 $\mathrm{kHz}$ and $100 \mathrm{~W}$, the colour of the permeate drastically changed from clear to white (similar to the feed solution). Figure 5-1 shows the permeate flux during 15 minutes of US-aided filtration using 
PCTE membrane. It was observed that around 3 minutes, $\mathrm{J} / \mathrm{J}_{\mathrm{o}}$, starts to increase significantly and it goes over 1, when it was supposed to go down. This behaviour is an indication of membrane damage.

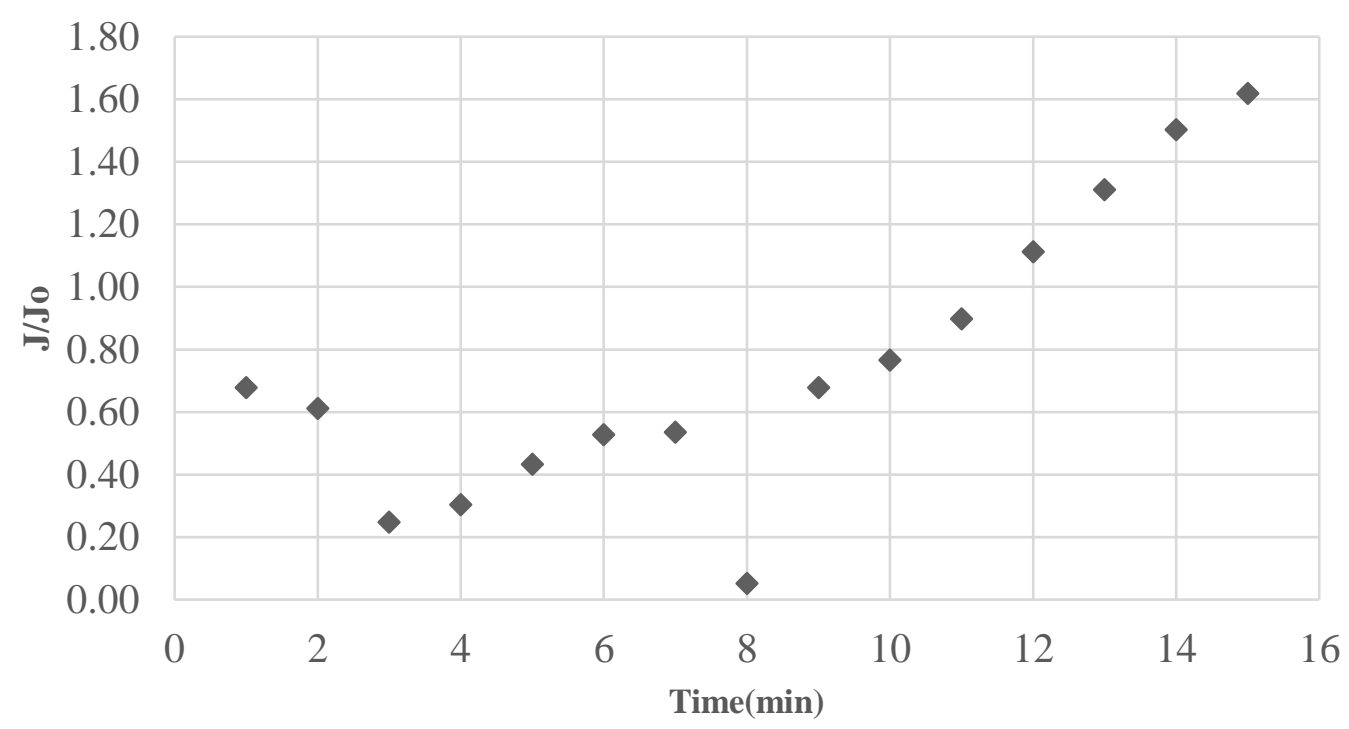

Figure 5-1. Normalized flux $\left(\mathrm{J} / \mathrm{J}_{\mathrm{o}}\right)$ over time of US-assisted filtration using PCTE membrane $(\mathrm{F}=28 \mathrm{kHz}, \mathrm{Pw}=100 \mathrm{~W}, \mathrm{Q}=1.0$ L.min-1, $\mathrm{P}=5.0 \mathrm{psi})$

For this reason, no further investigations were done using PTCE membrane, which was considered inadequate for this fouling control technique. PVDF membrane showed good resistance to ultrasound exposure without experiencing surface damage. After conducting all experiments using PVDF membrane, the total amount of permeate collected for each run is summarized in Figure 5-2. 


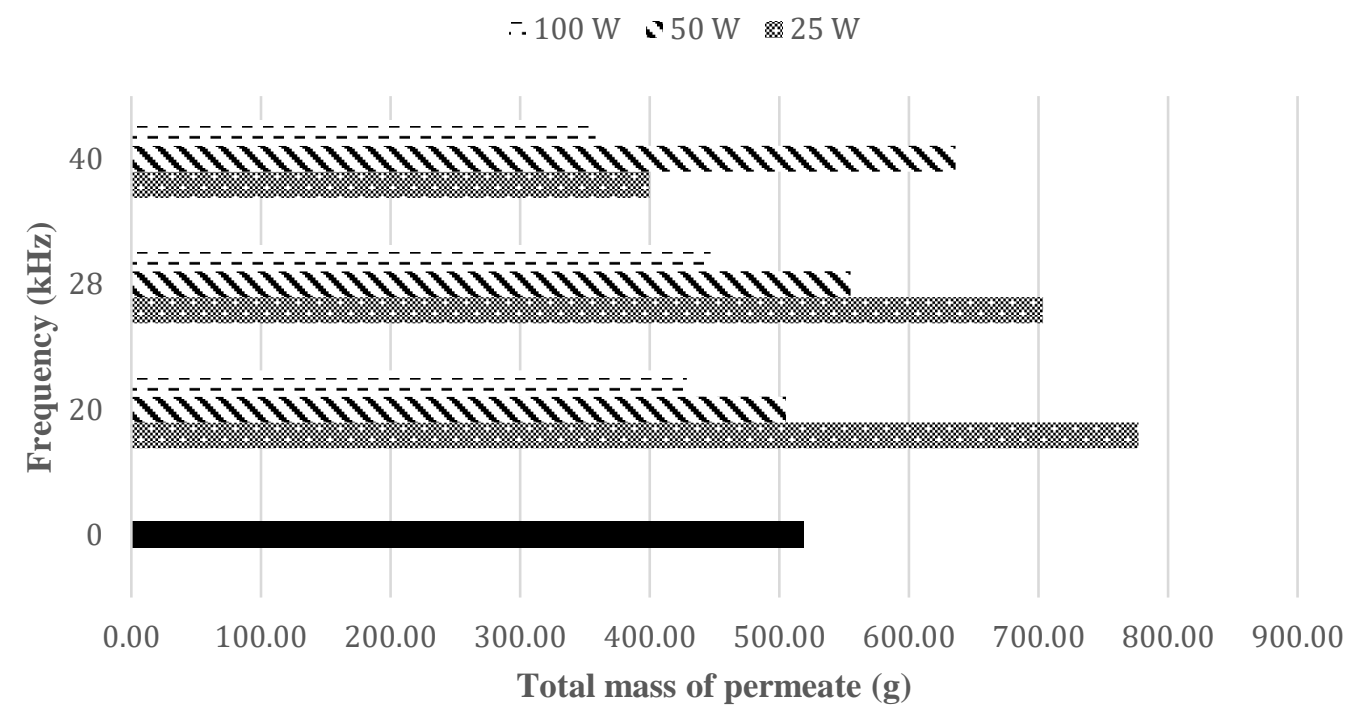

Figure 5-2. Total mass of permeate collected after 35 minutes using no ultrasound, $20 \mathrm{kHz}, 28$ $\mathrm{kHz}$ and $40 \mathrm{kHz}$ and various $\mathrm{Pw}$ levels $(\mathrm{Q}=1.0$ L.min-1, $\mathrm{P}=5.0 \mathrm{psi}, \mathrm{Cs}=0.15$ wt.\%)

When no ultrasound was applied during the filtration (black bar), the total amount of permeate collected was $518.65 \mathrm{~g}$. A significant increase in the total amount of permeate was observed for the runs using $20 \mathrm{kHz} / 25 \mathrm{~W}, 28 \mathrm{kHz} / 25 \mathrm{~W}$ and $40 \mathrm{kHz} / 50 \mathrm{~W}$. The total amount of permeate collected for these runs were $777.20 \mathrm{~g}, 703.70 \mathrm{~g}$ and $636.10 \mathrm{~g}$, respectively. It corresponds to increases of $49.8 \%, 35.7 \%$ and $22.6 \%$, respectively. Some of the cases (e.g., 20 $\mathrm{kHz} / 50 \mathrm{~W}, 28 \mathrm{kHz} / 100 \mathrm{~W}$ and $40 \mathrm{kHz} / 100 \mathrm{~W}$ ) presented similar or inferior performance to the case without ultrasound. In these cases, the application of ultrasound had a negative impact on the filtration. This could be attributed to the uneven pressure distribution created inside the membrane module and negative interferences in mass transfer. This phenomenon has not been observed in other published studies and can be attributed to the direct application of ultrasound on the feed side to an enclosed system.

When $100 \mathrm{~W}$ was applied, the performance of US-assisted ultrafiltration was inferior than the case without US for all frequency levels. At higher ultrasonic power, the number of cavitation bubbles is increased because there is more energy available to activate the growth of more preexisting bubbles in the feed solution. In an enclosed system like the membrane module designed for this study, the presence of too many cavitation bubbles can create a shielding bubble cloud. 
This can create an uneven pressure distribution on the feed side and intense localized cavitation. As a consequence, the application of ultrasound affects the mass transfer near the membrane surface while it is not effective in detaching particles from the cake layer.

Figure 5-3 shows the normalized permeate flux $\left(\mathrm{J} / \mathrm{J}_{\mathrm{o}}\right)$ decay for the runs with the best performances using US and the control run. The permeate flux (J) is normalized by dividing it by the water flux $\left(\mathrm{J}_{\mathrm{o}}\right)$ as shown in Equation (10). This normalization accounts for nonuniformities on the membrane porous structure. The error bar was based on the standard deviation calculated in Appendix C.

$$
\frac{J}{J_{o}}=\frac{\rho \Delta V_{\text {perm }}}{\Delta t A_{m}} \frac{1}{J_{o}}
$$

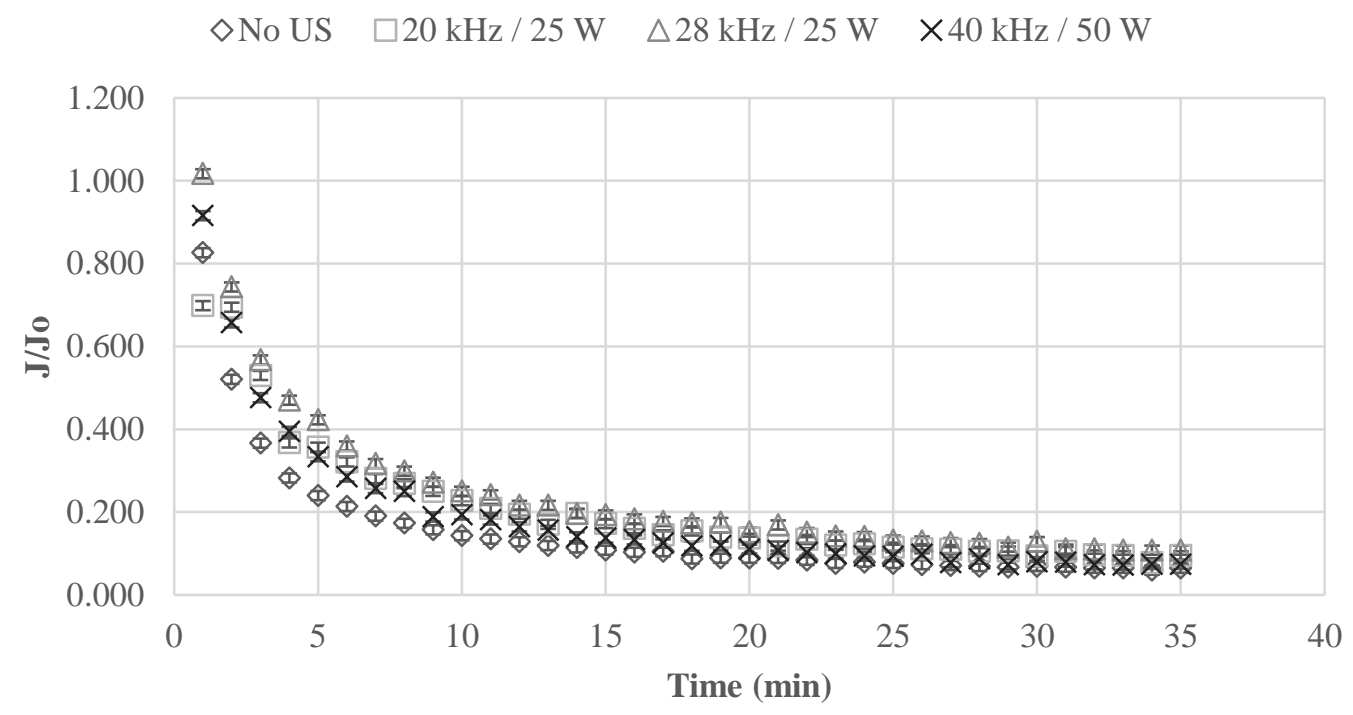

Figure 5-3. Normalized flux decay over 35 minutes of filtration for three best runs of preliminary investigation $(\mathrm{Q}=1.0$ L.min- $1, \mathrm{P}=5.0 \mathrm{psi}, \mathrm{Cs}=0.15 \mathrm{wt} . \%)$.

A faster decay of $\mathrm{J} / \mathrm{J}_{\mathrm{o}}$ was observed for the run without ultrasound, which indicates that the use of ultrasound can effectively improve ultrafiltration performance by controlling fouling. As the frequency was decreased, the percentage reduction of the initial permeate flux $\left(\mathrm{J}_{\mathrm{i}}\right)$ was decreased, indicating a lower degree of fouling. $\mathrm{J}_{\mathrm{i}}$ is the permeate flux within the first minute of filtration, and it was calculated using Equation (7). For example, when applying $28 \mathrm{kHz}$ and 25 
$\mathrm{W}$, the final flux $\left(\mathrm{J}_{\mathrm{f}}\right)$ corresponded to approximately $10.6 \%$ of the initial flux $\left(\mathrm{J}_{\mathrm{i}}\right)$. In this case, the total permeate flux decayed $89.4 \%$ after 35 minutes of filtration. The total permeate flux decay was calculated using Equation (9). Table 5-1 summarizes the values obtained for the total flux decay.

$$
\text { Total Flux Decay }(\%)=\left(1-\frac{J_{f}}{J_{i}}\right) 100
$$

Table 5-1. Total flux decay for best runs in preliminary investigation

\begin{tabular}{cccc}
\hline Frequency & Power & $\mathbf{J}_{\mathbf{f}} / \mathbf{J}_{\mathbf{i}}$ & Total flux decay (\%) \\
\hline 20 & 25 & 0.135 & 86.5 \\
28 & 25 & 0.106 & 89.4 \\
40 & 50 & 0.081 & 91.9 \\
n/a & n/a & 0.064 & 92.2 \\
\hline
\end{tabular}

As the frequency level was increased, an increase in total flux decay was observed. This demonstrates that US-assisted filtration had better performance at lower frequency, presenting lower fouling and higher productivity (for the same power level). The results obtained are in accordance to previous literature reports (Lamminen, 2004; Naddeo et al., 2015) and is related to the characteristics of the bubbles produced at different frequency levels. At lower frequencies, less bubbles are produced per unit of time, but they are larger and tend to collapse more energetically. As frequency is increased, more bubbles are produced per unit of time. However, these bubbles are smaller and collapse less energetically. With that, US-aided filtration presented better performance with the application of lower frequency $(20 \mathrm{kHz})$ at which particle detachment from the cake layer is more effective due to the characteristics of the cavitation bubbles formed.

With regards to the power level used in these three best runs, lower fouling was observed when a lower power level was applied. This trend is the opposite of what has been observed in other systems using ultrasonic baths. In previous studies, as the power level is increase so does the cleaning efficiency of the US application (Cai et al., 2014). The results obtained in the present investigation can be associated to the direct application of US and the design of the membrane module. As the power level is increased, more bubbles are produced, and the size of the cavitation 
zone is increased. In this system, as power is increased, a larger amount of bubbles is formed on both the feed side (where the transducer is placed) and the permeate side. This is expected to have a negative impact on the US-aided filtration as bubbles can coalesce and collapse before touching the membrane surface. Furthermore, the membrane module is an enclosed system and a large amount of bubbles can be trapped on the feed side as US is applied. The presence of too many bubbles as a consequence of the module design and direct application of US can interfere in mass transfer phenomenon and hinder filtration performance.

This preliminary investigation showed that the US application can be effective in controlling fouling of PVDF membrane when US is applied continuously and in direct contact with the feed side of the membrane module. With that, further investigations regarding the effect of ultrasonic frequency and power levels on the fouling were performed using feed solution of different concentrations.

\subsection{Response Surface Methodology (RSM)}

The aim of the RSM in this study was to investigate the impact of continuous application of ultrasound on the performance of ultrafiltration using latex wastewater. Furthermore, RSM was utilized to obtain a relationship between ultrasonic frequency, power intensity and feed solution concentration with the permeate flux. For this reason, the response variable analysed in the BoxBehnken design was $J_{u s}$ which represents the averaged permeate flux $\left(J_{\text {avg }}\right)$ multiplied by a correction factor. $\mathrm{J}_{\mathrm{avg}}$ was calculated by dividing the total (cumulative) mass of permeate to the filtration time $(35 \mathrm{~min})$ and the membrane surface area $\left(170 \mathrm{~cm}^{2}\right) . J_{\text {us }}$ was calculated using Equation (10), and is an indication of the overall US-assisted ultrafiltration performance. Sample calculations are shown in Appendix D.

$$
J_{u s}=J_{a v g} \delta
$$

$\delta$ represents a correction factor that accounts for water flux variability observed from one membrane sample to another. This variation is attributed to nonuniformities on the porous structure of the membrane which is purchased as one long sheet $\left(31.5 \times 100 \mathrm{~cm}^{2}\right)$ that had to be cut to size $\left(10 \times 17 \mathrm{~cm}^{2}\right)$ for the experiments. The calculation of $\delta$ is shown in Equation (11). Where $J_{o m}$ is the membrane water flux provided by the manufacturer. 


$$
\delta=\left(\frac{J_{o m}-J_{o}}{J_{o m}}\right)+1
$$

The decay of $\mathrm{J}_{\mathrm{us}}$ over time was used to analyse the occurrence of fouling in US-assisted ultrafiltration. This value was calculated for all of the experimental runs with a fixed filtration time of 35 minutes, according to Equations (6) and (7). The feed solution was at room temperature for all experiments. Also, feed flow rate and applied pressure were fixed at $1.0 \mathrm{~L}^{-\mathrm{min}^{-1}}$ and 5.0 psi in order to focus on the influence of the US application. Table 5-2 shows all experimental runs performed and the respective results. The value of $\mathrm{J}_{\mathrm{us}}$ obtained experimentally ranged from 0.037 and 0.151 ; and the mean value was 0.079 .

Table 5-2. Experimental runs and results from Box-Behnken design

\begin{tabular}{|c|c|c|c|c|}
\hline & & Factor & & Response Variable \\
\hline Run & $\begin{array}{c}\text { Frequency } \\
(\mathbf{k H z})\end{array}$ & $\begin{array}{c}\text { Power } \\
\left(\text { W.cm }{ }^{-2}\right)\end{array}$ & $\begin{array}{c}\text { Concentration } \\
\text { (wt.\%) }\end{array}$ & $\begin{array}{c}J_{u s} \\
\left(\mathrm{~g} \cdot \mathrm{min}^{-1} \cdot \mathrm{cm}^{-2}\right)\end{array}$ \\
\hline 1 & 20 & 0.15 & 0.15 & 0.140 \\
\hline 2 & 20 & 0.59 & 0.15 & 0.093 \\
\hline 3 & 20 & 0.29 & 0.075 & 0.151 \\
\hline 4 & 20 & 0.29 & 0.3 & 0.044 \\
\hline 5 & 28 & 0.15 & 0.075 & 0.100 \\
\hline 6 & 28 & 0.15 & 0.3 & 0.053 \\
\hline 7 & 28 & 0.29 & 0.15 & 0.060 \\
\hline 8 & 28 & 0.29 & 0.15 & 0.075 \\
\hline 9 & 28 & 0.29 & 0.15 & 0.070 \\
\hline 10 & 28 & 0.59 & 0.075 & 0.096 \\
\hline 11 & 28 & 0.59 & 0.3 & 0.042 \\
\hline 12 & 40 & 0.15 & 0.15 & 0.076 \\
\hline 13 & 40 & 0.29 & 0.075 & 0.097 \\
\hline 14 & 40 & 0.29 & 0.3 & 0.037 \\
\hline 15 & 40 & 0.59 & 0.15 & 0.065 \\
\hline
\end{tabular}




\subsubsection{Main Effects}

Figure 5-4 shows the main effects plot for $\mathrm{J}_{\mathrm{us}}$, which displays the mean response for each factor level. For example, the mean response for $20 \mathrm{kHz}$ is the mean of the $\mathrm{J}_{\mathrm{us}}$ value obtained in all experimental runs in which $20 \mathrm{kHz}$ was applied (runs 1, 2, 3 and 4 shown in Table 5-2). The reference (dashed) line represents the mean of all data points. The error bars were calculated by the software, based on the data of the triplicates of the centre point of the Box-Behnken statistical design. The fact that the lines connecting the points within the factors are not horizontal indicates that all factors affect the response variable differently.

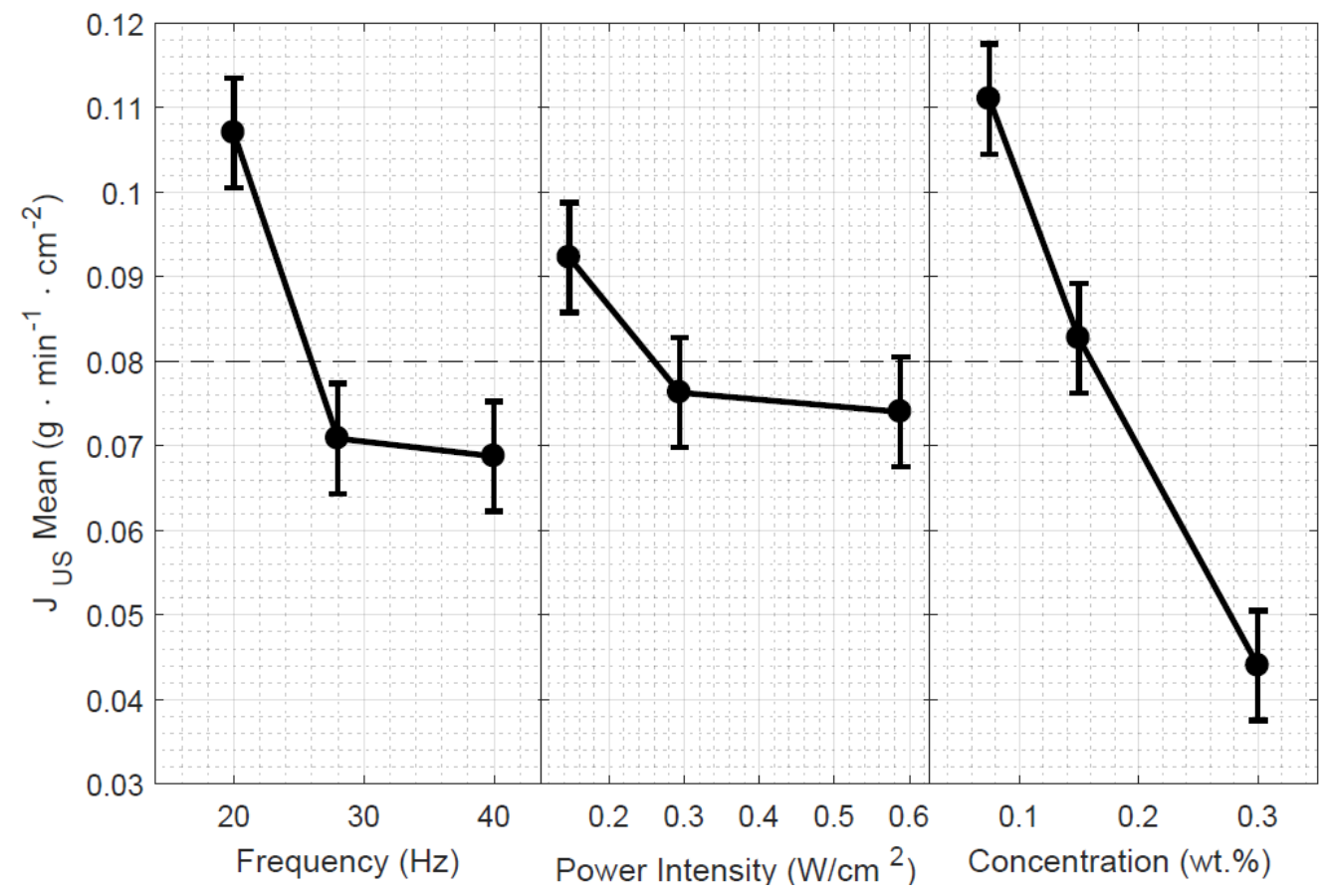

Figure 5-4. Main effects plot for $\mathrm{J}_{\mathrm{us}}$ using data means.

\subsubsection{Effect of Frequency}

The $\mathrm{J}_{\mathrm{us}}$ mean was higher when $20 \mathrm{kHz}$ was applied, and significantly decreased when frequency level was increased. This behaviour is similar to what have been observed in previous studies (Cai et al., 2014; Lamminen, 2004; Naddeo et al., 2015) as well as in the preliminary investigation of this study. 
This observation could be attributed to the characteristics of the bubbles produced and the energy attenuation suffered by the ultrasonic waves at different frequency levels. At lower frequencies, a smaller number of bubbles is produced per unit time, but these bubbles are larger and collapse more energetically at the membrane surface. Furthermore, at lower frequencies the ultrasonic waves suffer less energy attenuation, as per Equation (4). With that, the application of ultrasound is more effective in detaching particles from the cake layer, and hence, improving the permeate flux. At higher frequencies, more bubbles are produced per unit of time, but these bubbles are smaller and less energetic. Additionally, ultrasonic waves at higher frequencies suffer more attenuation; hence, less energy is available for detaching particles. For this reason, higher fouling is observed, and the average permeate flux is decreased.

Figure 5-5 shows the flux decay obtained in runs 3 and 13 from Table 5-2, and illustrates the change in performance for different frequency levels. US-assisted ultrafiltration was performed using $20 \mathrm{kHz}$ and $40 \mathrm{kHz}$, with $0.29 \mathrm{~W} . \mathrm{cm}^{-2}$ and $0.075 \mathrm{wt}$.\% solid concentration. The flux decay occurs much slower when $20 \mathrm{kHz}$ is applied, and the amount of permeate collected is $54.7 \%$ higher. The data collected in terms of mass of permeate collected over time can be found in Appendix A.

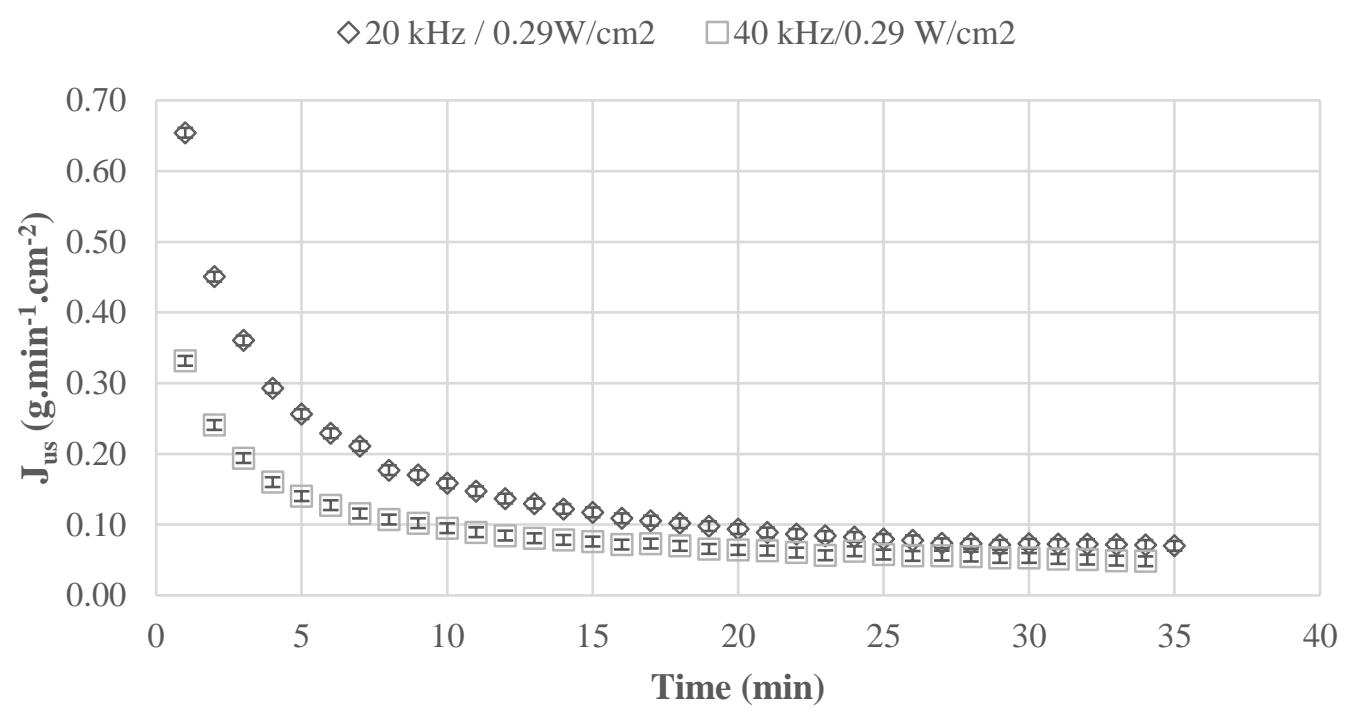

Figure 5-5. Permeate flux decay over 35 minutes of filtration using 20 and $40 \mathrm{kHz}$ $\left(\mathrm{Q}=1.0 \mathrm{~L} . \mathrm{min}^{-1}, \mathrm{P}=5.0 \mathrm{psi}, \mathrm{Pwi}=0.29 \mathrm{~W} . \mathrm{cm}^{-2}, \mathrm{Cs}=0.075 \mathrm{wt} . \%\right)$ 


\subsubsection{Effect of Power Intensity}

From the results shown in Figure 5-4, only slight changes around the overall mean response of $\mathrm{J}_{\mathrm{us}}$ were observed. This could be an indication that this main effect is not significant to the response variable. From previous literature reports in which ultrasound was applied using ultrasonic bath as well as applied directly to the module from the permeate side (Borea et al., 2018; Lamminen, 2004), the increase in power is expected to increase the efficiency of ultrasonic fouling control. This trend is attributed to the fact that at higher power, there is an increase in the number of bubbles formed as well as in the size of the cavitation zone. Hydrodynamic turbulence is also increased which can intensify the implosion of the bubbles.

In the present study, a different trend was observed, and it can be attributed to the membrane module design, the position of the US transducer and the properties of the feed solution. During the US-assisted ultrafiltration using high power intensity, there is enough energy to vibrate the entire membrane module. With that, many bubbles are formed on both feed and permeate side, and ultrasonic waves propagate in opposite directions. As consequence, it is believed that the waves interfere with each other reducing or increasing the resultant amplitude. Also, with a large amount of bubbles formed, it is possible that some coalesce into bigger bubbles, and are carried away from the membrane surface by the reject stream. Therefore, at higher power intensity, the application of ultrasound is less efficient, and fouling is more severe. To further understand how the power intensity affects fouling control, it would be necessary to look at the interactions with the two other main effects, frequency and concentration.

The quality of the permeate was significantly affected by the power intensity. Figure 5-6 shows the turbidity of the permeate collected after US-assisted filtrations and control runs (which have a power intensity of 0 ). The quality of the permeate for the control runs as well as for the cases using 0.15 W.cm ${ }^{-2}$ with 0.075 wt $\%$ and 0.15 wt. $\%$, and 0.29 W.cm ${ }^{-2}$ with 0.075 wt $\%$ and 0.15 wt.\% comply with the requirements from World Health Organization for drinking water, which indicates a good quality permeate. As shown in Figure 5-6, as the power intensity is increased, the turbidity of the permeate becomes higher. This is believed to be associated to a slight increase in membrane pore size during the filtration (Masselin et al., 2001), and the possibility of the particles being fragmented by the US application (Chai et al., 1998). According to Reuter et al. (2017), as power is increased the sound pressure distribution inside the module is affected by 
shielding bubble clouds. This results in increase in localized cavitation activity, increasing the particle detachment but also increasing pore size due to the properties of the polymeric membrane. This effect was more pronounced when a higher feed solution concentration was used.

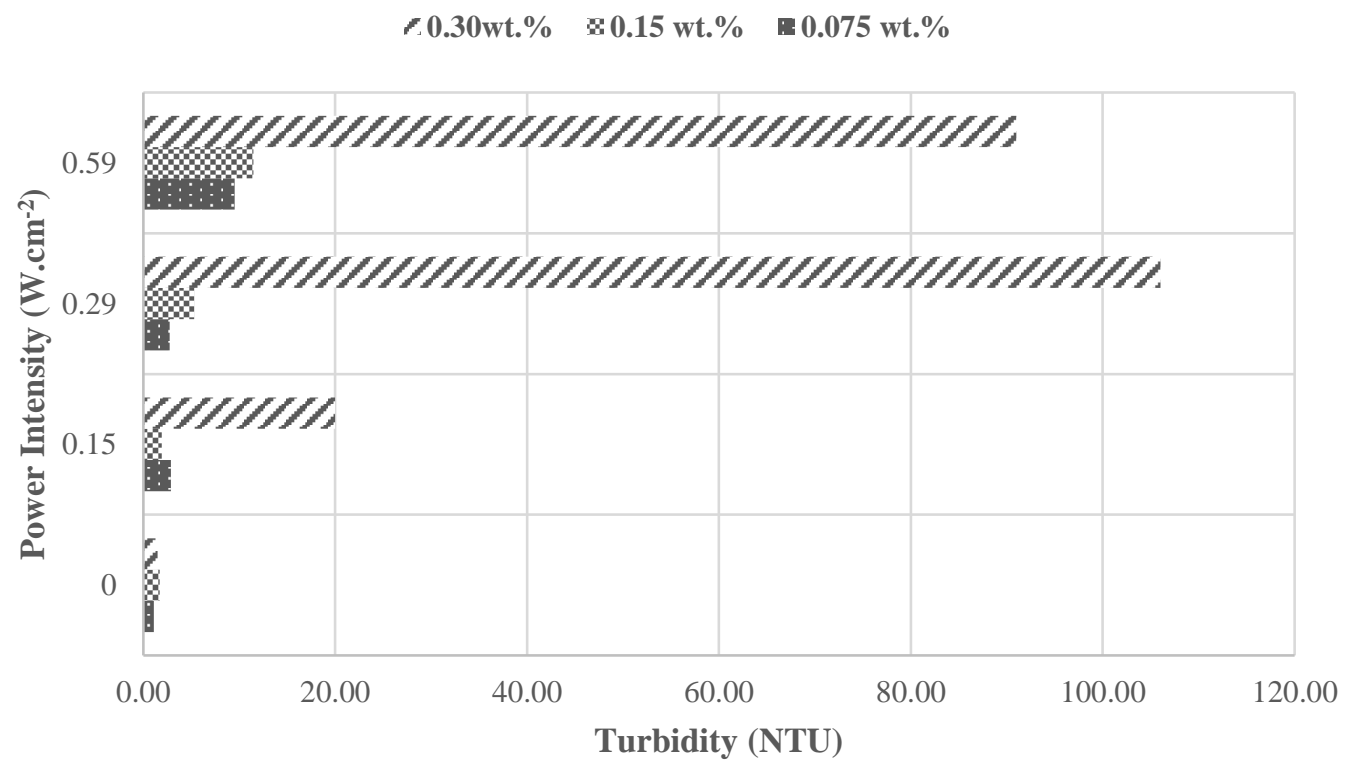

Figure 5-6. Turbidity of the permeate solution obtained applying $20 \mathrm{kHz}$ with various power intensity levels and various feed solution solid concentration

\subsubsection{Effect of Concentration}

As observed in Figure 5-6, with an increase in the feed solution concentration, the permeate solution presented higher turbidity. This is associated to a wider range of particle size for higher solid concentrations. Consequently, when the membrane pore size is affected by the ultrasonic power, it is natural that more particles would be able to pass through the membrane.

As depicted in Figure 5-4, by increasing the concentration of the feed solution, the mean of $\mathrm{J}_{\mathrm{us}}$ decreased linearly. Naturally, fouling is expected to occur faster when a higher solid concentration is used. Additionally, ultrasonic cleaning is not as efficient when applied at higher concentrations. With more suspended and dissolved solids in the solution, the attenuation of ultrasonic energy is increased due to scattering and absorption of energy by solid particles. Furthermore, at higher solid concentrations, the number of nuclei available for formation of cavitation bubbles is increased. The presence of a very large amount of bubbles inside the 
membrane module can have a negative impact on the filtration performance. Too many bubbles can lead to the formation of shielding bubble clouds and interfere in mass transfer at the membrane surface. It is important to verify if the interaction between the solid concentration with frequency and power intensity is significant to the overall performance.

\subsubsection{Interaction Effects}

Figure 5-7 shows the interaction plot for $\mathrm{J}_{\mathrm{us}}$ and displays how the permeate flux $\left(\mathrm{J}_{\mathrm{us}}\right)$ changes based on the interaction of the main effects. The top-left shows how $\mathbf{J}_{\mathrm{us}}$ obtained experimentally changes with frequency and power intensity at 0.15 wt.\% feed solution solid concentration. The top-right plot shows the trend of $\mathrm{J}_{\mathrm{us}}$ with frequency and concentration at 0.29 W. $\mathrm{cm}^{-2}$ of power intensity. Finally, the bottom-right graph shows the change in $\mathrm{J}_{\mathrm{us}}$ with power and concentration at $28 \mathrm{kHz}$.

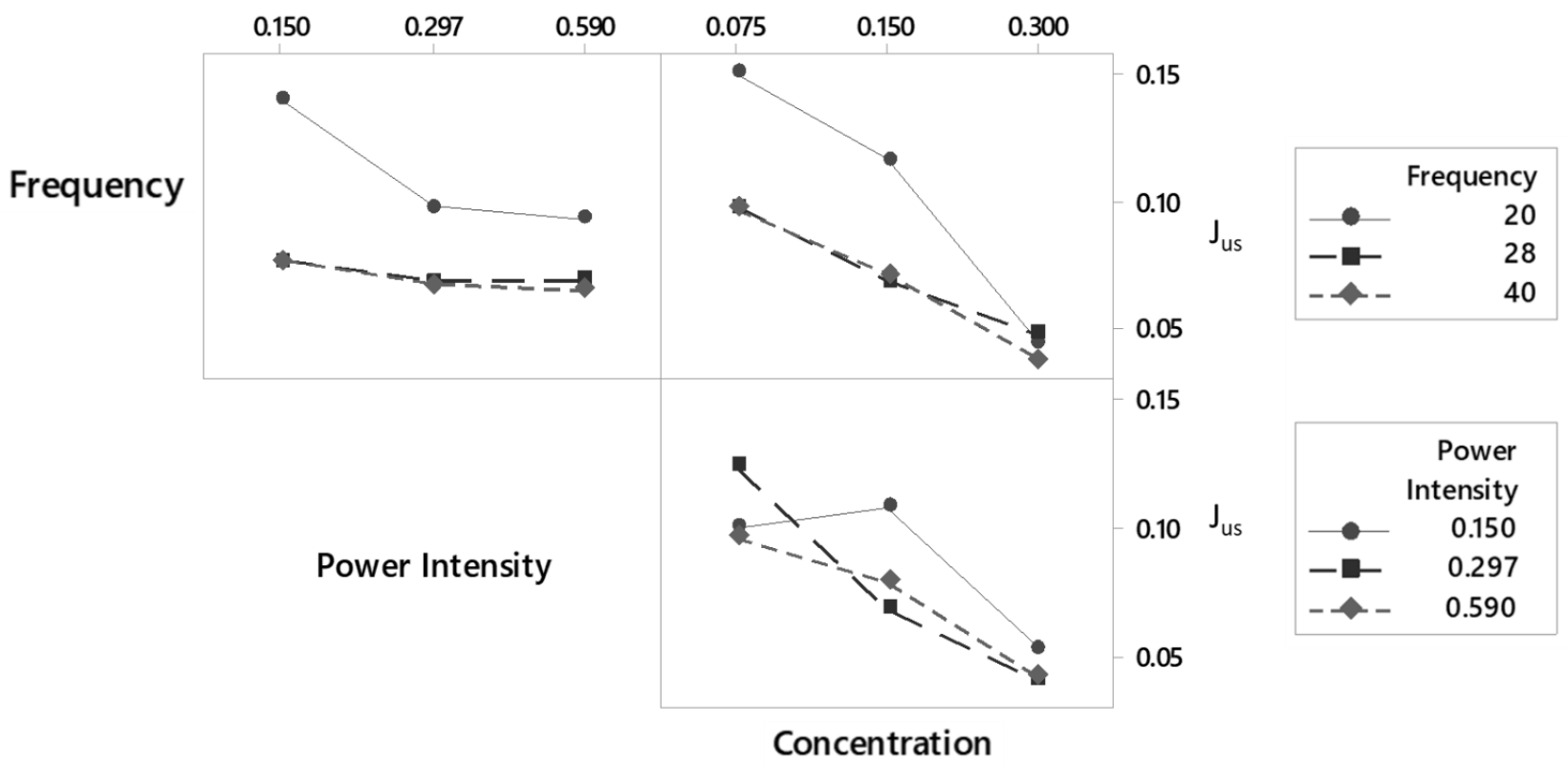

Figure 5-7. Interaction plot for J/Jo

From the top-left graph of Figure 5-7, the application of $20 \mathrm{kHz}$ resulted in higher $\mathrm{J}_{\mathrm{us}}$ for all power intensity levels, indicating better fouling control. Also, higher frequencies $(28 \mathrm{kHz}$ and $40 \mathrm{kHz}$ ) are less efficient in controlling fouling, thus $\mathbf{J}_{\mathrm{us}}$ is lower for all power intensity levels. The application of $28 \mathrm{kHz}$ and $40 \mathrm{kHz}$ presented very similar performance for all power intensity levels. 
This behaviour is in accordance to expectations due to the higher attenuation suffered by ultrasonic waves at higher frequencies and higher power intensity. Using these ultrasonic settings (high frequency and high power) the collapse of the cavitation bubbles is weaker. This leads to less energy available for detaching the particles from the membrane surface and hence fouling is more severe.

The top-right graph in Figure 5-7 shows the frequency-concentration interaction. It was observed that the application of $20 \mathrm{kHz}$ was more efficient in controlling fouling when feed solution with $0.075 \mathrm{wt} . \%$ and $0.15 \mathrm{wt} . \%$ solid concentration was used. When a higher feed solution solid concentration was used, the value of $J_{\text {us }}$ was similar for all frequency levels. This result should be a consequence of the higher degree of fouling naturally experienced at higher solid concentrations, and greater energy attenuation of ultrasonic waves due to scattering and absorption.

As the solid concentration was increased, the zeta potential of the feed solution was increased (less negative), as shown in Table 4-1. According to Lamminen (2004), particles with less negative zeta potential create thicker, more compact cake layer on the membrane surface. This behaviour is attributed to increased particle-to-particle repulsion and larger interparticle distance at more negative zeta potential. Furthermore, the higher the repulsion between particles, the easier it is to detach particles from each other and from the membrane surface, which, in turn renders US more effective.

The characteristics of the feed solution can explain the fact that at higher concentrations the permeate presented higher turbidity, as previously seen in Figure 5-6. At higher concentrations, a wider tail end of large particle sizes was observed in the particle size distribution curve, as shown in Figure 4.5. Therefore, a more porous cake layer would be formed on the membrane surface due to larger interparticle distance of larger particles. In addition, at higher concentrations the averaged particle size is slightly smaller. Consequently, more particles can make their way through the membrane, increasing the turbidity of the permeate.

The bottom-left graph in Figure 5-7 displays the effect of the interaction between power intensity and concentration on $\mathrm{J}_{\text {us. }}$ A similar trend was observed for $0.15 \mathrm{~W} . \mathrm{cm}^{-2}$ and $0.59 \mathrm{~W} . \mathrm{cm}^{-2}$ which indicates similar fouling control ability when these power intensities were applied. 0.59 W. $\mathrm{cm}^{-2}$ was expected to be more efficient for producing more (and more energetic) cavitation 
bubbles. However, due to the aforementioned interferences its efficiency was reduced, and $\mathrm{J}_{\mathrm{us}}$ was decreased. The power level of $0.29 \mathrm{~W} . \mathrm{cm}^{-2}$ showed better performance at lower concentration (0.075 wt.\%), but $\mathrm{J}_{\mathrm{us}}$ decreased when concentration was increased. This is associated to the decrease in particle-to-particle repulsion and greater attenuation as previously discussed.

\subsubsection{Statistical Analysis}

The results obtained experimentally were analysed using a multi-regression technique to identify significant effects of the process parameters. Figure 5-8 shows the Pareto chart in which the standardized effects appear in decreasing order of magnitude. It indicates that two of the main effects and one interaction term are statistically significant, with a confidence level of $95 \%$.

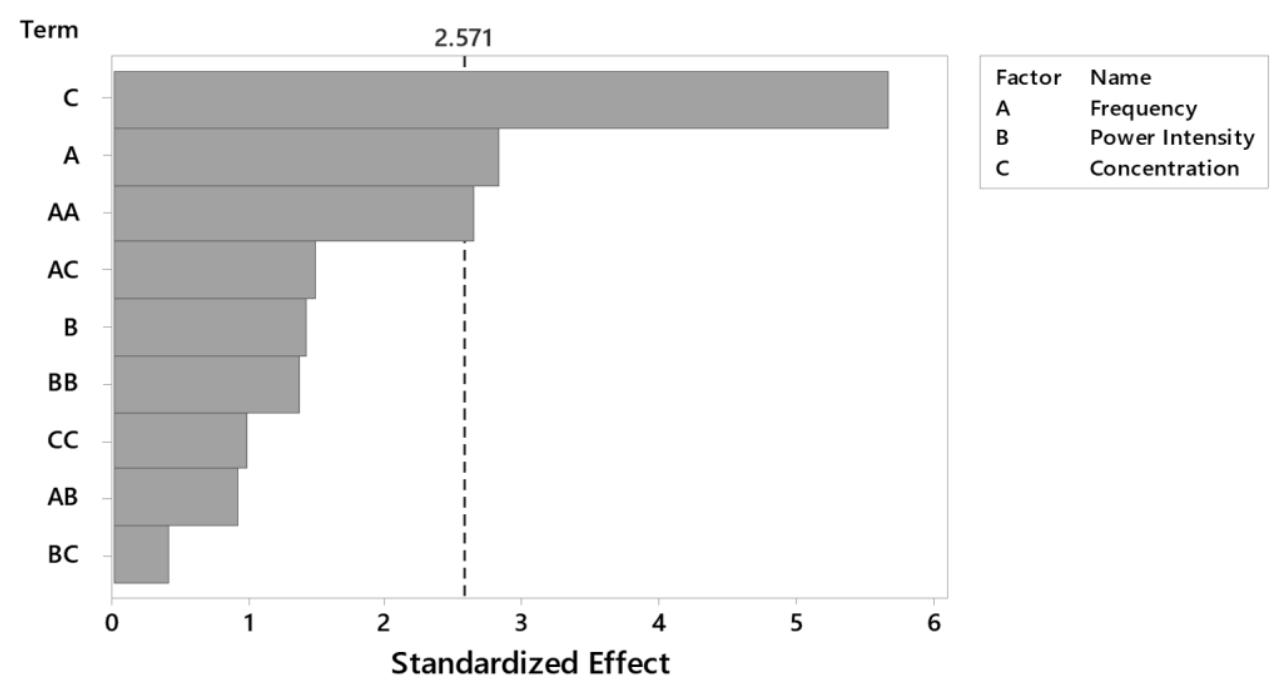

Figure 5-8. Pareto chart of standardized effects. Response is $\mathrm{J}_{\mathrm{us}}(\alpha=0.05)$.

In order to remove statistically non-significant effects and obtain a best-fitting model that describes the response variable in terms of the investigated factors, a stepwise backward elimination regression was performed using statistical software (Minitab® 18, Minitab Inc., USA). Initially, a model that includes all predictors is assumed. The software removes the least significant variable for each step. The elimination process stops when all variables in the model have p-values that are less than or equal to the specified level of confidence $(\alpha=0.05)$. Model hierarchy was enforced during the elimination process to obtain an equation in terms of uncoded units. 
The model fitting was evaluated by the coefficient of determination $\left(\mathrm{R}^{2}\right)$ and the analysis of variances (ANOVA). The ANOVA table (B-1), coded coefficient table (B-2), and residual plots (Figure B-1) can be found in Appendix B. The value of $\mathrm{R}^{2}$ obtained was $81.2 \%$ which indicates that this model adequately describes the response variable in terms of the selected independent variables. The value of the predictive $\mathrm{R}^{2}$ was $61.1 \%$ which indicates that this model has low predictability for new observations. The model obtained is presented in Equation (12).

$$
J_{u s}=0.361+0.000209 F^{2}-0.0145 F-0.288 C_{s}
$$

where $\mathrm{F}$ is the frequency level $[\mathrm{kHz}]$ and $\mathrm{C}_{\mathrm{s}}$ is the feed solution solid concentration [wt.\%]. This equation is valid for frequency levels between $20 \mathrm{kHz}$ and $40 \mathrm{kHz}$ and feed solution concentrations of $0.075 \mathrm{wt} . \%$ to $0.30 \mathrm{wt} . \%$. Although the power intensity is not a significant factor in the model, Equation (12) is valid for power intensity between $0.15 \mathrm{~W} . \mathrm{cm}^{-2}$ and $0.59 \mathrm{~W} . \mathrm{cm}^{-2}$. According to the model obtained, $\mathrm{J}_{\mathrm{us}}$ is a quadratic function of the frequency level, and a linear function of the concentration and the frequency level. The plot of $\mathrm{J}_{\mathrm{us}}$ as function of concentration and frequency is displayed in Figure 5-9

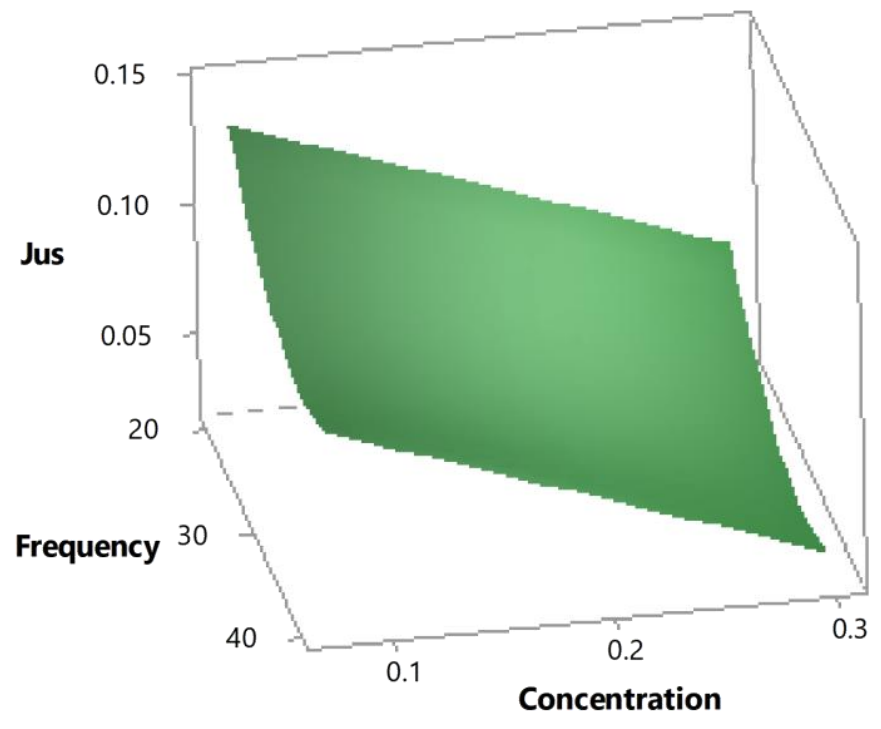

Figure 5-9. Response surface of $\mathrm{J}_{\text {us }}$ as a function of frequency and concentration.

The response of $\mathrm{J}_{\mathrm{us}}$ was maximized using the optimization tool in the statistical software. The result indicted that maximum $\mathrm{J}_{\text {us }}$ would be 0.134 and would correspond to the application of 
$20 \mathrm{kHz}$ with feed solution concentration at $0.075 \mathrm{wt} \%$. The only experimental run in the BoxBehnken design in which $20 \mathrm{kHz}$ was applied to the filtration of feed solution concentration at $0.075 \mathrm{wt} . \%$ had a power intensity of $0.29 \mathrm{~W} . \mathrm{cm}^{-2}$. The value of $\mathrm{J}_{\mathrm{us}}$ for this case was 0.151 and represented the highest response among all experiments performed.

In order to verify the predictability of the model, two additional experiments were performed using $0.15 \mathrm{~W} . \mathrm{cm}^{-2}$ and $0.59 \mathrm{~W} . \mathrm{cm}^{-2}$ for the same optimized conditions of frequency and concentration ( $20 \mathrm{kHz}$ and $0.075 \mathrm{wt}$.\%, respectively). The value of $\mathrm{J}_{\mathrm{us}}$ obtained experimentally for each of these runs is shown in Table 5-3 with the respective error which was calculating using the following Equation (13):

$$
\text { Error }=\left|\frac{J_{u s}^{\text {experimental }}-J_{u s}^{\text {predicted }}}{J_{u s}^{\text {predicted }}}\right| 100 \%
$$

Table 5-3. Permeate flux obtained experimentally for various power levels

\begin{tabular}{ccc}
\hline Power intensity & Jus $_{\text {us }}$ & Error (\%) \\
\hline 0.15 & 0.115 & 14.2 \\
0.29 & 0.151 & 12.7 \\
0.59 & 0.080 & 40.3 \\
Mean & $\mathbf{0 . 1 1 5}$ & $\mathbf{1 3 . 9}$ \\
\hline
\end{tabular}

The mean value of $\mathrm{J}_{\mathrm{us}}$ obtained experimentally using $20 \mathrm{kHz}, 0.075 \mathrm{wt} \%$ and various power intensity levels $\left(0.15,0.29\right.$ and $\left.0.59 \mathrm{~W} . \mathrm{cm}^{-2}\right)$ was 0.115 which represents an experimental error of $13.9 \%$, calculated according to Equation (13). It was noticed a significant increase in error for the case with highest power intensity. The mean value of $\mathrm{J}_{\text {us }}$ obtained in the runs with power intensities of $0.15 \mathrm{~W} . \mathrm{cm}^{-2}$ and $0.29 \mathrm{~W} . \mathrm{cm}^{-2}$ is 1.33 and the error is $0.75 \%$. This indicates that the model has better predictability when lower power intensity is applied. It is important to stress that the statistical model does not consider effects related to the design of the system, such as interference between ultrasonic waves. Attempts were made to find a model with higher predictability, but it was unsuccessful. 
Among all the experimental runs, the maximum $\mathrm{J}_{\text {us }}$ obtained was 0.151 when applying 20 $\mathrm{kHz}$ and $0.29 \mathrm{~W} . \mathrm{cm}^{-2}$ with a feed solution concentration at $0.075 \mathrm{wt} . \%$. When compared to a control run (performed without US application), this experimental condition yields an increase of $19.7 \%$ in Jus. The permeate collected had turbidity of 2.72 NTU which represents a $99.7 \%$ decrease from the feed solution (1067 NTU). The permeate flux ( $\left.\mathrm{Jus}_{\mathrm{us}}\right)$ decay for both runs is compared in Figure 5-10. The error bar is calculated as shown in Appendix C.

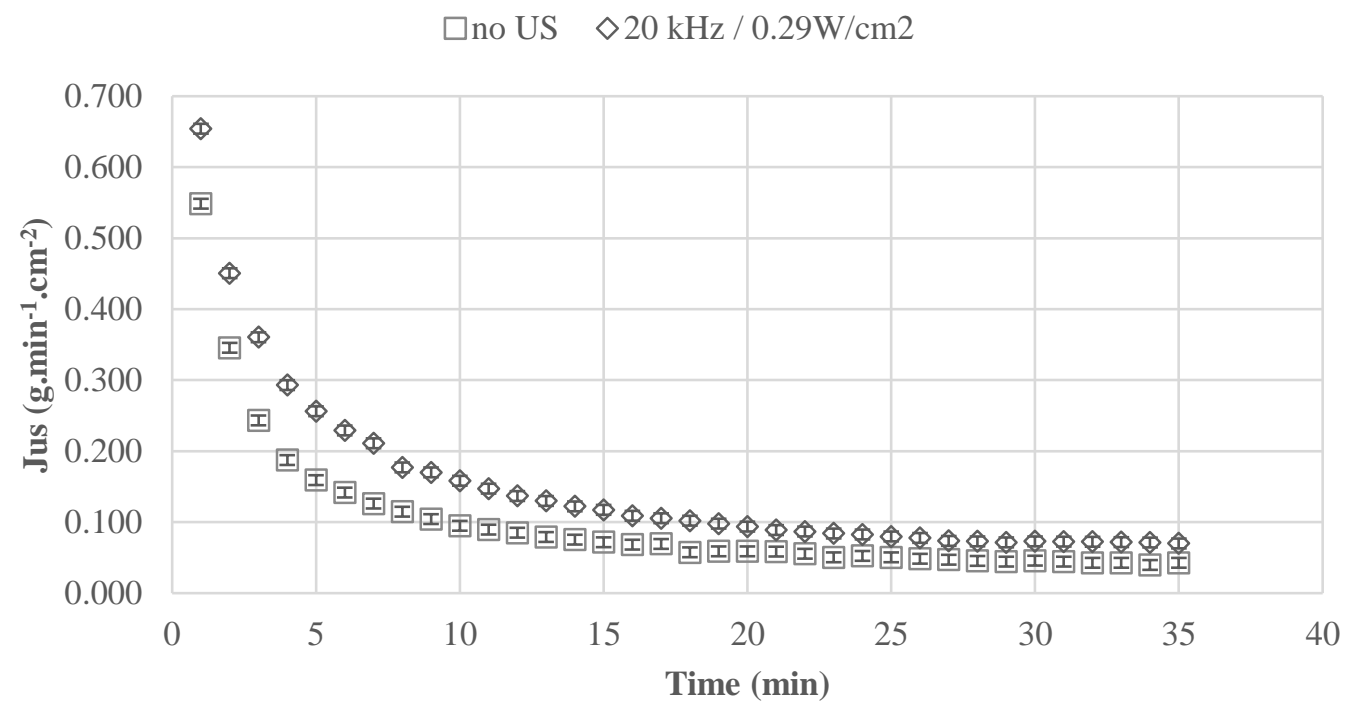

Figure 5-10. Permeate flux decay over 35 minutes of ultrafiltration using the best operating condition $\left(25 \mathrm{kHz}\right.$ and $\left.0.29 \mathrm{~W} . \mathrm{cm}^{-2}\right)$ and the control run (no US) $(\mathrm{Q}=1 \mathrm{~L} . \mathrm{min}-1, \mathrm{P}=5 \mathrm{psi}$, $\mathrm{Cs}=0.075 \mathrm{wt} . \%)$.

The RSM analysis indicated that the averaged permeate flux $\left(\mathrm{J}_{\mathrm{us}}\right)$ is maximized when $20 \mathrm{kHz}$ is applied to feed solution at $0.075 \mathrm{wt} . \%$. The power intensity is statistically non-significant to the response variable. From Table 5-3, it was observed that the experimental run with 0.29 W.cm ${ }^{-2}$ presented the lowest percentage error. With that, $20 \mathrm{kHz}$ and $0.29 \mathrm{~W} . \mathrm{cm}^{-2}$ operating condition is considered in this study the best ultrasonic setting for the system and further investigations will be performed. 


\subsubsection{Investigations Around the Best Operating Condition}

Using $20 \mathrm{kHz}$ and $0.29 \mathrm{~W} . \mathrm{cm}^{-2}$, the ultrafiltration experiment was performed using feed solution concentrations at $0.075 \mathrm{wt} . \%, 0.15 \mathrm{wt} . \%$ and $0.30 \mathrm{wt} . \%$. The case with feed solution concentration at $0.15 \mathrm{wt} . \%$ was not part of the Box-Behnken design and was performed afterwards. The data collected for the three feed solution concentrations can be found in A-6 at Appendix A. Figure 5-11 displays the permeate flux decay over 35 minutes for these three cases.

$\diamond 0.075$ wt. $\% \quad \square 0.15$ wt. $\% \quad \triangle 0.30$ wt. $\%$

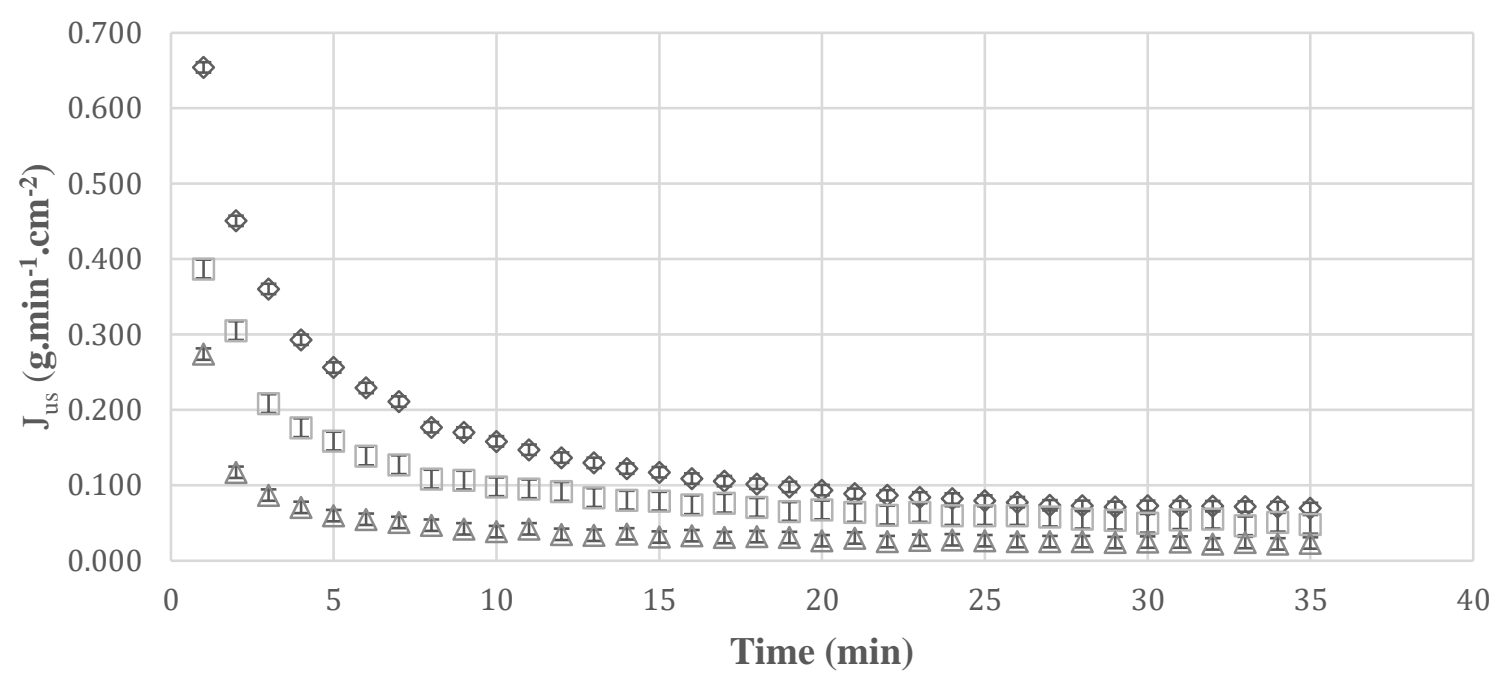

Figure 5-11. Permeate flux decay over 35 minutes of ultrafiltration the applying $25 \mathrm{kHz}$ and 0.29 $\mathrm{W} . \mathrm{cm}^{-2}$ and using various feed solution concentrations $(\mathrm{Q}=1 \mathrm{~L} . \mathrm{min}-1, \mathrm{P}=5 \mathrm{psi})$

The averaged value of $\mathrm{J}_{\mathrm{us}}$ was $0.151,0.089$ and 0.044 for $0.075 \mathrm{wt} . \%, 0.15 \mathrm{wt} . \%$ and 0.30 wt.\%, respectively. The overall flux decay was more severe for the highest concentration. This indicates that the fouling control strategy here proposed is more efficient for feed solutions with lower concentrations. As expected from previous analysis, when the feed solution concentration is increased, fouling occurs faster. The application of ultrasound becomes less efficient and the flux decay occurs faster.

These three US-assisted filtrations were compared to control runs with different feed solution concentrations. The total mass of permeate collected after 35 minutes for all six cases is shown in Figure 5-12. The runs with application of $20 \mathrm{kHz}$ and $0.29 \mathrm{~W} . \mathrm{cm}^{-2}$ yielded more permeate 
then control run using $0.075 \mathrm{wt} . \%$ and $0.15 \mathrm{wt} . \%$. The application of the same ultrasonic setting to the feed solution with $0.30 \mathrm{wt} . \%$ resulted in less permeate then the control run. Due to the higher concentration of solid particles, fouling tends to occur faster, and the results obtained indicate that the application of ultrasound is not effective in controlling fouling at concentrations higher then $0.30 \mathrm{wt} . \%$. This indicates that the application of this fouling control technique is disadvantageous for solutions with higher concentrations.

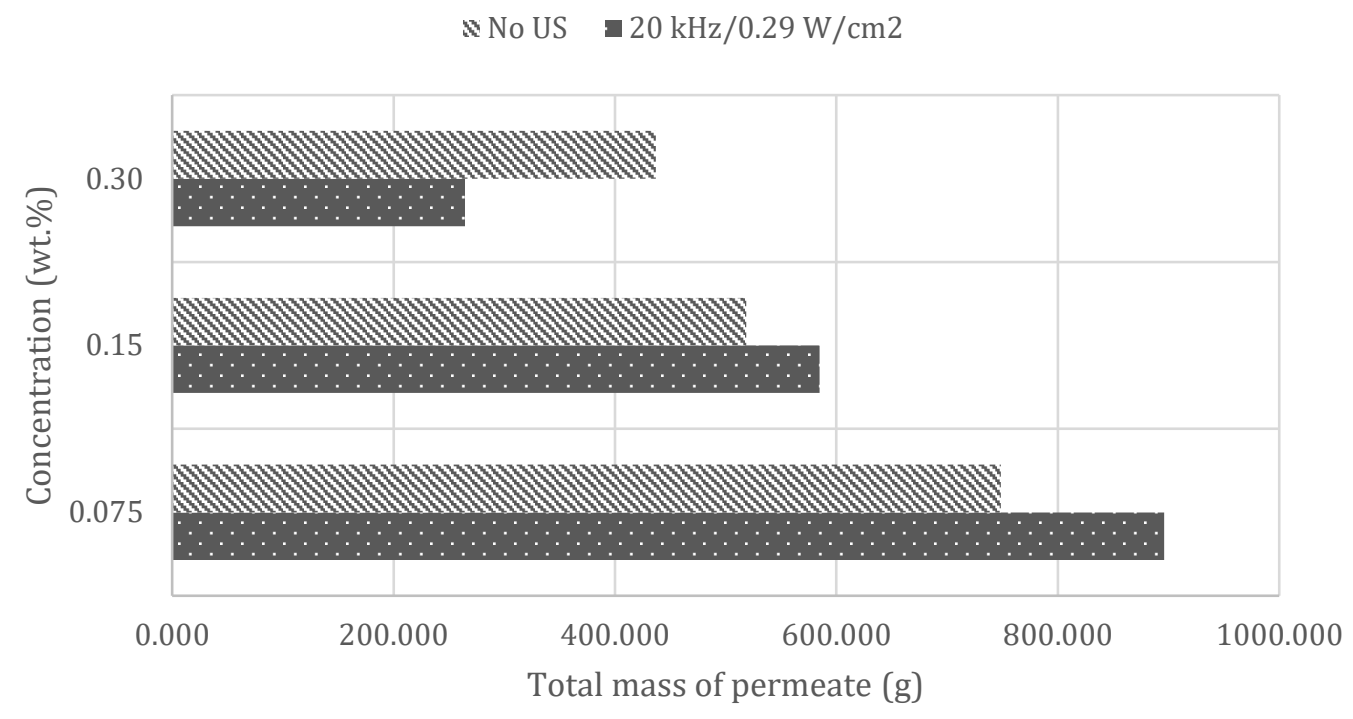

Figure 5-12. Mass of permeate collected after 35 minutes of US-assisted filtration applying 20 $\mathrm{kHz}$ and $0.29 \mathrm{~W} . \mathrm{cm}^{-2}$ and using various feed solution concentrations

This trend is believed to be associated to properties of feed solution molecules and the position of the ultrasonic transducer. Previous studies have demonstrated that the application of US from the feed side is more advantageous for UF membranes (Kyllönen et al., 2006) . However, it is believed that, in this study, the application from the feed side is causing latex particles to break into smaller ones. As consequence, smaller particles can accumulate within the pores and cause more irreversible fouling. Furthermore, at higher solid concentrations, the feed solution presented less negative zeta potential. With that, there is less repulsion between particles and it becomes harder to separate them. According to Abdelrasoul (2015), particle-to-particle and particle-tomembrane attachments are the main cause of irreversible fouling. 
Another phenomenon that can be associated to this observation regarding solid concentration is the formation of shielding bubble clouds. At higher solid concentrations there is an increase in the number of nuclei available for generation of cavitation bubbles. The presence of these clouds leads to the significant change in pressure distribution and intense localized cavitation. Leading to increase in pore size of the membrane due to its polymeric nature. Consequently, the permeate solution has its turbidity increased.

The turbidity of permeate solutions obtained from feed solutions of the different solid concentrations is shown in Figure 5-13. The permeate obtained from 0.30 wt. $\%$ feed solution presented significantly higher turbidity.

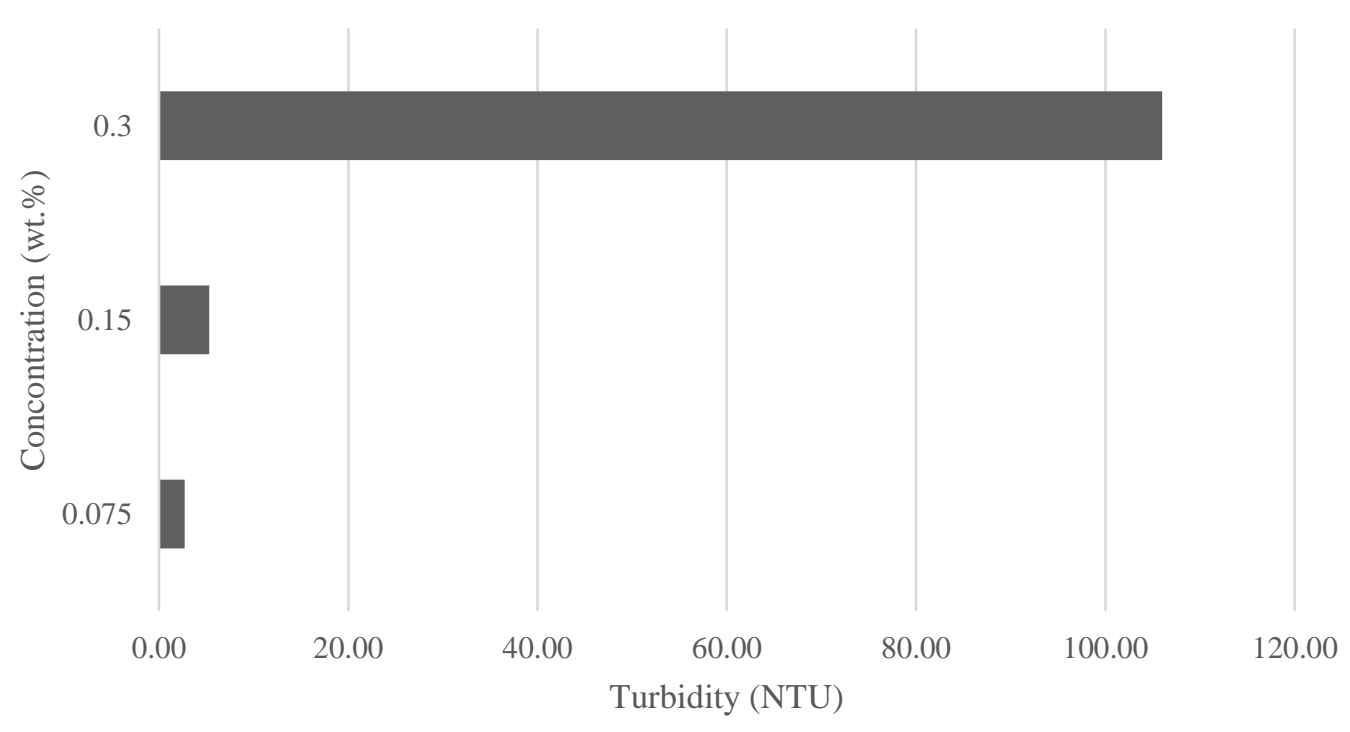

Figure 5-13 Turbidity of permeate solution obtained from different feed solutions with different solid concentrations $\left(\mathrm{F}=20 \mathrm{kHz}, \mathrm{P}_{\mathrm{wi}}=0.29 \mathrm{~W} . \mathrm{cm}^{-2}, \mathrm{Q}=1.0 \mathrm{~L} \cdot \mathrm{min}^{-1}, \mathrm{P}=5.0 \mathrm{psi}\right)$

The feed solution containing higher solid concentration has a wider particle size distribution that includes a larger portion of significantly bigger particles, as seen in Figure 4-6. Consequently, the cake layer formed on the membrane surface is more porous due to larger interparticle distances. This way, more particles can pass through the cake layer reaching the membrane and then the permeate side. To confirm this observation, the particle size of the same permeate solutions was measured. The result is shown in Figure 5-14 and it was confirmed that the permeate solution obtained using $0.30 \mathrm{wt} . \%$ feed solution had larger particles. 


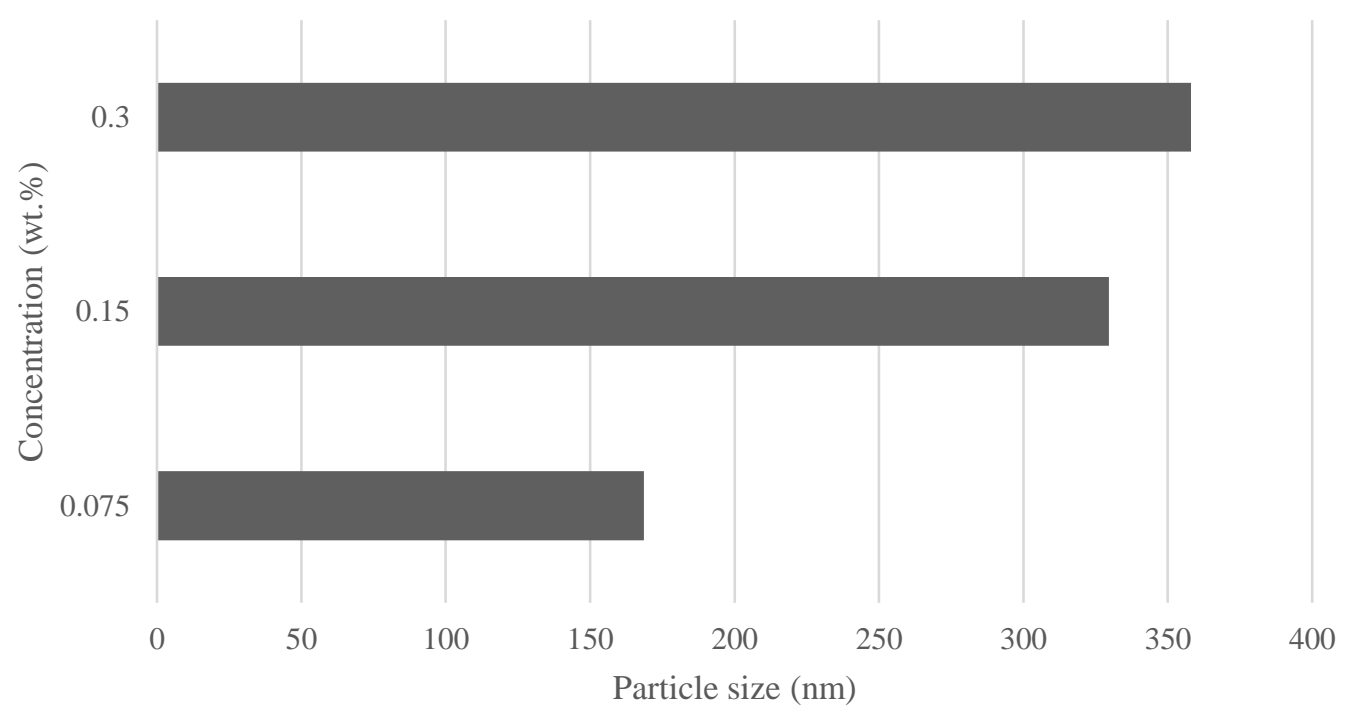

Figure 5-14. Average particle size of permeate solution obtained from different feed solution with different solid concentrations $\left(\mathrm{F}=20 \mathrm{kHz}, \mathrm{P}_{\mathrm{wi}}=0.29 \mathrm{~W} . \mathrm{cm}^{-2}\right)$

The effect of feed flow rate on the performance of US-assisted UF was also evaluated. For this, the best operating condition $\left(20 \mathrm{kHz}, 0.29\right.$ w.cm ${ }^{-2}$ and 0.075 wt.\%) was applied in 5 experiments using feed flow rate of 1.0, 2.0, 3.0, 4.0 and 5.0 L.min ${ }^{-1}$. Similarly, 5 experiments with similar flow rates were performed without US application. The Reynolds number and fluid velocity for each case is shown in Table 5-4. The data collected is presented in A-7 and A-8 in Appendix A.

Table 5-4. Flow conditions inside membrane module for flow rate investigation

\begin{tabular}{|c|c|c|}
\hline $\begin{array}{l}\text { Feed flow rate } \\
\quad\left(\text { L.min }^{-1}\right)\end{array}$ & Reynolds Number & $\begin{array}{l}\text { Fluid velocity } \\
\qquad\left(\mathbf{m} . \mathbf{s}^{-1}\right)\end{array}$ \\
\hline 1 & 322 & 0.021 \\
\hline 2 & 645 & 0.042 \\
\hline 3 & 967 & 0.063 \\
\hline 4 & 1289 & 0.083 \\
\hline 5 & 1612 & 0.104 \\
\hline
\end{tabular}


Figure 5-1 displays the $\mathrm{J}_{\mathrm{us}}$ calculated for the experiments without US application using various feed cross-flow velocities. For the cases without ultrasound application, as the feed flow rate is increased, $\mathrm{J}_{\mathrm{us}}$ is initially increased and then it decays slightly.

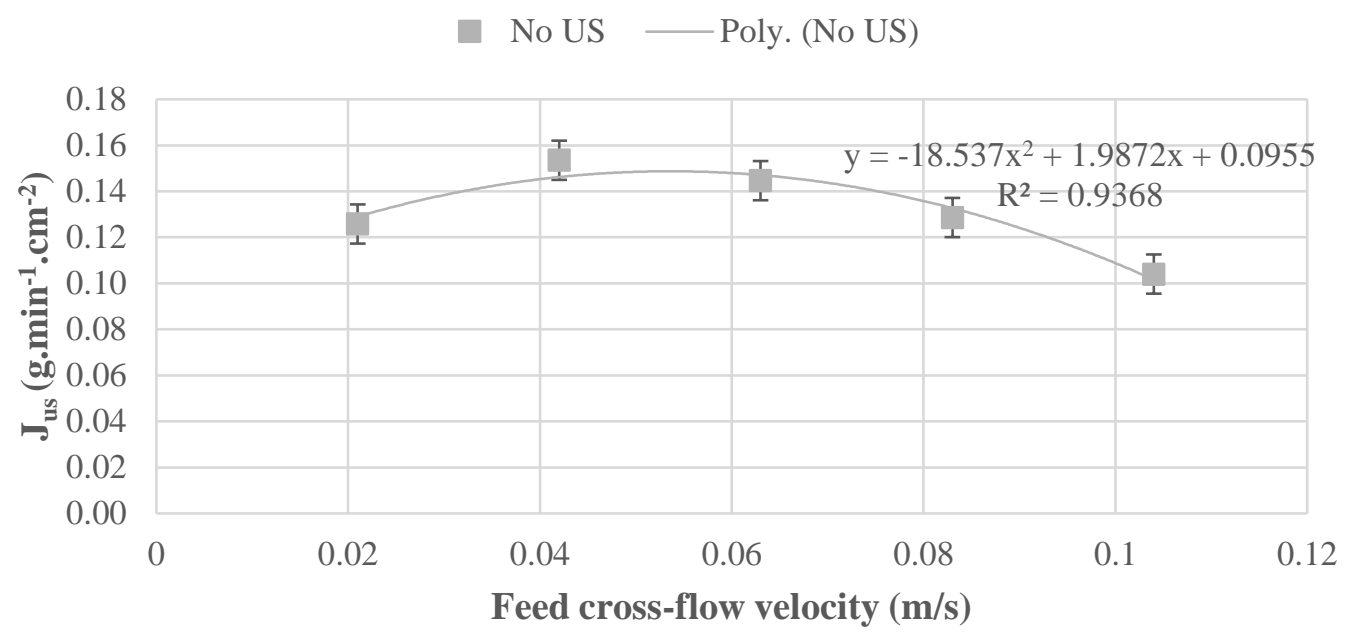

Figure 5-15. Permeate flux ( $\mathrm{J}_{\mathrm{us}}$ ) obtained using various feed cross-flow velocities without US application after 35 minutes of filtration $(\mathrm{Cs}=0.075 \mathrm{wt} . \%)$

Figure 5-16 displays $J_{\text {us }}$ calculated for the experiments with application of $20 \mathrm{kHz}$ and 0.29 W. $\mathrm{cm}^{-2}$. For the cases with ultrasound application, as feed flow rate is increased, $\mathrm{J}_{\mathrm{us}}$ is decreases linearly, and it is lower than the cases without ultrasound for cross-flow velocity higher then 0.02 $\mathrm{m} . \mathrm{s}^{-1}$. Furthermore, the total flux decay was higher for the cases with ultrasound application, indicating a higher degree of fouling. These results can be associated to the position of the feed inlet and the length of the membrane. With the feed inlet perpendicular to the top of the membrane, it creates an impingement point, and it affects the hydrodynamics on the feed side of the membrane module. Furthermore, because the membrane is only $17 \mathrm{~cm}$ long, it is possible that the flow is not fully developed. 


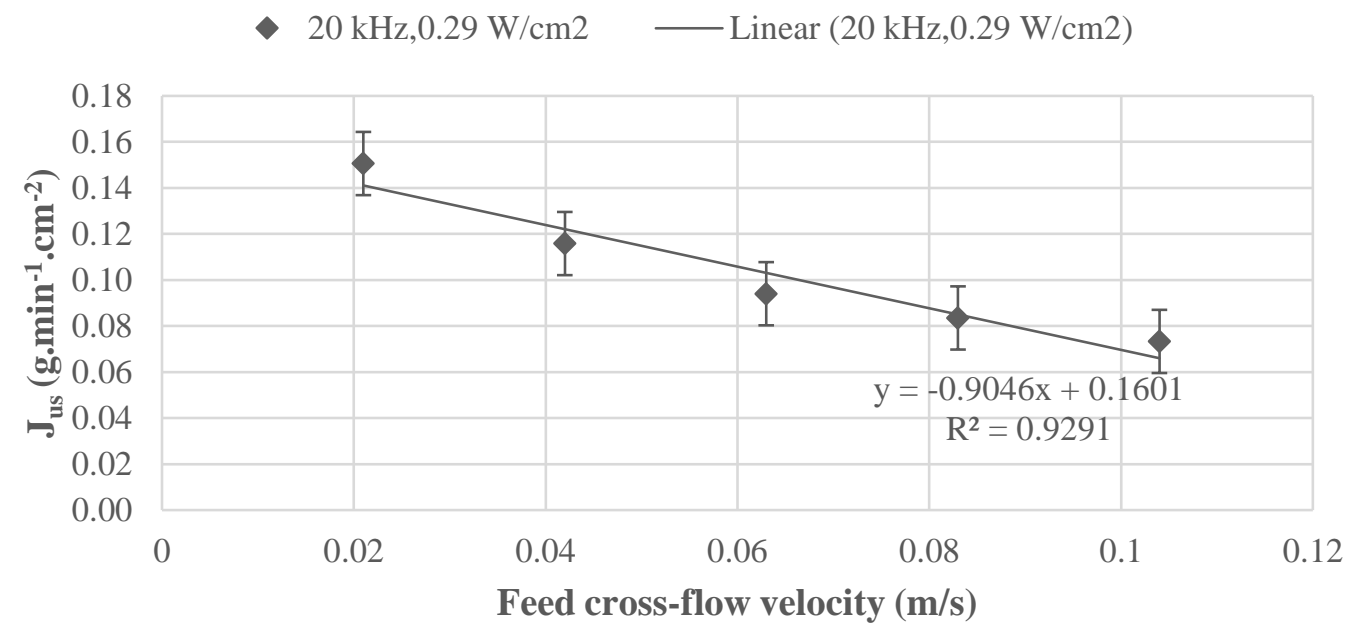

Figure 5-16. Permeate flux ( $\left.\mathrm{J}_{\mathrm{us}}\right)$ obtained using various feed cross-flow velocities with and without US application after 35 minutes of filtration $(\mathrm{Cs}=0.075 \mathrm{wt} . \%)$

Figure 5- shown the amount of permeate collected after 35 minutes of filtration for the cases with and without ultrasound application and various feed cross-flow velocities. It was observed that the amount of permeate collected during the US-assisted filtrations is smaller then the cases without ultrasound for cross-flow velocity higher than $0.021 \mathrm{~m} . \mathrm{s}^{-1}$.

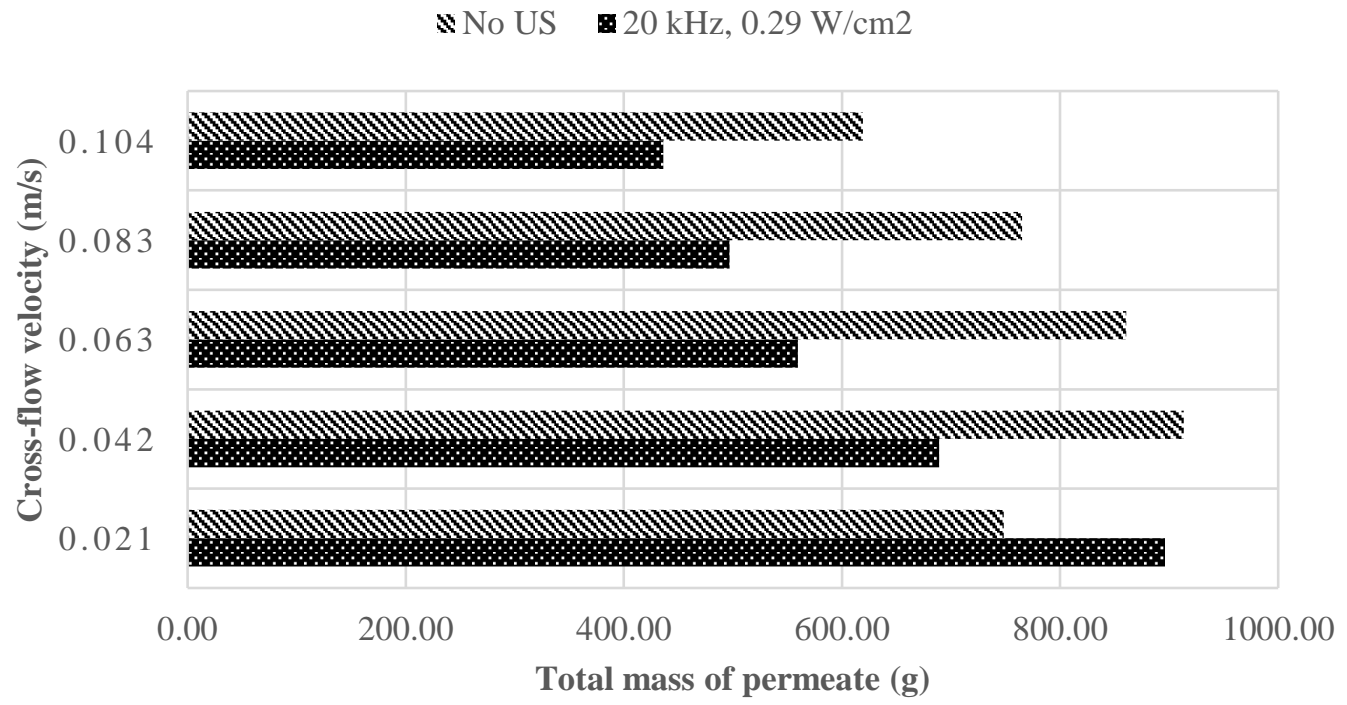

Figure 5-17. Total mass of permeate collected in 35 minutes of filtration using various feed cross-flow velocities with and without ultrasound application $\left(20 \mathrm{kHz}, 0.29 \mathrm{~W} . \mathrm{cm}^{-2}\right), \mathrm{P}=5 \mathrm{psi}$, $\mathrm{C}_{\mathrm{s}}=0.075 \mathrm{wt} . \%$ 
The increase in feed flow rate demonstrated to be disadvantageous to the presented fouling control technique. The feed flow rate plays a major role in fouling of polymeric membranes. For this reason, it is believed that lower feed flow rates would be more beneficial to the process. Due to limitations of the experimental setup, $1.0 \mathrm{~L} \cdot \mathrm{min}^{-1}$ was the lowest flow rate possible. The presence of cavitation bubbles might have a negative impact on US-assisted performance at higher feed flow rates due to interference in mass transfer phenomenon inside the membrane module.

Figure 5- shows effect of US application on the cake layer formation. The SEM images of the membrane surface after 35 minutes of ultrafiltration without and with US application $(20 \mathrm{kHz}$, $0.29 \mathrm{~W} . \mathrm{cm}^{-2}$ ) are presented. The cake layer formed during US-assisted UF was less dense and it was possible to see the marks left from the cavitation bubbles. Additionally, it is possible to see in the SEM image that the cake layer formed under ultrasound application is formed by smaller particles. This can be attributed to the increased hydrodynamic turbulence under acoustic cavitation. Larger particles have less negative zeta potential and experience more lift and drag. This way, larger particles can be detached form the cake layer and washed away easier then smaller particles. From these photos it is evident that the membrane exposed to US applications experienced lower fouling.

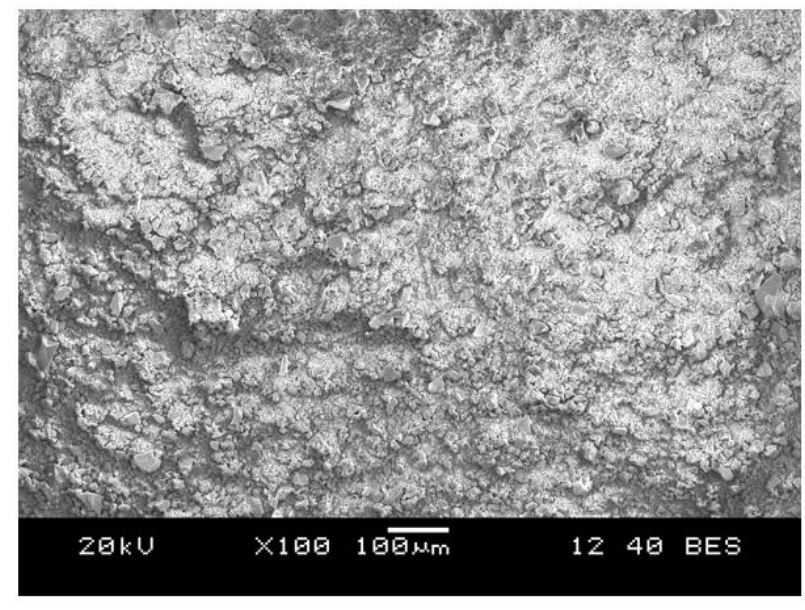

(a)

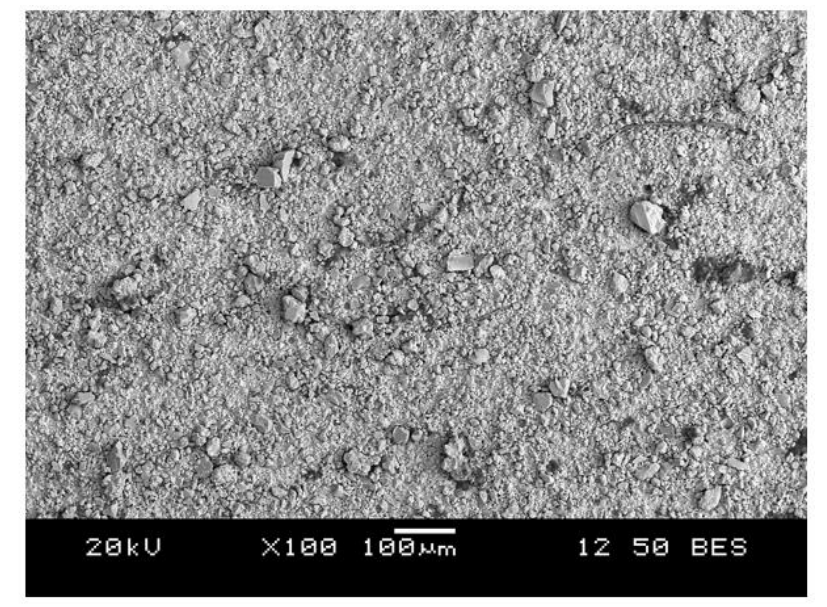

(b)

Figure 5-16. SEM image of PVDF membrane surface after 35 minutes of ultrafiltration (a) without ultrasound and (b) with application of $20 \mathrm{kHz}$ and $0.29 \mathrm{~W} \cdot \mathrm{cm}^{-2}\left(\mathrm{Q}=1.0 \mathrm{~L} \cdot \mathrm{min}^{-1}, \mathrm{P}=5.0\right.$ psi, Cs=0.075 wt.\%) 


\section{Chapter 6}

\section{Conclusions and Recommendations}

In this chapter, the work performed for this investigation is summarized. The conclusions drawn from the analysis of results are presented. Recommendations are made to further investigate ultrasound -assisted control of polymeric membrane fouling.

\subsection{Conclusions}

In the present study, in-situ continuous application of ultrasound was tested for two polymeric membranes. PTCE membranes suffered sever damage to its surface within 3 minutes of US-assisted ultrafiltration. On the other hand, it was observed that ultrasound can effectively be applied in situ during ultrafiltration to control fouling of PVDF membrane.

The effect of ultrasonic frequency, power intensity and feed solution solid concentration on the permeate flux was analysed. At lower frequencies, the application of ultrasound is more effective in detaching particles from the cake layer and hence controlling fouling. The increase in power intensity led to a decrease in productivity and the permeate had high turbidity. A negative effect of ultrasound application was observed for high power intensity and high solid concentration. This behaviour was associated to the direct and continuous application of US in an enclosed system and properties of the feed solution. An increase in feed solution solid concentration hindered US-aided UF performance. The characteristics of the solid particles on the cake layer made particle detachment via cavitation harder and less effective. The properties of the 
cavitation bubbles and level of energy attenuation experienced in different ultrasonic settings was also an important aspect.

Using RSM, a best-fitting model that describes the changes in $\mathbf{J}_{\mathrm{us}}$ as a function of US frequency, power intensity and feed solution solid concentration was obtained. The model presented low predictability since it does not account for mechanical, physical or chemical phenomena.

The best operating condition was found to be $20 \mathrm{kHz}, 0.29 \mathrm{~W} . \mathrm{cm}^{-2}$ and $0.075 \mathrm{wt} . \%$. When operating at 1.0 L.min ${ }^{-1}$ and 5 psi, the maximum average permeate flux obtained was 0.151 . This represented a $19.7 \%$ increase in average permeate flux compared to non-US-aided filtration. Increasing feed flow rate is not beneficial to the US-assisted filtration proposed by this study.

\subsection{Recommendations}

Based on what was observed in this study, some further investigations are recommended to obtain a deeper understanding of the US-assisted fouling control of polymeric membrane.

- Investigate the effect of applying US intermittently during the filtration process. Significant energy attenuation and ultrasonic wave interferences can happen in this system. Applying US intermittently can reduce the amount of bubbles near the membrane surface, reducing localized cavitation. This way, there should be enough energy to detach particles form the cake layer without affecting pore size, breaking molecules or interfering in mass transfer phenomena.

- Consider the applicability of this fouling control technique for different polymeric membranes and feed solutions. The properties of both were demonstrated to play a major role on the US-assisted UF performance.

- Enhance model predictability by incorporating mechanistical effects. The low predictability of the obtained model is attributed to applied pure statistical nature, and not considering physical, mechanical or chemical phenomena. Incorporating these aspects would be beneficial to predict new observations. 


\section{Appendix A}

\section{Experimental data collected}

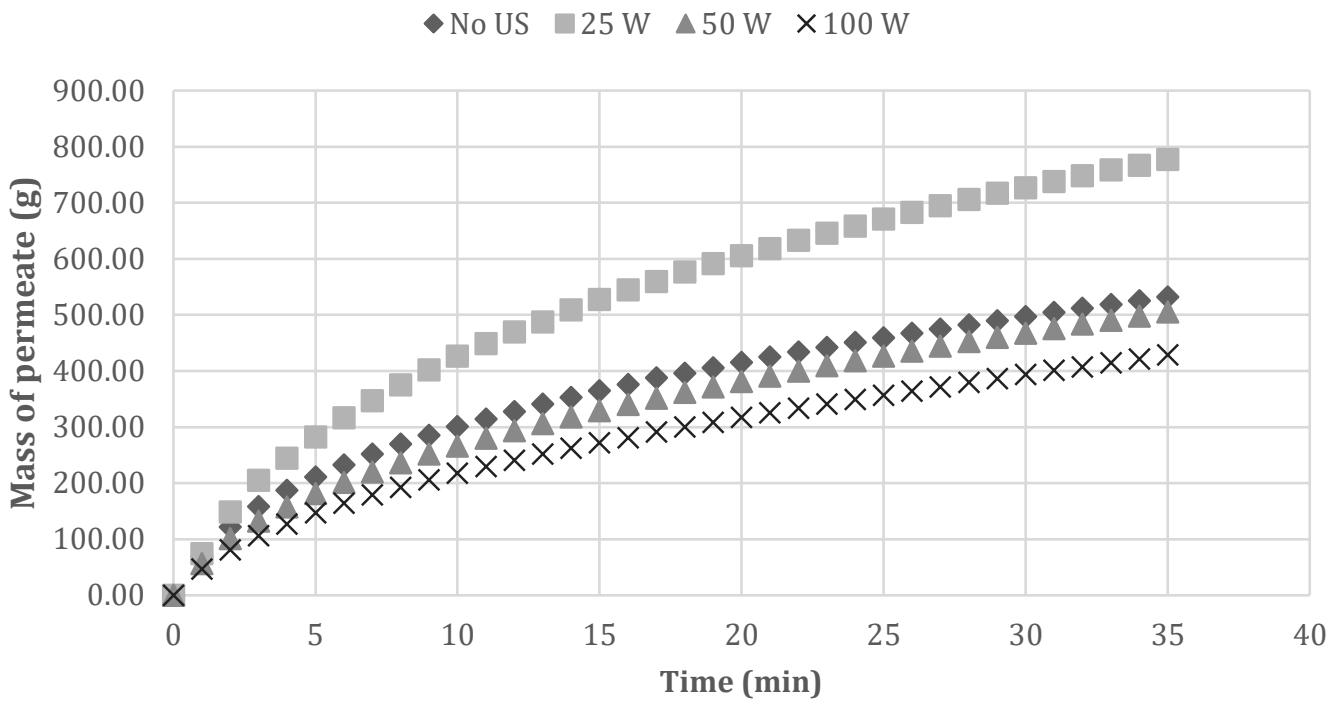

A-1 Permeate mass collected over 35 minutes of filtration applying $20 \mathrm{kHz}$ and various power levels, $\mathrm{Q}=1.0$ L.min-1, $\mathrm{P}=5.0 \mathrm{psi}, \mathrm{Cs}=0.15$ wt.\%

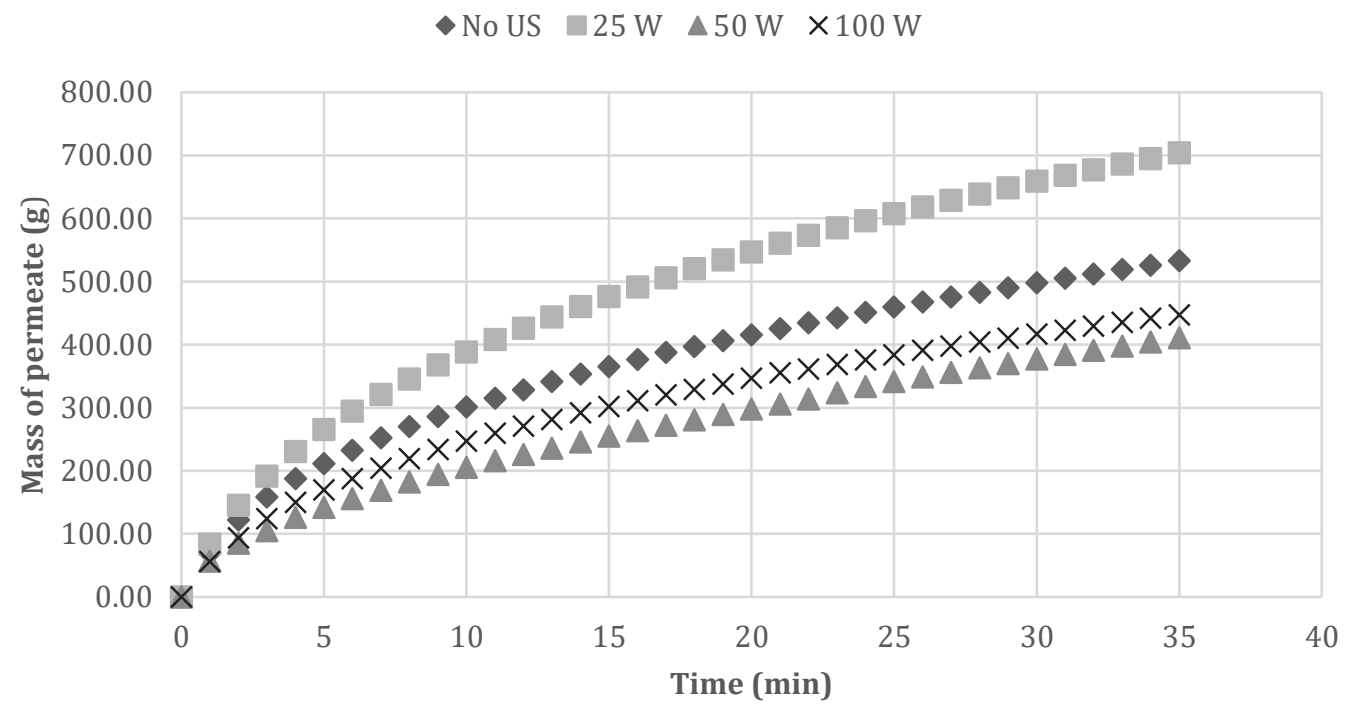

A-2 Permeate mass collected over 35 minutes of filtration applying $28 \mathrm{kHz}$ and various power levels, $\mathrm{Q}=1.0$ L.min-1, $\mathrm{P}=5.0 \mathrm{psi}, \mathrm{Cs}=0.15$ wt.\%. 
$\bullet$ No US $\quad 25 \mathrm{~W} \triangle 50 \mathrm{~W} \times 100 \mathrm{~W}$

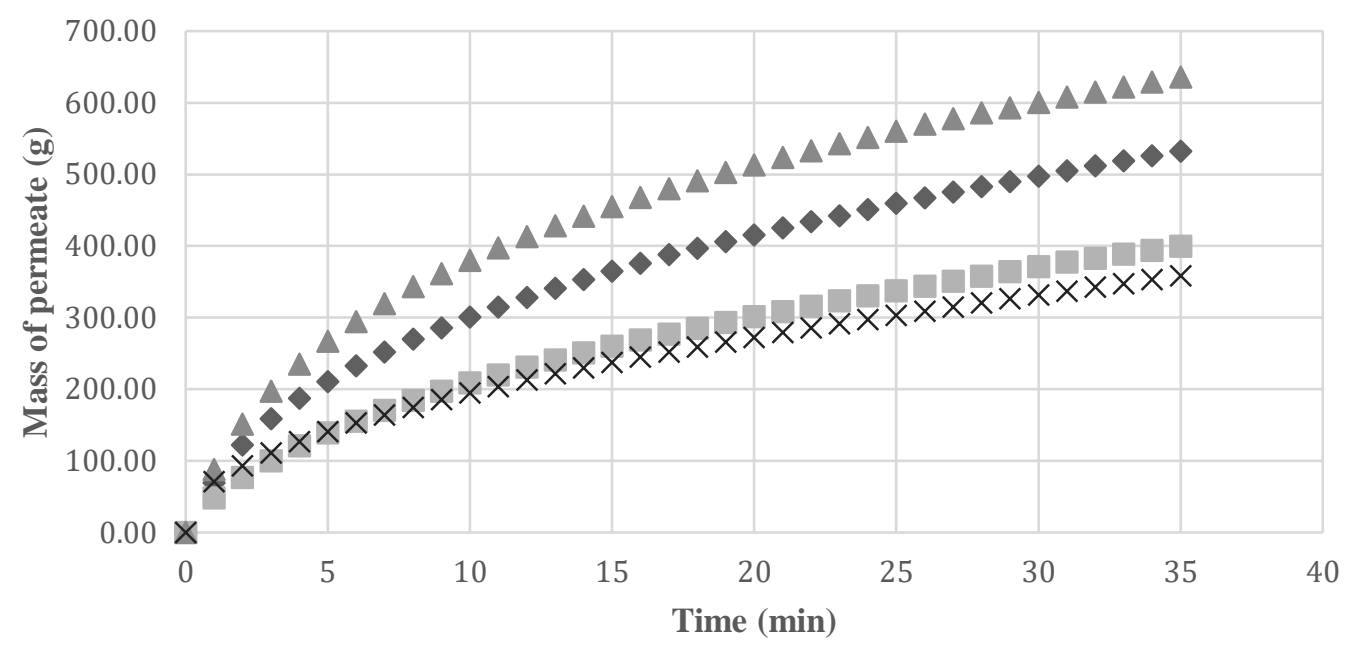

A-3 Permeate mass collected over 35 minutes of filtration applying $40 \mathrm{kHz}$ and various power levels, $\mathrm{Q}=1.0$ L.min-1, $\mathrm{P}=5.0 \mathrm{psi}, \mathrm{Cs}=0.15$ wt.\%.

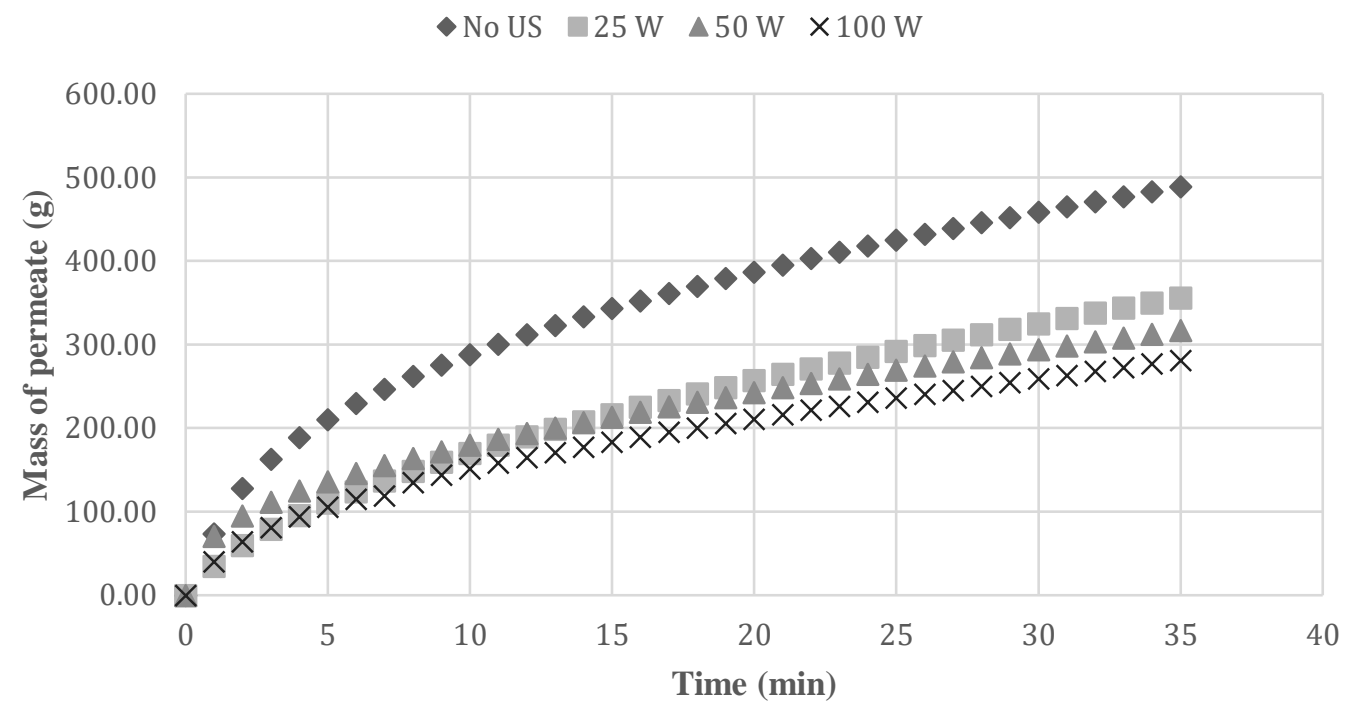

A-4 Permeate mass collected over 35 minutes of filtration applying $28 \mathrm{kHz}$ and various power levels, $\mathrm{Q}=1.0$ L.min-1, $\mathrm{P}=5.0 \mathrm{psi}, \mathrm{Cs}=0.30 \mathrm{wt} . \%$. 


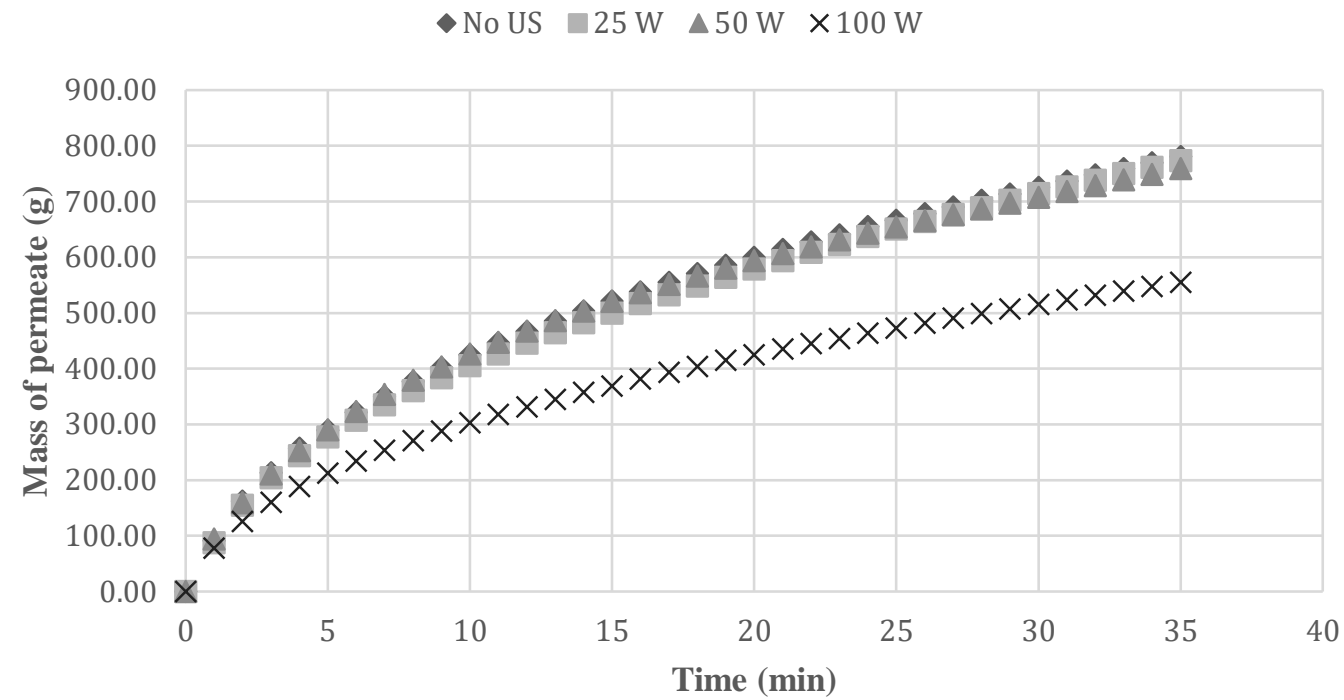

A-5 Permeate mass collected over 35 minutes of filtration applying $20 \mathrm{kHz}$ and various power levels, $\mathrm{Q}=1.0$ L.min-1, $\mathrm{P}=5.0$ psi, $\mathrm{Cs}=0.075$ wt.\%.

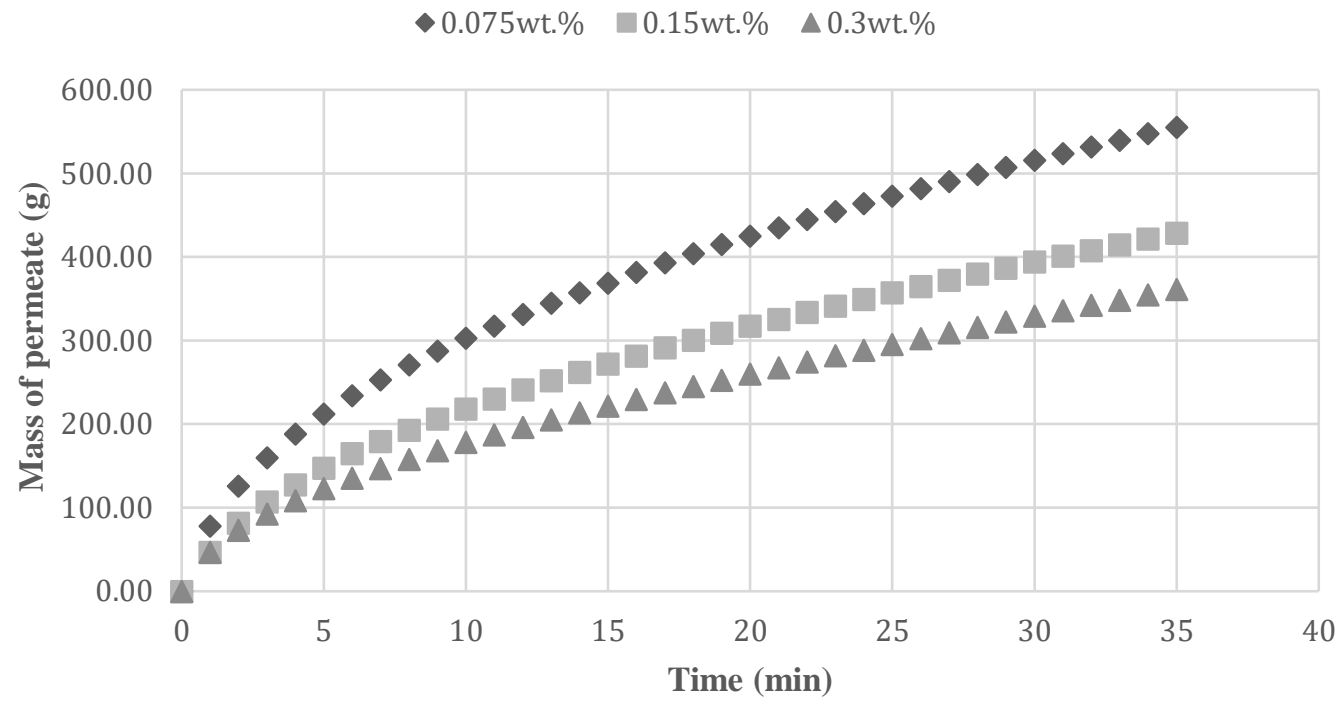

A-6 Permeate mass collected over 35 minutes of filtration applying $20 \mathrm{kHz}$ and $0.29 \mathrm{~W} . \mathrm{cm}^{2}$ with various feed solution concentrations, $\mathrm{Q}=1.0$ L.min- $1, \mathrm{P}=5.0 \mathrm{psi}$. 


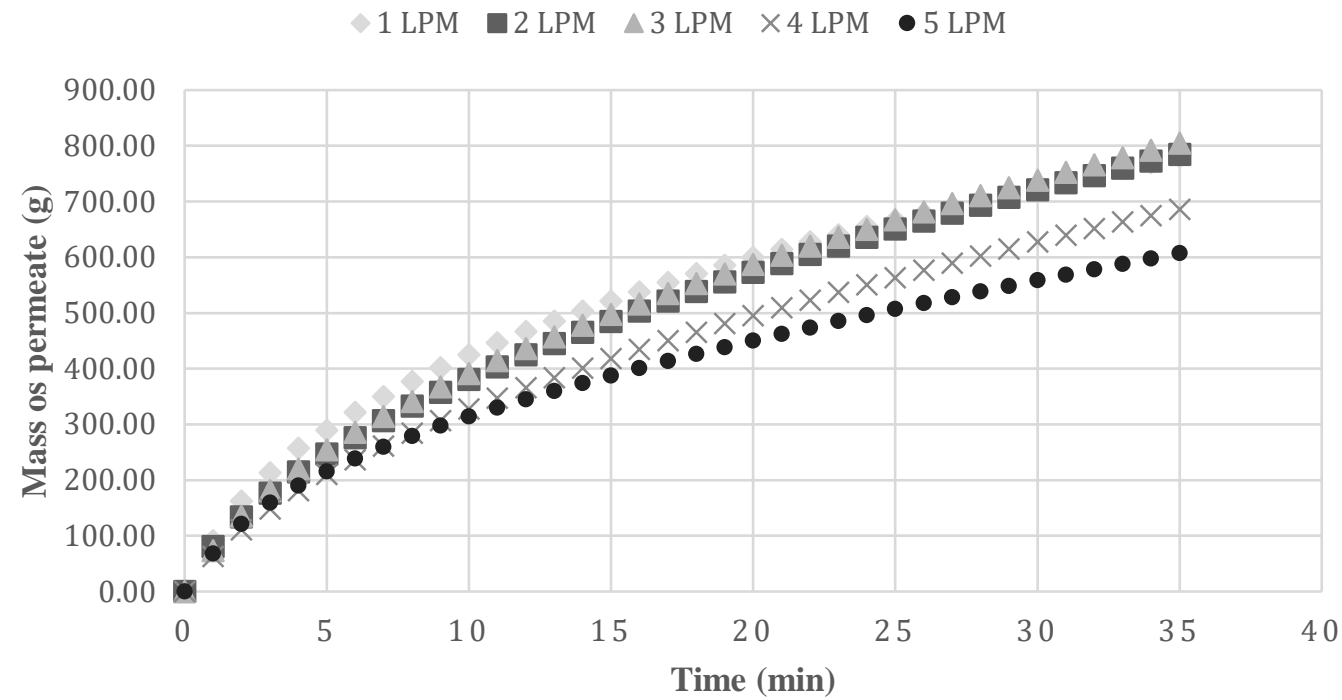

A-7. Permeate mass collected over 35 minutes of filtration using various feed flow rates and no ultrasound application, $\mathrm{P}=5.0 \mathrm{psi}, \mathrm{Cs}=0.075 \mathrm{wt} . \%$.

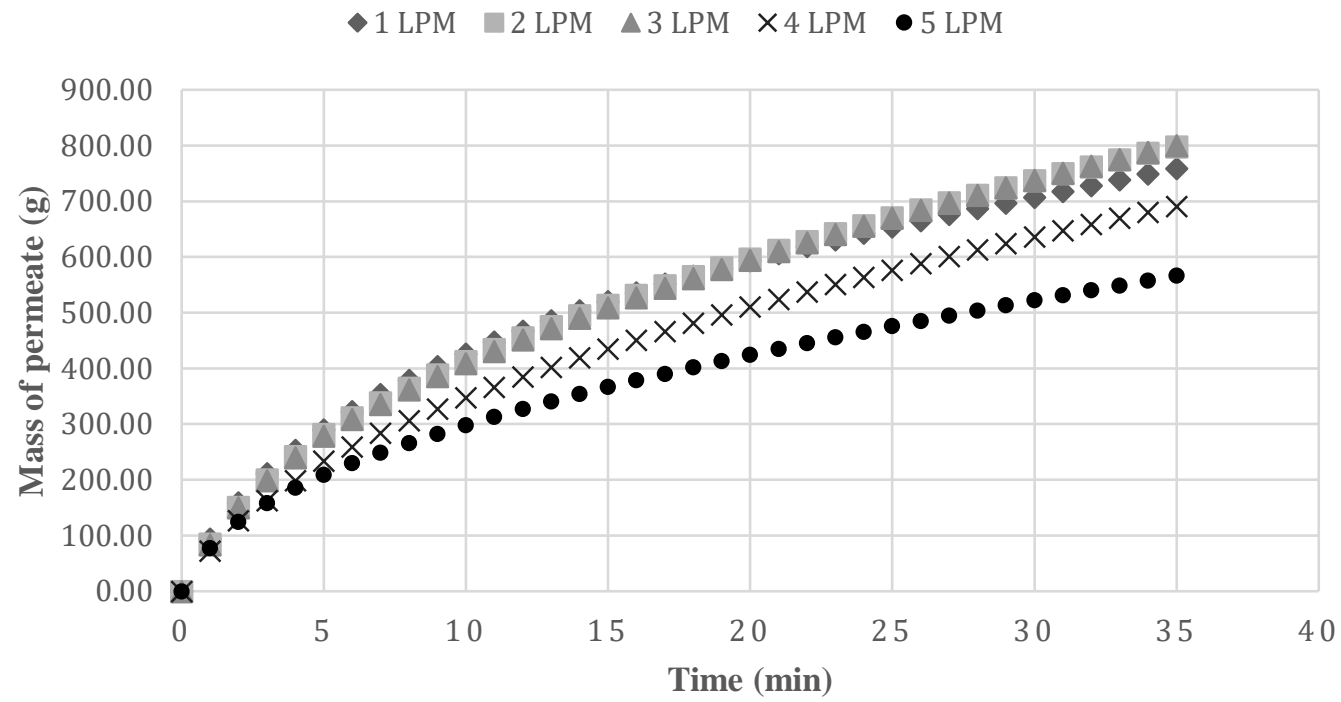

A-8. Permeate mass collected over 35 minutes of filtration using various feed flow rates and application of $20 \mathrm{kHz}$ and $0.29 \mathrm{~W} . \mathrm{cm}-2, \mathrm{P}=5.0 \mathrm{psi}, \mathrm{Cs}=0.075$ wt. $\%$. 


\section{Appendix B}

Response Surface Regression - Backward elimination $(\alpha=0.05)$

B-1. Analysis of variances table

\begin{tabular}{lccccc}
\hline Source & DF & Adj SS & Adj MS & F-Value & P-Value \\
\hline Model & 3 & 0.012865 & 0.004288 & 15.86 & 0.000 \\
$\quad$ Linear & 2 & 0.011784 & 0.005892 & 21.79 & 0.000 \\
$\quad$ Frequency & 1 & 0.002926 & 0.002926 & 10.82 & 0.007 \\
$\quad$ Concentration & 1 & 0.008858 & 0.008858 & 32.76 & 0.000 \\
$\quad$ Square & 1 & 0.001476 & 0.001476 & 5.46 & 0.039 \\
$\quad$ Frequency*Frequency & 1 & 0.001476 & 0.001476 & 5.46 & 0.039 \\
Error & 11 & 0.002974 & 0.000270 & & \\
$\quad$ Lack-of-Fit & 9 & 0.002857 & 0.000317 & 5.44 & 0.165 \\
Pure Error & 2 & 0.000117 & 0.000058 & & P-Value \\
Total & & & & & 0.000 \\
Source & 14 & 0.015839 & & & 0.000 \\
Model & DF & Adj SS & Adj MS & F-Value \\
Linear & 3 & 0.012865 & 0.004288 & 15.86 \\
$\quad$ Frequency & 2 & 0.011784 & 0.005892 & 21.79 \\
\hline
\end{tabular}

B-2. Coded Coefficients

\begin{tabular}{lrrrrr}
\hline Term & Coef & SE Coef & T-Value & P-Value & VIF \\
\hline Constant & 0.06156 & 0.00664 & 9.27 & 0.000 & \\
Frequency & -0.01912 & 0.00581 & -3.29 & 0.007 & 1.02 \\
Concentration & -0.03245 & 0.00567 & -5.72 & 0.000 & 1.00 \\
Frequency*Frequency & 0.02091 & 0.00895 & 2.34 & 0.039 & 1.02 \\
\hline
\end{tabular}



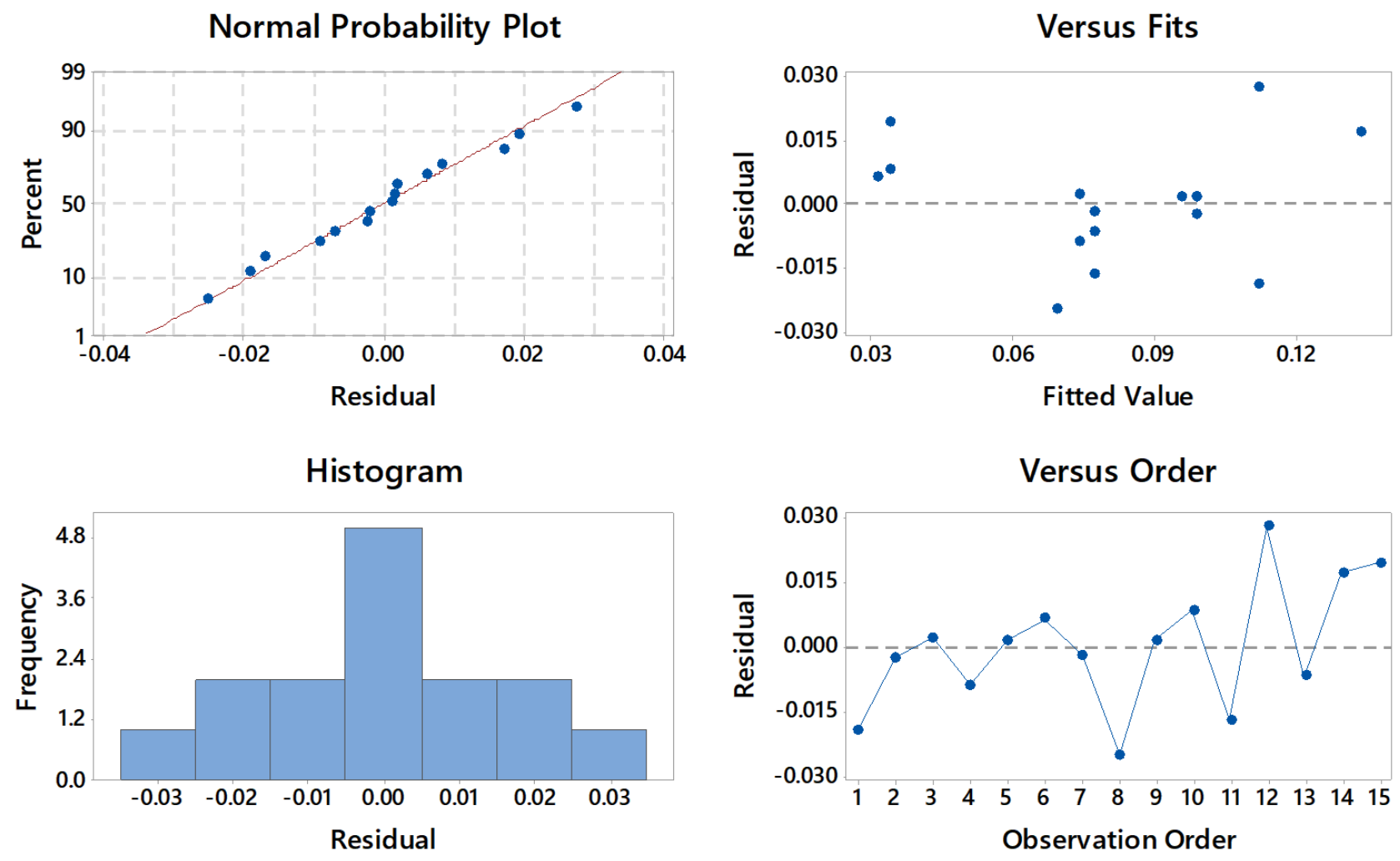

B-3. Residual plots 


\section{Appendix C}

\section{Reproducibility}

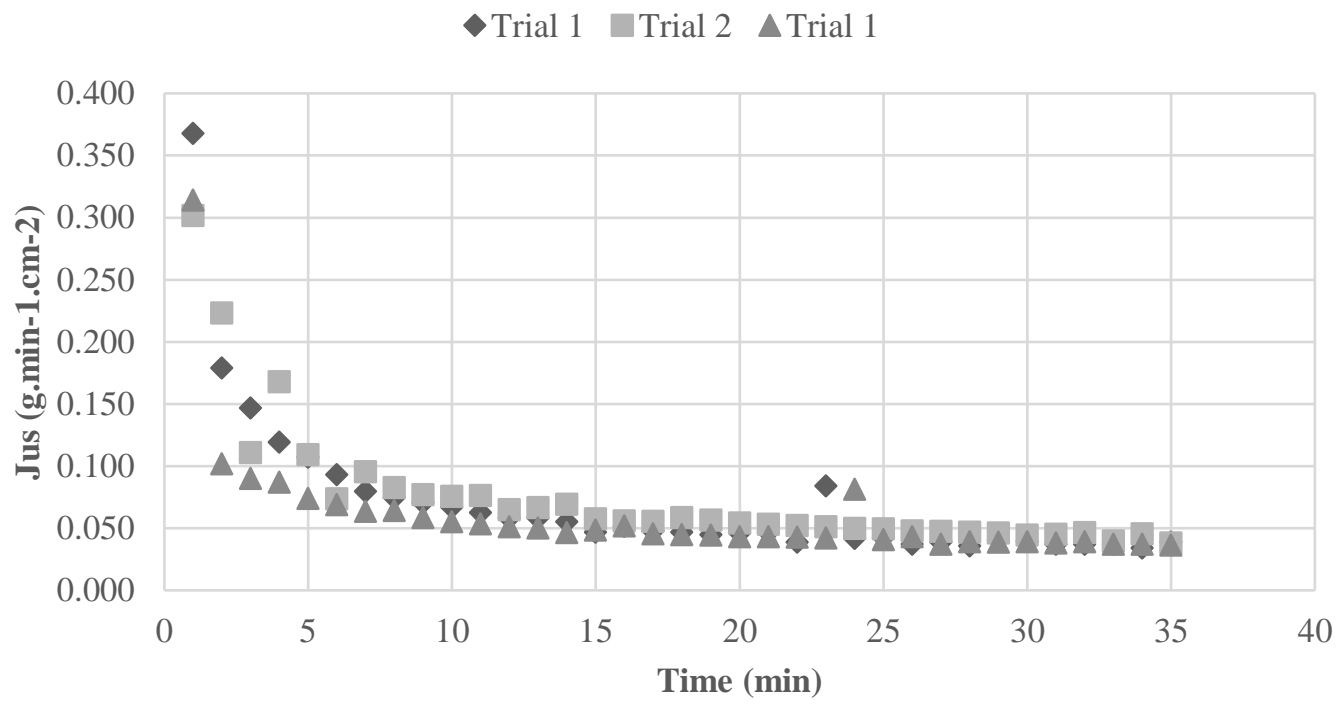

C-1. Permeate flux decay over 35 minutes of filtration applying $28 \mathrm{kHz}, 0.29 \mathrm{~W} . \mathrm{cm}^{-2}(\mathrm{Q}=1.0$ L. $\min ^{-1}, \mathrm{P}=5.0 \mathrm{psi}, \mathrm{Cs}=0.15$ wt. $\left.\%\right)-3$ replicates

C-2. Water fluxand permeate flux for repeated trials

\begin{tabular}{ccccc}
\hline Trial & Jo & Javg & Javg/Jo & Jus \\
\hline 1 & 0.699 & 0.062 & 0.088 & 0.060 \\
2 & 0.807 & 0.093 & 0.116 & 0.075 \\
3 & 0.654 & 0.068 & 0.104 & 0.070 \\
\hline
\end{tabular}

C-3. Mean and standad deviation of permeate flux and averaged normalized permeate flux

\begin{tabular}{cccc}
\hline & Javg $_{\text {avg }}$ & Javg/Jo & Jus \\
\hline Mean & 0.074 & 0.103 & 0.069 \\
Std & $\mathbf{0 . 0 1 4}$ & $\mathbf{0 . 0 1 1}$ & $\mathbf{0 . 0 0 6}$ \\
\hline
\end{tabular}




\section{Appendix D}

\section{Sample calculations}

- Calculation of normalized averaged flux used

Before the filtration, the membrane was precondition and the water flux was obtained by passing distilled water through the membrane using $1.0 \mathrm{~L} \cdot \mathrm{min}^{-1}$ and 5 psi.

D-1. Data collected for water flux calculation

\begin{tabular}{|c|c|c|}
\hline Time (min) & $\boldsymbol{m}_{\text {water }}$ & Water Flux $\left(\mathbf{g} \cdot \mathbf{m i n}^{\mathbf{- 1}} \mathbf{. c m}^{\mathbf{2}}\right)$ \\
\hline 0 & 0 & 0 \\
\hline 1 & 119.2 & 0.701 \\
\hline 2 & 225.8 & 0.627 \\
\hline 3 & 333.8 & 0.635 \\
\hline 4 & 446.2 & 0.661 \\
\hline 5 & 556 & 0.646 \\
\hline Average flux $\left(\mathbf{J}_{\mathbf{o}}\right)$ & & $\mathbf{0 . 6 5 4}$ \\
\hline
\end{tabular}

\section{$\mathrm{J}_{0}=0.654 \mathrm{~g} \cdot \mathrm{min}^{-1} \cdot \mathrm{cm}^{-2}$}

The water flux was calculated according to Equation (6) where $A_{m}=10 \times 17=170 \mathrm{~cm}^{2}$.

$$
J_{o}=\frac{\Delta\left(m_{\text {water }}\right)}{\Delta t \cdot A_{m}}
$$

The following table shows the permeate mas collected over 35 minutes of ultrafiltration using 28 $\mathrm{kHz}, 0.29 \mathrm{~W} . \mathrm{cm}^{-2}$ and $0.15 \mathrm{wt} . \%$.

D-2. Data collected for permeate flux calculation

\begin{tabular}{|c|c|c|c|}
\hline Time (min) & Weight $\mathbf{( g )}$ & $\mathbf{J}\left(\mathbf{m L} \cdot \mathbf{m i n}^{-\mathbf{1}} \mathbf{.} \mathbf{c m}^{\mathbf{2}}\right)$ & $\mathbf{J} / \mathbf{J}_{\mathbf{o}}$ \\
\hline 0 & 0 & 0 & 0 \\
\hline 1 & 60.4 & 0.355 & 0.543 \\
\hline 2 & 89.8 & 0.173 & 0.264 \\
\hline 3 & 113.9 & 0.142 & 0.217 \\
\hline 4 & 133.5 & 0.115 & 0.176 \\
\hline 5 & 151.1 & 0.104 & 0.158 \\
\hline 6 & 166.4 & 0.090 & 0.138 \\
\hline 7 & 179.5 & 0.077 & 0.118 \\
\hline 8 & 191.8 & 0.072 & 0.111 \\
\hline 9 & 203.4 & 0.068 & 0.104 \\
\hline
\end{tabular}




\begin{tabular}{|l|c|c|c|}
\hline 10 & 214.4 & 0.065 & 0.099 \\
\hline 11 & 224.7 & 0.061 & 0.093 \\
\hline 12 & 234.3 & 0.056 & 0.086 \\
\hline 13 & 243.9 & 0.056 & 0.086 \\
\hline 14 & 253 & 0.054 & 0.082 \\
\hline 15 & 260.7 & 0.045 & 0.069 \\
\hline 16 & 269.2 & 0.050 & 0.076 \\
\hline 17 & 277.1 & 0.046 & 0.071 \\
\hline 18 & 284.8 & 0.045 & 0.069 \\
\hline 19 & 292.2 & 0.044 & 0.067 \\
\hline 20 & 299.8 & 0.045 & 0.068 \\
\hline 21 & 307.5 & 0.045 & 0.069 \\
\hline 23 & 313.9 & 0.038 & 0.058 \\
\hline 24 & 327.7 & 0.081 & 0.124 \\
\hline 25 & 334.6 & 0.041 & 0.062 \\
\hline 26 & 341.6 & 0.041 & 0.063 \\
\hline 27 & 347.7 & 0.036 & 0.055 \\
\hline 28 & 354.1 & 0.038 & 0.058 \\
\hline 29 & 360 & 0.035 & 0.053 \\
\hline 30 & 366.7 & 0.039 & 0.060 \\
\hline 32 & 373.2 & 0.038 & 0.055 \\
\hline 33 & 379.3 & 0.036 & 0.055 \\
\hline 34 & 385.4 & 0.036 & 0.055 \\
\hline 35 & 391.5 & 0.036 & 0.050 \\
\hline & 397.1 & 0.033 & 0.058 \\
\hline & 403.5 & 0.038 & \\
\hline & & & 0.068 \\
\hline
\end{tabular}

The permeate flux was calculated using Equation (7) and the normalized flux was obtained dividing $\mathrm{J}$ by the average water flux previously calculated $\left(\mathrm{J}_{\mathrm{o}}\right)$.

$$
J=\frac{\Delta\left(m_{\text {perm }}\right)}{\Delta t A_{m}}
$$

$\mathrm{J}_{\text {avg }}=0.068 \mathrm{~g} \cdot \mathrm{min}^{-1} \cdot \mathrm{cm}^{-2}$

$\mathbf{J}_{\text {avg }} / \mathbf{J}_{\mathbf{o}}=0.104$ g.min ${ }^{-1} \cdot \mathrm{cm}^{-2}$ 
- Calculation of permeate flux used to assess the performance of ultrafiltration in the RSM investigation.

Similarly, the water flux was obtained prior to the ultrafiltration procedure.

D-3. Data collected for water flux calculation (RSM)

\begin{tabular}{|c|c|c|}
\hline $\begin{array}{c}\text { Time } \\
\text { (min) }\end{array}$ & Weight (g) & $\begin{array}{c}\text { Water flux } \\
\text { (g.min }^{-1} \mathbf{. c m}^{-2} \text { ) }\end{array}$ \\
\hline 0 & 0 & 0 \\
\hline 1 & 100.1 & 0.589 \\
\hline 2 & 204.3 & 0.613 \\
\hline 3 & 304.2 & 0.588 \\
\hline 4 & 400.1 & 0.564 \\
\hline 5 & 485.4 & 0.502 \\
\hline 6 & 575.1 & 0.528 \\
\hline 7 & 661.1 & 0.506 \\
\hline \multicolumn{2}{|c|}{ Average } & $\mathbf{0 . 5 5 6}$ \\
\hline
\end{tabular}

$\mathrm{J}_{0}=0.556 \mathrm{~g} \cdot \mathrm{min}^{-1} \cdot \mathrm{cm}^{-2}$

The calculation of $\delta$ is shown in Equation (11). Where $J_{o m}$ is the membrane water flux provided by the manufacturer. $\delta$ represents a correction factor that accounts for water flux variability observed from one membrane sample to another.

$$
\delta=\left(\frac{J_{o m}-J_{o}}{J_{o m}}\right)+1=\left(\frac{0.678-0.556}{0.678}\right)+1=1.12
$$

D-4. Data collected for permeate flux calculation (RSM)

\begin{tabular}{|c|c|c|c|}
\hline Time (min) & Weight (g) & Flux $\left(\right.$ g.min $\left.{ }^{-1} \cdot \mathrm{cm}^{-2}\right)$ & $\begin{array}{l}\text { Corrected Flux } \\
\left(\text { g.min }^{-1} \cdot \mathbf{c m}^{-2}\right)\end{array}$ \\
\hline 0 & 0 & 0.000 & 0 \\
\hline 1 & 94.2 & 0.554 & 0.654 \\
\hline 2 & 159.1 & 0.382 & 0.451 \\
\hline 3 & 211 & 0.305 & 0.360 \\
\hline 4 & 253.2 & 0.248 & 0.293 \\
\hline 5 & 290.1 & 0.217 & 0.256 \\
\hline 6 & 323.1 & 0.194 & 0.229 \\
\hline 7 & 353.5 & 0.179 & 0.211 \\
\hline 8 & 379 & 0.150 & 0.177 \\
\hline
\end{tabular}




\begin{tabular}{|c|c|c|c|}
\hline 9 & 403.5 & 0.144 & 0.170 \\
\hline 10 & 426.3 & 0.134 & 0.158 \\
\hline 11 & 447.5 & 0.125 & 0.147 \\
\hline 12 & 467.2 & 0.116 & 0.137 \\
\hline 13 & 485.9 & 0.110 & 0.130 \\
\hline 14 & 503.5 & 0.104 & 0.122 \\
\hline 15 & 520.4 & 0.099 & 0.117 \\
\hline 16 & 536.1 & 0.092 & 0.109 \\
\hline 17 & 551.3 & 0.089 & 0.106 \\
\hline 18 & 566 & 0.086 & 0.102 \\
\hline 19 & 580.1 & 0.083 & 0.098 \\
\hline 20 & 593.6 & 0.079 & 0.094 \\
\hline 21 & 606.4 & 0.075 & 0.089 \\
\hline 22 & 618.9 & 0.074 & 0.087 \\
\hline 23 & 631 & 0.071 & 0.084 \\
\hline 24 & 642.9 & 0.070 & 0.083 \\
\hline 25 & 654.4 & 0.068 & 0.080 \\
\hline 26 & 665.6 & 0.066 & 0.078 \\
\hline 27 & 676.2 & 0.062 & 0.074 \\
\hline 28 & 686.7 & 0.062 & 0.073 \\
\hline 29 & 697 & 0.061 & 0.072 \\
\hline 30 & 707.5 & 0.062 & 0.073 \\
\hline 31 & 717.95 & 0.061 & 0.073 \\
\hline 32 & 728.37 & 0.061 & 0.072 \\
\hline 33 & 738.72 & 0.061 & 0.072 \\
\hline 34 & 748.99 & 0.060 & 0.071 \\
\hline 35 & 759.07 & 0.059 & 0.070 \\
\hline verage & & 0.128 & 0.151 \\
\hline
\end{tabular}

$\mathrm{J}_{\mathrm{us}}$ which represents the averaged permeate flux ( $\mathrm{J}_{\text {avg }}$ ) multiplied by a correction factor. $\mathrm{J}_{\mathrm{us}}$ was calculated using Equation (10), and is an indication of the overall US-assisted ultrafiltration performance.

$$
J_{u s}=J_{\text {avg }} \delta
$$

$$
\begin{aligned}
& \mathrm{J}_{\text {avg }}=0.128 \mathrm{~g} \cdot \mathrm{min}^{-1} \cdot \mathrm{cm}^{-2} \\
& \mathrm{~J}_{\text {us }}=0.128 * 1.12=0.151 \mathrm{~g} \cdot \mathrm{min}^{-1} \cdot \mathrm{cm}^{-2}
\end{aligned}
$$




\section{References}

Abdelrasoul, A. (2015). Investigation on Membrane Fouling in Ultrafiltration on Latex Solution. Ryrson University, Toronto, Canada.

Abdelrasoul, A., Doan, H., \& Lohi, A. (2016). Membrane fouling remediation in ultrafiltration of latex contaminated wastewater. Water Quality Research Journal of Canada, 51(3), 256-269. https://doi.org/10.2166/wqrjc.2015.011

Ahmad, A. L., Che Lah, N. F., \& Ismail, S. (2018). Ultrasonically Aided Cross-flow Membrane Filtration for Latex Wastewater. Journal of Physical Science, 29(Suppl. 1), 57-65. https://doi.org/10.21315/jps2018.29.s1.8

Alventosa-Delara, E., Barredo-Damas, S., Alcaina-Miranda, M. I., \& Iborra-Clar, M. I. (2014). Study and optimization of the ultrasound-enhanced cleaning of an ultrafiltration ceramic membrane through a combined experimental-statistical approach. Ultrasonics Sonochemistry, 21(3), 1222-1234. https://doi.org/10.1016/j.ultsonch.2013.10.022

APHA/AWWA/WEF. (2012). Standard Methods for the Examination of Water and Wastewater. Standard Methods, 541. https://doi.org/ISBN 9780875532356

Baker, R. W. (1996). Membrane technology no. 72. Membrane Technology (3rd ed., Vol. 1996). Newark, California: John Wiley and Sons Ltd. https://doi.org/10.1016/S09582118(96)90133-0

Bedasie, R. (2010). An Investigation Into The Fouling Phenomena Of Polycarbonate Membranes Used In The Treatment Of Latex Paint Wastewater.

Birtwell, I. K., Farrell, M., \& Jonsson, A. (2008). The Validity of Including Turbidity Criteria For Aquatic Resource Protection in Land Development Guideline (Pacific and Yukon Region). Vancouver, British Columbia.

Borea, L., Naddeo, V., Shalaby, M. S., Zarra, T., Belgiorno, V., Abdalla, H., \& Shaban, A. M. (2018). Wastewater treatment by membrane ultrafiltration enhanced with ultrasound: Effect of membrane flux and ultrasonic frequency. Ultrasonics, 83, 42-47. https://doi.org/10.1016/j.ultras.2017.06.013

Cai, M., Li, W., \& Liang, H. (2014). Effects of ultrasound parameters on ultrasound-assisted ultrafiltration using cross-flow hollow fiber membrane for Radix astragalus extracts. Chemical Engineering and Processing: Process Intensification, 86, 30-35. https://doi.org/10.1016/j.cep.2014.10.008 
Cai, M., Zhao, S., \& Liang, H. (2010). Mechanisms for the enhancement of ultrafiltration and membrane cleaning by different ultrasonic frequencies. Desalination, 263(1-3), 133-138. https://doi.org/10.1016/j.desal.2010.06.049

Chai, X., Kobayashi, T., \& Fujii, N. (1998). Ultrasound effect on cross-flow filtration of polyacrylonitrile ultrafiltration membranes. Journal of Membrane Science, 148(1), 129-135. https://doi.org/10.1016/S0376-7388(98)00145-8

Chai, X., Kobayashi, T., \& Fujii, N. (1999). Ultrasound-associated cleaning of polymeric membranes for water treatment. Separation and Purification Technology, 15(2), 139-146. https://doi.org/10.1016/S1383-5866(98)00091-4

Dixit, S., \& Pal, S. (2016). Recent advanced technologies in the processing of hybrid reinforced polymers for applications of membranes. Polymers and Polymer Composites, 24(4), 289305.

Field, R., Bekassy-Molnar, E., Lipnizki, F., \& Vatai, G. (2017). Engineering aspects of membrane separation and application in food processing. Engineering Aspects of Membrane Separation and Application in Food Processing. https://doi.org/10.4324/9781315374901

Fuchs, J. (2011). Ultrasonics - Number and Size of Cavitation Bubbles. Retrieved from http://books.google.com/books?hl=en\&lr=\&id=eyCB2vJQA9cC\&oi=fnd\&pg=PA151\&dq= the+principles+of+cavitation\&ots=RJ0NOVgCLz\&sig=Bs9895CIRCVGIj2CluDgWzhung A\%5Cnhttp://books.google.com/books?hl=en\&lr=\&id=eyCB2vJQA9cC\&oi=fnd\&pg=PA1 $51 \& d q=9+$ The + principles + of + cavita

Gao, W., Liang, H., Ma, J., Han, M., Chen, Z. lin, Han, Z. shuang, \& Li, G. bai. (2011). Membrane fouling control in ultrafiltration technology for drinking water production: A review. Desalination, 272(1-3), 1-8. https://doi.org/10.1016/j.desal.2011.01.051

Ghidossi, R., Veyret, D., \& Moulin, P. (2006). Computational fluid dynamics applied to membranes: State of the art and opportunities. Chemical Engineering and Processing: Process Intensification, 45(6), 437-454. https://doi.org/10.1016/j.cep.2005.11.002

Hengl, N., Jin, Y., Pignon, F., Baup, S., Mollard, R., Gondrexon, N., .. Paineau, E. (2014). A new way to apply ultrasound in cross-flow ultrafiltration: Application to colloidal suspensions. $\begin{array}{lll}\text { Ultrasonics } & \text { Sonochemistry, } & \text { 1018-1025. }\end{array}$ https://doi.org/10.1016/j.ultsonch.2013.11.008

Hoek, E. M. V. (2017). MF/UF Membrane Filtration: A State-of-the-Art Review. Retrieved from 
www.waterplanet.com

Keir, G., \& Jegatheesan, V. (2014). A review of computational fluid dynamics applications in pressure-driven membrane filtration. Reviews in Environmental Science and Bio/Technology, 13(2), 183-201. https://doi.org/10.1007/s11157-013-9327-x

Kim, Y.-J., Jung, J., Lee, S., \& Sohn, J. (2015). Modeling fouling of hollow fiber membrane using response surface methodology. Desalination and Water Treatment, 54(4-5), 966-972. https://doi.org/10.1080/19443994.2014.912593

Kobayashi, T., Kobayashi, T., Hosaka, Y., \& Fujii, N. (2003a). Ultrasound-enhanced membranecleaning processes applied water treatments: Influence of sonic frequency on filtration treatments. Ultrasonics, 41(3), 185-190. https://doi.org/10.1016/S0041-624X(02)00462-6

Kobayashi, T., Kobayashi, T., Hosaka, Y., \& Fujii, N. (2003b). Ultrasound-enhanced membranecleaning processes applied water treatments: Influence of sonic frequency on filtration treatments. Ultrasonics. https://doi.org/10.1016/S0041-624X(02)00462-6

Koros, William J; MA, Y, H; Shimidzu, T. (1996). Terminology for Membranes and. Pure \& Appl. Chemicals, 68(7), 1479-1489. https://doi.org/10.1351/pac199668071479

Kyllönen, H. M., Pirkonen, P., \& Nyström, M. (2005). Membrane filtration enhanced by ultrasound: $\quad$ A $\quad$ review. Desalination, 181(1-3), 319-335. https://doi.org/10.1016/j.desal.2005.06.003

Kyllönen, H., Pirkonen, P., Nyström, M., Nuortila-Jokinen, J., \& Grönroos, A. (2006). Experimental aspects of ultrasonically enhanced cross-flow membrane filtration of industrial $\begin{array}{llll}\text { wastewater. } & \text { Ultrasonics } & \text { Sonochemistry, }\end{array}$ https://doi.org/10.1016/j.ultsonch.2005.04.006

Lamminen, M. O. (2004). Ultrasonic Cleaning of Latex Particle Fouled Membranes.

Latt, K. K., \& Kobayashi, T. (2006). Ultrasound-membrane hybrid processes for enhancement of filtration properties. Ultrasonics Sonochemistry, 13(4), 321-328. https://doi.org/10.1016/j.ultsonch.2005.05.002

Leighton, T. G. (1998). The principles of cavitation. Ultrasound in Food Processing. Retrieved from

http://books.google.com/books?hl=en\&lr=\&id=eyCB2vJQA9cC\&oi=fnd\&pg=PA151\&dq= the+principles+of+cavitation\&ots=RJ0NOVgCLz\&sig=Bs9895CIRCVGIj2CIuDgWzhung A\%5Cnhttp://books.google.com/books?hl=en\&lr=\&id=eyCB2vJQA9cC\&oi=fnd\&pg=PA1 
$51 \& d q=9+$ The + principles + of + cavita

Li, N. N., Fane, A. G., Ho, W. S. W., \& Matsuura, T. (2008). Advanced Membrane Technology and Applications. John Wiley and Sons Ltd.

Luján-Facundo, M. J., Mendoza-Roca, J. A., Cuartas-Uribe, B., \& Álvarez-Blanco, S. (2016a). Cleaning efficiency enhancement by ultrasounds for membranes used in dairy industries. Ultrasonics Sonochemistry, 33, 18-25. https://doi.org/10.1016/j.ultsonch.2016.04.018

Luján-Facundo, M. J., Mendoza-Roca, J. A., Cuartas-Uribe, B., \& Álvarez-Blanco, S. (2016b). Study of membrane cleaning with and without ultrasounds application after fouling with three model dairy solutions. Food and Bioproducts Processing, 100, 36-46. https://doi.org/10.1016/j.fbp.2016.06.011

Masselin, I., Chasseray, X., Durand-Bourlier, L., Lainé, J. M., Syzaret, P. Y., \& Lemordant, D. (2001). Effect of sonication on polymeric membranes. Journal of Membrane Science, 181(2), 213-220. https://doi.org/10.1016/S0376-7388(00)00534-2

Mohammad, A. W., Ng, C. Y., Lim, Y. P., \& Ng, G. H. (2012). Ultrafiltration in Food Processing Industry: Review on Application, Membrane Fouling, and Fouling Control. Food and Bioprocess Technology, 5(4), 1143-1156. https://doi.org/10.1007/s11947-012-0806-9

Muthukumaran, S., Kentish, S., Lalchandani, S., Ashokkumar, M., Mawson, R., Stevens, G. W., $\&$ Grieser, F. (2005). The optimisation of ultrasonic cleaning procedures for dairy fouled ultrafiltration membranes. Ultrasonics Sonochemistry, 12(1-2), 29-35. https://doi.org/10.1016/j.ultsonch.2004.05.007

Naddeo, V., Borea, L., \& Belgiorno, V. (2015). Sonochemical control of fouling formation in membrane ultrafiltration of wastewater: Effect of ultrasonic frequency. Journal of Water Process Engineering, 8, e92-e97. https://doi.org/10.1016/j.jwpe.2014.12.005

Qasim, M., Darwish, N. N., Mhiyo, S., Darwish, N. A., \& Hilal, N. (2018). The use of ultrasound to mitigate membrane fouling in desalination and water treatment. Desalination, 443, 143164. https://doi.org/10.1016/j.desal.2018.04.007

Rautenbach, R., \& Voßenkaul, K. (2001). Pressure driven membrane processes-the answer to the need of a growing world population for quality water supply and waste water disposal. Separation and Purification Technology, 22-23, 193-208. https://doi.org/10.1016/S13835866(00)00130-1

Reuter, F., Lauterborn, S., Mettin, R., \& Lauterborn, W. (2017). Membrane cleaning with 
ultrasonically driven bubbles. Ultrasonics Sonochemistry, 37, 542-560. https://doi.org/10.1016/j.ultsonch.2016.12.012

Rouvet, F., Fiaty, K., Laurent, P., \& Liou, J. K. (1998). Modelling and simulation of membrane fouling in batch ultrafiltration on pilot plant. Computers \& Chemical Engineering, 22, S901S904. https://doi.org/10.1016/S0098-1354(98)00176-8

Seader, J. D., Seider, W. D., Lewin, D. R., Boulle, L., \& Rycrof, A. (2006). Separation Process Principles. JS Afr. L. (3rd ed.). John Wiley and Sons Ltd.

Singh, R. (2015a). Introduction to Membrane Technology. In Membrane Technology and Engineering for Water Purification - Application, Systems Design and Operation (2nd ed., pp. 1-80). Boston, MA: Elsevier.

Singh, R. (2015b). Water and membrane treatment. In Membrane Technology and Engineering for Water Purification - Application, Systems Design and Operation (pp. 81-178).

Strathmann, H. (2011a). Introduction. In Introduction to Membrane Science and Technology (pp. 1-19). Wiley-VCH.

Strathmann, H. (2011b). Membrane Separation Processes. In Ullmann's Encyclopedia of Industrial Chemistry (pp. 413-454). Weinheim, Germany: Wiley-VCH Verlag GmbH \& Co. KGaA. https://doi.org/10.1002/14356007.a16_187.pub3

Vigneswaran, S., Sathananthan, S., Shon, H. K., Kandasamy, J., \& Visvanathan, C. (2012). Delineation of Membrane Processes. In S. Vigneswaran, S. Sathananthan, H. K. Shon, J. Kandasamy, \& C. Visvanathan (Eds.), Membrane Technology and Environmental Applications (1st ed., pp. 41-74). Reston, Virginia: American Society of Civil Engineers. https://doi.org/10.1061/9780784412275.ch02

Waterman, D. A., Walker, S., Xu, B., \& Narbaitz, R. M. (2016). Bench-scale study of ultrafiltration membranes for evaluating membrane performance in surface water treatment. Water Quality Research Journal of Canada, 51(2), 128-140. https://doi.org/10.2166/wqrjc.2016.039

World Health Organization. (2017). Water Qualtity and Health - Review of Turbidity: Information for regulators and water suppliers. Who/Fwc/Wsh/17.01.

Xie, F., Chen, W., Wang, J., \& Liu, J. (2016). CFD and experimental studies on the hydrodynamic performance of submerged flat-sheet membrane bioreactor equipped with micro-channel turbulence promoters. Chemical Engineering and Processing: Process Intensification, 99, 72-79. https://doi.org/10.1016/j.cep.2015.10.012 
Yapicioglu, P. (2018). Investigation of Environmental-friendly Technology for a Paint Industry Wastewater Plant in Turkey. Journal of Natural and Applied Sciences, 22, 98-106. https://doi.org/10.19113/sdufbed.22148

Zhang, T. C., Surampalli, R. Y., \& Vigneswaran, S. (2012). The Values of Membrane Science and Technology: Introduction and Overview. In T. C. Zhang, R. Y. Surampalli, \& S. Vigneswaran (Eds.), Membrane Technology and Environmental Applications (1st ed., pp. 1-40). Reston, Virginia: American Society of Civil Engineers. 